\title{
Science Instruction in Newark Public Schools
}

\author{
By \\ Thomas B. Corcoran \\ and \\ Gail B. Gerry
}

Consortium for Policy Research in Education Teachers College, Columbia University

The Consortium for Policy Research in Education includes:

University of Pennsylvania Teachers College Columbia University Harvard University Stanford University 


\section{About the Consortium for Policy Research in Education (CPRE)}

Established in 1985, CPRE unites researchers from seven of the nation's leading research institutions in efforts to improve elementary and secondary education through practical research on policy, finance, school reform, and school governance. CPRE studies alternative approaches to education reform to determine how state and local policies can promote student learning. The Consortium's member institutions are the University of Pennsylvania, Teachers College-Columbia University, Harvard University, Stanford University, the University of Michigan, University of Wisconsin-Madison, and Northwestern University.

In March 2006, CPRE launched the Center on Continuous Instructional Improvement (CCII), a center engaged in research and development on tools, processes, and policies intended to promote the continuous improvement of instructional practice. CCII also aspires to be a forum for sharing, discussing, and strengthening the work of leading researchers, developers and practitioners, both in the United States and across the globe.

To learn more about CPRE and CCII, visit our web sites at www.cpre.org and www.ccii-cpre.org.

\section{CPRE Research Report Series}

Research Reports are issued by CPRE to facilitate the exchange of ideas among policymakers, practitioners, and researchers who share an interest in education policy. The views expressed in the reports are those of individual authors, and not necessarily shared by CPRE or its institutional partners. 


\title{
Science Instruction in Newark Public Schools
}

\author{
by \\ Thomas B. Corcoran \\ and \\ Gail B. Gerry
}

Consortium for Policy Research in Education Teachers College, Columbia University

The research presented in this report was funded by the Merck Institute for Science Education (MISE) to the Consortium for Policy Research in Education (CPRE). Opinions expressed in this report are those of the authors and do not necessarily reflect the views of CPRE, MISE, the Horizon Research Institute (HRI), the Newark Public Schools (NPS), or its institutional members. 



\section{Table of Contents}

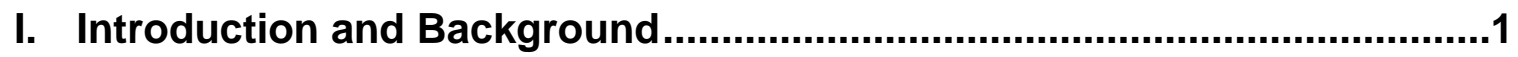

The MISE Partnership with Newark Public Schools..................................... 1

The 2010 Assessment of Science Instruction .............................................. 3

The 2011 MISE External Review of the Science Program................................ 3

Newark Background Information ........................................................... 4

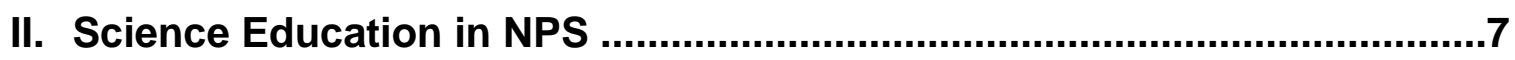

III. Science Teachers and Science Teaching in Newark ...................................

Newark Teachers Perceptions of their Teaching .......................................... 9

Teaching and Learning in Newark Classrooms ............................................. 10

Findings from the Elementary Level Classroom Observations ......................... 11

Findings from the Middle Level Classroom Observations ............................... 14

Findings from the High School Classroom Observations................................ 16

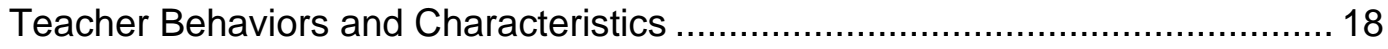

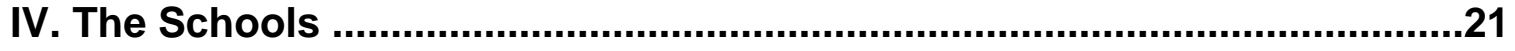

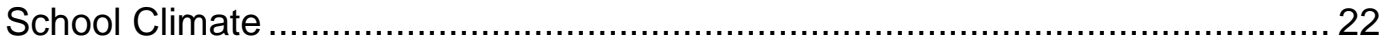

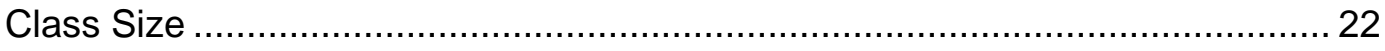

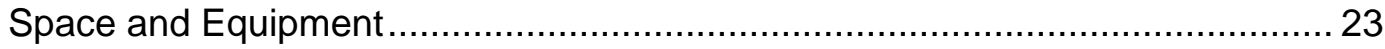

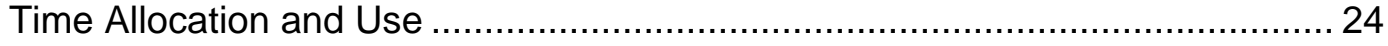

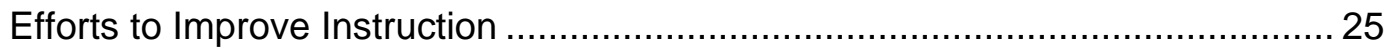

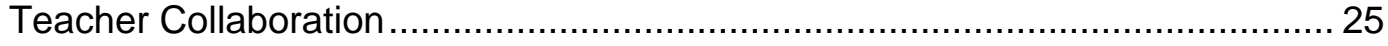

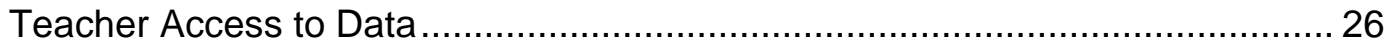

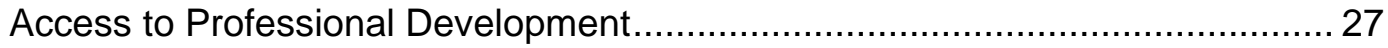

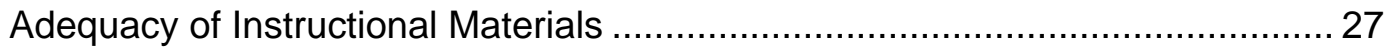

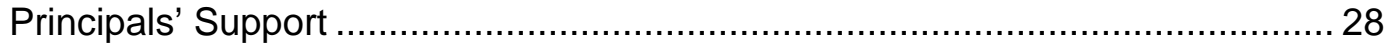

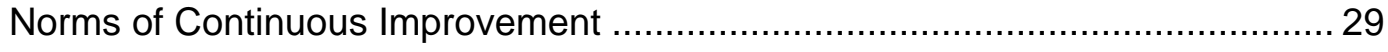

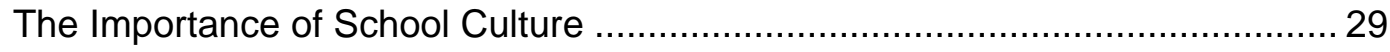

V. System Issues Related to Science Education .....................................31

The MISE Review of Curriculum Materials.................................................. 31

HRI Review of the NPS Benchmark Assessments ....................................... 32

VI. The Challenges and Opportunities......................................................35

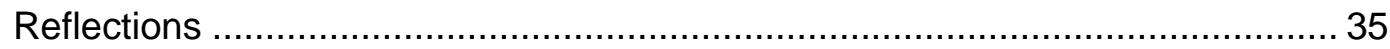

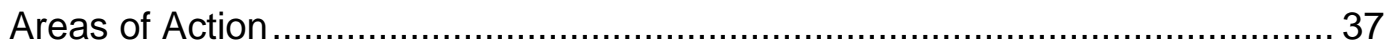




\section{Appendices}

Appendix A: Definition of the School Quality Indicators.........................47

Appendix B: Definition of the Classroom Quality Indicators ...................49

Appendix C: Classroom Observation Protocol ....................................51

Appendix D: The MISE Teacher Survey ...........................................53

Appendix E: School Vignettes ..........................................................71

Appendix F: The MISE Review of the NPS Curriculum Documents ........79

Appendix G: HRI Review of the Interim Assessments...........................89

\section{List of Tables}

Table I: 2009-2010 Student Demographics in Newark Public Schools.......................... 5

Table II: 2011 Average Achievement Scores........................................................ 5

Table III: Basic Data on Comprehensive High Schools and Magnet Schools in NPS ...... 8

Table IV: K-12 Teachers' Perceptions of Their Effectiveness .................................... 10

Table V: Ratings of Elementary Instructional Practices .......................................... 11

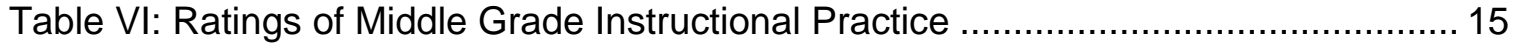

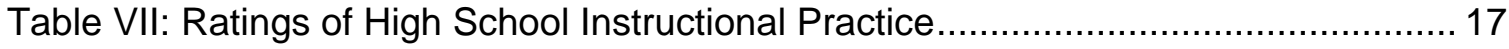

Table VIII: Summary of Teacher Behaviors and Characteristics .............................. 19

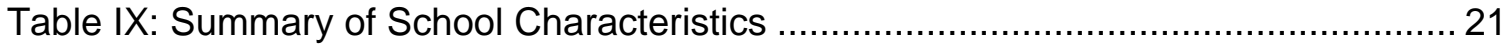

Table X: K-8 Teacher Responses on the Need and Current Availability of Equipment .. 23

Table XI: High School Teacher Responses on the Need and Current Availability of

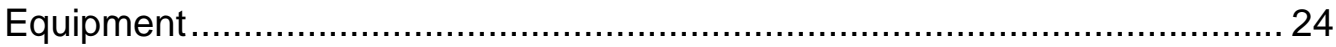

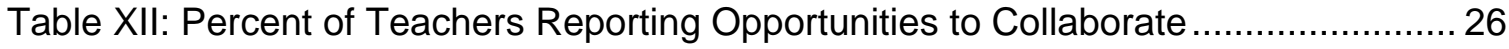




\section{Introduction and Background}

The Consortium for Policy Research in Education (CPRE) has prepared this report on the Newark Public Schools (NPS) for the Merck Institute for Science Education (MISE) to assist them with the development of a strategic plan for improving science education in the district. The data used in the report have been gathered and analyzed through the collaborative efforts of CPRE, MISE, and Horizon Research, Inc. (HRI). MISE and CPRE collaborated on two rounds of school site visits; CPRE conducted interviews with district officials; MISE staff analyzed Newark's curriculum documents and administered a survey of Newark teachers and administrators; and HRI reviewed a sample of interim science assessments developed by the NPS staff. Most of this work has been done under considerable time pressure and we want to thank all of those who contributed to this report. We believe that the report presents a rich and detailed portrait of science instruction in Newark.

\section{The MISE Partnership with Newark Public Schools}

In August 2010, the Merck Institute for Science Education (MISE) entered into a partnership with Newark Public Schools (NPS). The goals of the collaboration were to:

- Raise the participation and performance of NPS students in science

- Make science teaching and learning a priority in the district

- Adopt, promote, and support the use of inquiry in science teaching and learning

- Build capacity to sustain and continuously improve science teaching and learning at scale

In the Memorandum of Understanding (MOU), the collaborating organizations commit to:

- Developing a five-year strategic plan that:

$>$ Demonstrates the district's priority to science

$>$ Undertakes systemic reforms to support continuous improvements in science teaching and learning

$>$ Provides a strategy for scale-up

$>$ Sets benchmarks for progress toward improving teaching and learning in science

- Aligning district policies to support teaching and learning in science

$>$ Commit to using evidence to guide decisions and to collecting and analyzing an array of data needed to inform these decisions

$>$ Align district policies in finance, curriculum, assessment, professional development, and personnel evaluation with the vision of the collaborative work

- Leveraging resources to support improvements in teaching and learning in science

$>$ Obtain and use available resources effectively and efficiently

$>$ Leverage external resources including grants and partnerships with professional and local organizations

$>$ Enlist community support for the science program 
- Developing and maintaining a coherent science curriculum

$>$ Implement a field-tested process for the selection of instructional materials that support active engagement of students in scientific investigations

$>$ Ensure that the adopted curriculum is used effectively in all classrooms

$>$ Provide on-going support for an instructional materials management system

$>$ Commit to reviewing all initiatives to improve science teaching and learning to ensure their coordination and alignment

- Providing professional development for teachers of science

$>$ Build the capacity to sustain and continuously improve professional development that supports effective teaching and learning of science and aligns with research-based criteria

$>$ Encourage and support sustained involvement of teachers in a range of professional activities to improve their instruction through release time, incentives for participation, etc.

$>$ Gain participation of a minimum of $X$ percent of science teachers in $Y$ hours of professional development over a five year period. The two partners will reach an agreement on these numbers after completing the strategic planning process

- Providing on-site support for improvements in science teaching and learning

$>$ Actively encourage and support principals of schools participating in the Academy for Leadership in Science Instruction ("Academy") to participate in professional development opportunities focused on science and to serve as advocates for the collaborative work

$>$ Develop a system of on-site support that provides each Academy school with the necessary time and expertise for the improvement of science teaching

- Enhancing student interest in and aspirations for science learning

$>$ Make pathways to science careers more visible and accessible

$>$ Actively recruit and provide incentives for students to enroll in challenging science courses

$>$ Prepare and support teachers and administrators to understand and respond to the cultural, economic, and social backgrounds of students

- Participating actively in the management of the collaborative work

$>$ Appoint and charge a team and team leader ("liaison") to oversee and manage the collaborative work and ensure the team members' regular participation

$>$ Actively communicate the terms of this MOU and the collaborative activities to all stakeholders, including NPS Board of Education, administrators, principals, teachers, parents, and the community

$>$ Provide access to data needed to inform the design and delivery of the professional development programs and to assess the impact on teaching practice, student performance, and school and district culture

The first step taken to implement this MOU was the conduct of an assessment of science education in the district, which produced the data presented in this report. 


\section{The 2010 Assessment of Science Instruction}

In October 2010, MISE, in cooperation with the Consortium for Policy Research in Education (CPRE) at Teachers College, Columbia University, undertook an assessment of the science education program in the Newark Public Schools. The assessment included document reviews, including NPS's science curriculum and scope and sequences, and site visits to 10 randomly selected schools in order to obtain a statistically significant and representative sample of the district's science instruction in classrooms. The purpose of the site visits was to observe teaching and learning in science in the district and the general conditions for science instruction.

However, the initial 10 schools selected for site visits were primarily located in the southern region of the district as district officials initially thought this was where MISE would begin its work. Therefore, the sample of schools visited was not representative of the district as a whole. The visits were conducted in October, 2010 by two-person teams (typically one science expert from MISE and one instructional researcher from CPRE) and each site visit lasted one full day. The teams completed five data collection activities:

1. A review of school profiles and student achievement data;

2. An interview with the building principal;

3. A "walk-through" of the building, during which the visitors considered school and classroom climate and the general nature of instructional activities;

4. Four to eight brief (20-30 minute) classroom observations of science teaching; math or language arts classrooms were sometimes substituted; and

5. A focus group with 3-15 teachers. Typically this was conducted during a planning period, a lunch break, or after school.

In addition, phone interviews were conducted with key district office staff and external partners working with NPS on science education and/ or school reform initiatives. The observations and interviews focused on two sets of quality indicators shown by research to be related to student learning (See Appendix A for a discussion of the school indicators and Appendix B for the classroom indicators). The indicators cover inputs (class size), conditions (school climate), and instructional processes (cognitive demand of lessons). The teams used a classroom observation protocol that was adapted from previous protocols developed by CPRE for research projects (see Appendix C). The assessment teams used rubrics, and compared and mediated their judgments to determine the status of these indicators in each school.

The data were coded and analyzed and a preliminary report was made to the Merck Institute for Science Education Advisory Board on November, 17, 2010. The data collected from the 10 schools also were displayed and discussed at a strategic planning retreat held in January, 2011. At the retreat, MISE and Newark's leaders reviewed a preliminary report from CPRE based on the school visits. School vignettes (see Appendix E) were constructed to illustrate the typical conditions for science learning observed in the elementary and middle grades. Participants in the January retreat identified priorities for the partnership.

\section{The 2011 MISE External Review of the Science Program}

After discussing the district's priorities at the retreat, MISE determined that a broader review of the organization, curriculum, and implementation of the district's science program was needed 
and that an external team should be recruited to conduct it. The external review team will be composed of experienced science educators including members with extensive urban experience. This report has been prepared to inform them.

MISE and the district also agreed that data should be collected from a more representative set of schools to provide the visiting team with a more complete and representative portrait of the science education program. In April, 2011, site visits were conducted in a second set of schools. The same observation protocol used in the first 10 schools was used in these sites. The second set of 10 schools was randomly selected from the 75 schools in the district by CPRE researchers. Due to scheduling conflicts with spring testing, however, only 8 of the 10 schools were visited.

In addition, surveys were sent to 20 schools, including five high schools, to obtain the perceptions of teachers and administrators (the survey is attached in Appendix D). According to response information from 14 of these schools, the teacher response rate was 90 percent. Eighteen of the 20 principals responded but responses from one school had to be excluded as all of the administrators in the building responded and we could not identify the survey completed by the principal. As a consequence, the $\mathrm{N}$ for the principals' survey is 17 . Two hundred and thirty-five K-8 teachers, fifty-two 9-12 teachers and nineteen principals completed the surveys.

Additional phone interviews were also conducted to reach a broader group of district content directors and supervisors as well as additional science support staff and personnel responsible for professional development. And MISE science specialists conducted a more in-depth review of the curriculum (Appendix F) and the staff of Horizon Research, Inc. conducted a review of two benchmark assessments developed by the Newark central office staff (Appendix $G$ ).

This report combines all of these sources, including the 18 school visits, to provide a detailed description of science instruction for the visiting team. The external review team is scheduled to meet in October and will work with the MISE and Newark staffs to develop a plan to support the unique challenges Newark faces in the implementation of good science instruction.

\section{Newark Background Information}

Although the city of Newark has seen a slight decline in population over the past three years, it is still the largest city in New Jersey, and in 2010, Newark had a population of 277,140. Newark also is one of the state's poorer cities; in 2009, 23.9 percent of the families in Newark lived in poverty, more than two and one-half times the rate for the state of New Jersey. ${ }^{1}$

The Newark Public Schools (NPS) continues to be the largest school district in New Jersey, although its enrollment has been declining over the past several years. According to statistics obtained from the New Jersey Department of Education (NJDOE), in 2010-11, NPS had an enrollment of 33,253 students, including preschool enrollment. ${ }^{2}$ The student population is diverse, as indicated by the data presented in Table I below.

\footnotetext{
${ }^{1}$ United States Census Data, www.census.gov. All data cited in this report are the most recent data available.

${ }^{2}$ State of New Jersey Depart of Education, All DOE Data \& Reports, http://www.nj.gov/education/data.
} 


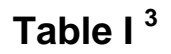

\begin{tabular}{lrlr} 
& 2009-2010 Student Demographics in Newark Public Schools \\
\hline White & $7.5 \%$ & Female & $48.7 \%$ \\
Black & $55.9 \%$ & Male & $51.3 \%$ \\
Asian/PI & $0.2 \%$ & Limited English Proficiency & $8.3 \%$ \\
Hispanic & $35.6 \%$ & Students w/Disabilities & $17.7 \%$ \\
Native Am & $0.1 \%$ & Economic Disabilities & $73.3 \%$ \\
\hline
\end{tabular}

According to the NJDOE data, in 2010-2011 the Newark Public Schools had 4,362 employees: 2,924 teachers; 406 administrators; and 1,032 support services staff. In 2009-2010, the starting teacher salary was $\$ 50,000$ and the median teacher salary was $\$ 66,200$. In $2009-2010$, student funding was $\$ 19,951$ per pupil, one of the highest levels in the country. At that time, the district operated 75 schools: 50 elementary (many K-8); 4 middle schools; 15 high schools; and 6 alternative schools. ${ }^{4}$

Student achievement has been consistently below state and national averages and some schools in Newark have been identified as significantly low performing. This past year NPS was on the federal list of districts in need of improvement for the seventh consecutive year. Average achievement scores on the state tests are shown in Table II.

\begin{tabular}{|c|c|c|}
\hline \multicolumn{3}{|c|}{$\begin{array}{c}\text { Table II }^{5} \\
2011 \text { Average Achievement Scores }\end{array}$} \\
\hline & NPS & State of $\mathrm{NJ}$ \\
\hline \multicolumn{3}{|l|}{ Grade 4} \\
\hline Science - At or Above Proficient (\%) & 80.2 & 93.4 \\
\hline Math - At or Above Proficient (\%) & 54.6 & 77.0 \\
\hline \multicolumn{3}{|l|}{ Grade 8} \\
\hline Science - At or Above Proficient (\%) & 60.6 & 82.9 \\
\hline Math - At or Above Proficient (\%) & 40.6 & 68.5 \\
\hline \multicolumn{3}{|l|}{ High School } \\
\hline Science - At or Above Proficient (\%) & $\mathrm{n} / \mathrm{a}$ & $\mathrm{n} / \mathrm{a}$ \\
\hline Math - At or Above Proficient (\%) & 46.4 & 71.1 \\
\hline
\end{tabular}

In 2007-2008, 1,848 students were tested on the SAT and the average combined score was 1212 , which is well below the state average of 1500 . NJDOE reports the graduation rate for 2009 as 90.2 percent, but this is based on the percentage of all 12th graders who graduated, not the percentage of the cohort that entered kindergarten in 1995 or the cohort that entered high school in 2005. An accurate cohort rate is not available, but notably, the goals and priorities in the NPS curriculum guides for science state that " $80 \%$ of students will be on track for graduation, up from 38\%".

${ }^{3}$ Ibid.
${ }^{4}$ Ibid.
${ }^{5}$ Ibid. 


\section{Science Education in Newark Public Schools}

The Newark Public School District has made a significant investment in science education. Prior to 2010-2011, the district adopted FOSS modules for use in grades K-8 and supported the use of the modules through professional development for teachers at the Banneker Science Center, with the support of lead science teachers assigned to each school, and by contracting with a firm to replenish and distribute the K-6 modules. The lead science teachers helped other teachers use the modules, organized science labs, taught and co-taught lessons, provided teachers with feedback to improve science instruction, and replenished the middle grade modules. Each of the four administrative regions in the district had a Science Resource Teacher Coordinator (SRTC) who worked with the lead science teachers and led professional development, curriculum and assessment work.

In addition to the FOSS modules, the central office science staff developed instructional units on topics such as measurement that teachers were expected to use in-between the modules. The central office science staff also developed benchmark assessments based on the Cumulative Progress Indicators (CPIs) for science and on modules; these assessments have been administered regularly throughout the year to give the teachers and schools feedback on how well students are doing.

Much of this support infrastructure for K-8 science was eliminated in 2010-11 as a result of budget cuts required by changes in state aid. The lead science teacher positions were eliminated in all of the schools and the Banneker Center was closed. Further budget cuts have been made for the 2011-12 school year. The Science Resource Teacher Coordinators who worked with grade K-8 classroom teachers have been reduced in number from four to two. In addition, the adoption of the newly-developed science curriculum has been tabled.

The nature and quality of the secondary school science program varies widely from school to school. Schedules and class lengths are determined by the school site, so there is considerable variation. The high school curriculum has been undergoing some changes with an earlier commitment to a "Physics First" philosophy giving way to beginning high school science in ninth grade with Biology. The sequences of courses are different in each school and this decision seems to depend upon the philosophy and expertise of the teaching staff, whether the school received additional funding to participate in outside programs (e.g., Progressive Science Initiative) and whether teachers received training through those programs.

These curriculum issues, while significant, seem much less important than the striking differences noted between neighborhood, comprehensive high schools and exam schools. To understand how dissimilar the schools truly are one only has to look at the student information and performance data for schools in each category. Table III below reflects actual 2009-2010 data from two of the schools we visited: a comprehensive high school and a magnet secondary school. 
Table III

Basic Data on Comprehensive High Schools And Magnet High Schools in NPS ${ }^{6}$

\begin{tabular}{lcccc}
\hline Indicator & $\begin{array}{c}\text { Comprehensive } \\
\text { High School (9-12) }\end{array}$ & $\begin{array}{c}\text { Secondary Magnet } \\
\text { School (7-12) }\end{array}$ & District & State \\
\hline Average Student Enrollment & 781 & 534 & $\mathrm{n} / \mathrm{a}$ & $\mathrm{n} / \mathrm{a}$ \\
Students with Disabilities (\%) & 21.5 & 9.0 & 14.1 & 16.4 \\
LEP Students (\%) & 5.1 & 0.4 & 8.3 & 4.0 \\
Mobility Rate (\%) & 23.5 & 3.5 & 20.3 & 10.5 \\
HSPA Language Arts (\%) & 36.4 & 84.1 & 55.0 & 69.3 \\
HSPA Mathematics (\%) & 19.6 & 71.9 & 40.4 & 50.7 \\
SAT Math (mean) & 369 & 465 & 407 & 520 \\
SAT Verbal (mean) & 362 & 426 & 396 & 496 \\
AP Participation (\%) & 14.2 & 23.5 & $\mathrm{n} / \mathrm{a}$ & 19.9 \\
Graduation Rate (\%) & 95.5 & 100.0 & 87.8 & 94.7 \\
\hline
\end{tabular}

With the loss of some district staff and the pressure this places on a system that is already unable to meet the needs of the schools and teachers, the science program faces serious challenges. Additionally, the district has announced it is increasing "principal autonomy" and this also may impact the science program. One content supervisor, not in science, indicated that "principal autonomy" would hurt science instruction:

"Frankly, science is not a priority. Most principals were not science teachers and will gravitate toward and support subject areas where they are most comfortable. Couple that with the fact that literacy and math are the primary tested areas and this does not bode well for science."

On a more positive note, the district did support the participation of 90 teachers in MISE's Peer Teacher Workshops (PTW's) in the summer of 2011. These workshops provided teachers with professional development on the use of science modules included in the existing curriculum. Also, teams of teachers and administrators from four schools participated in the Academy for Leadership in Science Instruction to strengthen their understanding of effective science instruction and build leadership skills.

\footnotetext{
${ }^{6}$ New Jersey Department of Education, www.state.nj.us/education/schools/achievement/2011; Newark Public Schools, www.nps.k12.nj.us; United States Department of Education, Common Core of Data, Tabulated from Build a Table tool, www.nces.ed.gov/ccd/
} 


\section{Science Teachers and Science Teaching in Newark}

Over 1,000 teachers teach science in the Newark Public Schools; the exact number is not known. In grades K-5, these are largely teachers who hold elementary teaching diplomas and do not have much, if any preparation in science. Among the self-contained classroom teachers who teach science and who were surveyed by MISE, 97 percent held general elementary certificates and 2 percent held an elementary certificate with a science specialization. In grades $6-8$, science is departmentalized. All of the middle-grade NPS teachers who participated in the MISE survey held elementary teaching certificates with a science specialization.

All of the teachers in the high schools who responded to the MISE survey held certification in science; 60 percent held certification in biology, 12 percent in chemistry, 26 percent in physics or physical sciences, and 2 percent in earth science. Sixty-one percent held advanced degrees, but we do not know if these degrees were in science.

Teachers of science also vary widely in their experience; results from the survey indicate that 51 percent of the K-8 teachers and 66 percent of the high school teachers who responded have 6 or more years of experience as science teachers. However, 34 percent of the K-8 teachers and 16 percent of the high school teachers have 2 years or less experience teaching science, although some have more extensive experience in other teaching assignments. This situation is partly a result of the changes in teaching assignments and elimination of science departments in grades 4-6 that followed the 2010 budget cuts. Many teachers with years of experience were teaching primary or intermediate grade science for the first time in 2010-11.

\section{Newark Teachers Perceptions of their Teaching}

Based on the responses to the MISE survey, Newark teachers have a rather positive view of their instructional practices. The responses to10 items selected from the MISE survey show that as a group Newark science teachers at all grade levels are highly confident and positive about their teaching (see Table IV). The responses show only small variations across the four groups of teachers beyond some differences in their feelings of efficacy across schools, with elementary teachers feeling they have somewhat less power to influence their schools than their departmentalized colleagues in the middle grades and high schools.

Overall, the data reveal a teaching force that is confident about their effectiveness and their ability to motivate their students. The responses to the first three items suggest that many K-8 teachers are either not consulted frequently or choose not to participate in decisions about the science program in their schools. But the rest of the items indicate that they overwhelmingly believe they are influencing learning, are effective in the classroom and are able to motivate students. As we shall see later in the report, the respondents' perceptions of their efficacy are at odds with the quality of the instruction that was observed in most schools. 
Table IV

K-12 Teachers' Perceptions of Their Effectiveness: Percent Agree and Strongly Agree $(n=235)$

\begin{tabular}{lcccc}
\hline \multicolumn{1}{c}{ Item } & $\begin{array}{c}\text { Self-Contained } \\
\text { Classrooms } \\
\text { (\%) }\end{array}$ & $\begin{array}{c}\text { Departmental } \\
\text { Teachers } \\
\text { Grades 7-8 (\%) }\end{array}$ & $\begin{array}{c}\text { Departmental } \\
\text { Teachers } \\
\text { Grades 9-12 } \\
\text { (\%) }\end{array}$ & $\begin{array}{c}\text { Special Ed } \\
\text { Teachers } \\
\text { K-8 } \\
\text { (\%) }\end{array}$ \\
\hline $\begin{array}{l}\text { I contribute to planning and } \\
\text { improving the science program at } \\
\text { my school }\end{array}$ & 41 & 54 & 77 & 52 \\
$\begin{array}{l}\text { I influence the quality of science } \\
\text { instruction for all students at my } \\
\text { school }\end{array}$ & 44 & 40 & 71 & 55 \\
$\begin{array}{l}\text { Science teachers at my school } \\
\text { have a shared vision of effective } \\
\text { science instruction }\end{array}$ & 65 & 74 & 75 & 68 \\
$\begin{array}{l}\text { The quality of my teaching } \\
\text { influences student achievement in } \\
\text { science }\end{array}$ & 91 & 100 & 98 & 96 \\
I continually find better ways to \\
teach
\end{tabular}

\section{Teaching and Learning in Newark Classrooms}

During both the fall and spring site visits, the CPRE/MISE teams observed science classes at all grade levels. The goal was to observe four to six lessons in each of the 20 schools. In fact, site visits were made to 18 schools and 121 lessons were observed. These observations lasted from 20 to 45 minutes. Using an observation protocol developed by CPRE that focused on critical aspects of classroom practice and lesson design (See Appendix B), the observers rated 11 dimensions of classroom practice for each lesson, and at the end of the visit, collaborated on rating the school overall.

The 11 classroom indicators were selected based on reviews of research on instruction conducted by CPRE that focused on high leverage practices that consistently have been associated with large effects on learning. Descriptions of these practices and the supporting citations are presented in Appendix A. The indicators include conditions of teaching (classroom organization and climate), teaching performances (clarity of concepts and knowledge of content), and teachers' use of specific high-impact strategies (student discussion or teaming). For each of these 11 indicators, the observers recorded a rating of one to five, with a five indicating an excellent condition or performance or a high level of use of a strategy and a one indicating a poor condition or performance or no use of the strategy.

In some instances, observing science instruction was difficult due to scheduling or teacher decisions to address instruction in other subjects. Current conditions - increased emphasis on literacy and mathematics resulting from NCLB accountability and budget cuts resulting in the elimination of the lead science teachers - appear to have yielded a decrease in the actual time spent on science instruction in some of the elementary schools. However, this observation from 
the school visits appears to be in conflict with teacher survey data, where K-8 teachers report teaching, on average, nearly three hours of science per week.

\section{Findings from the Elementary Level Classroom Observations}

Twenty-two elementary classrooms (grades K- 5) were observed during October and 33 additional elementary classrooms were observed in April. Table $\mathrm{V}$ presents data from these observations of these 55 classrooms, indicating the ratings that the observers assigned to eleven key indicators of classroom practice. The elementary classrooms observed were generally orderly; most of the teachers successfully created a warm and caring classroom climate. However, significant disciplinary problems were observed in about 20 percent of the classrooms. These problems are noted under the Classroom Climate indicator. The learning goals were clear in most cases, but the goals were often low level (define, list, identify, etc.) and the posted goals did not always match the instruction observed.

Most of the teachers observed seemed to know the content they were teaching, but in at least 30 percent of the classrooms, the observers were uncertain about the teachers' depth of content knowledge. Moreover, the observers felt the concepts being studied were not clearly presented or were not ascertainable in about half of the classes. Only 29 percent of the teachers received high ratings on this indicator.

Table V

Ratings of Elementary Instructional Practices $(\mathrm{n}=55)$

\begin{tabular}{|c|c|c|c|c|c|c|}
\hline \multirow[b]{2}{*}{ Indicator } & \multicolumn{6}{|c|}{ Rating (\% of teachers observed) } \\
\hline & $\begin{array}{c}\mathbf{1} \\
\text { (low/poor) }\end{array}$ & 2 & 3 & 4 & $\begin{array}{c}\mathbf{5} \\
\text { (high/ex- } \\
\text { cellent) } \\
\end{array}$ & n/a \\
\hline 1. Classroom organization & 16 & 13 & 13 & 24 & 35 & - \\
\hline 2. Classroom climate & 11 & 11 & 25 & 24 & 29 & - \\
\hline 3. Clear learning goals & 9 & 13 & 18 & 31 & 24 & 5 \\
\hline $\begin{array}{l}\text { 4. Lesson linked to prior } \\
\text { knowledge }\end{array}$ & 22 & 15 & 15 & 18 & 22 & 9 \\
\hline $\begin{array}{l}\text { 5. Concepts clearly } \\
\text { presented }\end{array}$ & 25 & 26 & 18 & 18 & 11 & 2 \\
\hline $\begin{array}{l}\text { 6. Students engaged in } \\
\text { higher order thinking }\end{array}$ & 22 & 25 & 18 & 22 & 9 & 7 \\
\hline $\begin{array}{l}\text { 7. Student discussion } \\
\text { encouraged }\end{array}$ & 18 & 29 & 22 & 22 & 9 & - \\
\hline 8. Effective use of teams & 31 & 22 & 11 & 11 & 15 & 11 \\
\hline $\begin{array}{l}\text { 9. Teacher understood } \\
\text { subject matter }\end{array}$ & 15 & 15 & 24 & 27 & 13 & 7 \\
\hline $\begin{array}{l}\text { 10. Teacher monitored } \\
\text { student progress }\end{array}$ & 18 & 27 & 18 & 22 & 15 & - \\
\hline $\begin{array}{l}\text { 11. Closing with review } \\
\text { and reflection }\end{array}$ & 36 & 16 & 15 & 11 & 7 & 15 \\
\hline
\end{tabular}

Source: CPRE/MISE site visits, Oct 2010 \& April, 2011; Rows may not add to 100 due to rounding error. 
In only 31 percent of the observed lessons were students engaged in challenging tasks or higher-order thinking. The typical lesson focused on defining terms, completing worksheets, copying notes from the board or a text. Only a handful included activities could be categorized as hands-on, inquiry-based investigations. Only a few of the observed classes were using lessons from district-adopted science modules.

While students were typically sitting in small groups, the groups were seldom used to promote learning. Research has shown that effective use of groups increases learning as peers provide motivation for students to engage in the assigned task, support in completing the task, and feedback on work to each other. Most of the lessons involved independent work and students cooperated on tasks in only about a third of the classes. Extended student discussions were rarely observed, although some teachers did use questions to engage the class. In most cases, the teachers sought factual answers and there were no follow-up questions.

Finally, teachers typically ended lessons without any discussion or reflection on what had been learned, or any effort to check for student understanding. In only 18 percent of the classrooms did the teams observe well-developed closings.

The site visits lead to an inference that there may be little science instruction actually taking place in some of the elementary schools.

"I really want to do more science; I just do not have the time to prepare. You have to run around and get the materials and sometimes you are in the middle of a lesson and you realize you don't have everything you need, like when you came in (to observe) and the scales didn't work because the batteries were old."

- Fifth-Grade Teacher

Even when the schedules indicated a block of science instruction, the observers often walked into classrooms where the "science" time was used for a math or language arts lesson. Boxes of science modules were often evident in the rooms but in some cases had not been opened. In some schools, the assigned modules had not been received or distributed to teachers.

"When you came in this morning I was still doing math because we hadn't finished the lesson and, as you saw, the students didn't understand it."

- Second-Grade Teacher

In the focus group sessions, elementary teachers identified five key issues that were affecting the amount and quality of science teaching: the elimination of the science lead teachers; the reassignment of many teachers to different grade levels as a result of reductions in staff; the late arrival and premature pick-up of science modules to the schools; the lack of science textbooks or supporting texts; and the heavy emphasis on improving student achievement in areas of focus on the state assessment, namely, literacy and mathematics.

"The FOSS kits are hands-on, the kids love them. But now it is hard to monitor their use without the lead teacher. The teachers complain that they do not have time to set up labs. They just arrived last week, so little has been done so far this year."

- Elementary Principal 
"In theory we say that science is a priority. In practice, it is not tested [on the state test] so we don't pay much attention to teaching it. Sorry, but that's the truth."

- Fifth-Grade Teacher

"Many of the children can't read. In my seventh-grade class, I have four or five students reading at the second grade level, and perhaps five or six who are on grade level. Most of my class cannot read the material. To use the modules well, children have to be able to read."

- Seventh-Grade Teacher

Teachers also mentioned the lack of alignment between the science modules, the CPIs and the district science assessments.

"In each region, the distribution of the modules varies at any given point in time. They are all used during the year, but at different times. The district assessment doesn't match what I'm given to teach, so it doesn't make sense. And the kids move around so they may have the same module twice."

- Sixth-Grade Teacher

One other barrier may be the poor condition and inadequate resources of the designated science labs in several of the elementary schools. In two schools, the labs were cluttered with extra furniture, books, and other materials and were not set up to use for lab work.

"We want to use the labs but we don't have time to get them set up. Plus we need additional funds to buy consumable materials."

\section{- Fifth-Grade Teacher}

In spite of these observed challenges, there were some bright spots. Several stellar lessons were observed where the excitement and expertise of the teacher, along with the pure joy of the students, signaled the teachers' and students' readiness for better science learning. In these classes, one observed more challenging tasks assigned to teams of students who worked together on investigations and on presentations of their observations and findings. There was student discussion of the evidence and how to interpret it and how to explain it. Teachers monitored student understanding of the key ideas and used peer tutoring or re-taught when they noticed that some students were struggling.

"When the students come back from lunch and see the goggles and the bags of materials on their desks, they clap their hands and you can hear the excitement in their voices. They love doing science."

-First-Grade Teacher

"The students love working with their science team. They manage their own behavior because they want so much to have this time and they know if I constantly have to stop them to get them on task, they won't have time to complete the module and write in their notebooks. They feel so "grown up" when they are writing about what they are observing." 
"When there are concrete examples that students can hold, like the rocks you saw me working with today, the students can compare and contrast and talk in very specific ways about what they are observing. The language they use is much more descriptive and they have really interesting conversations with their classmates. This provides us with a structure to really expand their conceptual knowledge and build their scientific vocabulary."

-Third-Grade Teacher

\section{Findings from the Middle Level Classroom Observations}

Twenty-five middle-level classrooms (grades six, seven and eight) were observed during the October school visits; 12 additional middle-level classrooms were observed in April. Table VI presents the ratings given by the observers for all 37 classrooms. The patterns for the middle grades are similar to those in elementary classrooms, classroom organization was generally good and there were clear learning goals. However, the classroom climate was somewhat less positive than in the elementary schools and less student-centered, and disciplinary problems were observed more frequently and often disrupted instruction.

Again, the observers felt that the concepts were unclear or poorly presented. Only 16 percent of the teachers were given high ratings for presentation of concepts. Many students seemed bored and disengaged. Observers noted other instructional weaknesses similar to those observed in the elementary classrooms: relatively low effectiveness in areas of student engagement in higher-order thinking; creating opportunities for student discussion; effective use of student teams; monitoring student progress during the lesson; and limited provision of closings with review and reflection.

"It really is a challenge to motivate these students. They really don't behave well enough to trust them to do the labs."

- Seventh-Grade Teacher

The higher level of teacher understanding of subject matter is a result of using teachers who are certified as science specialists in the middle grades. Typically, these teachers were responsible for teaching science to all students or in some cases, math and science; unlike most elementary teachers, they did not have responsibility for teaching all four core content areas.

"I have the desire to teach science and I am prepared to teach it, but without assistance such as another adult or someone to help me the students just can't do this without constant support; if they get frustrated and I'm not there, then they start acting up and breaking the equipment."

-Eighth Grade Teacher 
Table VI

Ratings of Middle Grade Instructional Practice

\begin{tabular}{|c|c|c|c|c|c|c|}
\hline \multirow[b]{2}{*}{ Indicator } & \multicolumn{4}{|c|}{$(\mathrm{n}=37)$} & (ed) & \\
\hline & $\begin{array}{c}1 \\
\text { (low/poor) }\end{array}$ & 2 & 3 & 4 & $\begin{array}{c}\mathbf{5} \\
\text { (high/ } \\
\text { excellent) }\end{array}$ & $\mathrm{n} / \mathrm{a}$ \\
\hline 1. Classroom organization & 8 & 11 & 16 & 24 & 38 & 3 \\
\hline 2. Classroom climate & 16 & 19 & 14 & 27 & 24 & - \\
\hline 3. Clear learning goals & 11 & 19 & 16 & 24 & 27 & 3 \\
\hline $\begin{array}{l}\text { 4. Lesson linked to prior } \\
\text { knowledge }\end{array}$ & 32 & 5 & 14 & 22 & 16 & 11 \\
\hline $\begin{array}{l}\text { 5. Concepts clearly } \\
\text { presented }\end{array}$ & 36 & 22 & 22 & 11 & 8 & - \\
\hline $\begin{array}{l}\text { 6. Students engaged in } \\
\text { higher order thinking }\end{array}$ & 43 & 19 & 24 & 8 & 8 & - \\
\hline $\begin{array}{l}\text { 7. Student discussion } \\
\text { encouraged }\end{array}$ & 43 & 19 & 19 & 11 & 8 & - \\
\hline 8. Effective use of teams & 43 & 16 & 5 & 11 & 16 & 8 \\
\hline $\begin{array}{l}\text { 9. Teacher understood } \\
\text { subject matter }\end{array}$ & 16 & 8 & 14 & 30 & 22 & 11 \\
\hline $\begin{array}{l}\text { 10. Teacher monitored } \\
\text { student progress }\end{array}$ & 32 & 16 & 27 & 19 & 5 & - \\
\hline $\begin{array}{l}\text { 11. Closing with review and } \\
\text { reflection }\end{array}$ & 57 & 8 & 14 & 3 & 3 & 16 \\
\hline
\end{tabular}

Source: CPRE/MISE site visits, Oct 2010 \& April, 2011; Rows may not add to 100 due to rounding error.

In the middle grades, few "hands-on" investigations were observed and most of the lessons were not engaging or investigative in nature. The reduction in staff has had less impact on the middle-grade science teachers, but still some teachers indicated that they would be teaching modules for the first time as their grade assignments, and in some instances, subject assignments had changed. Complaints about the timeliness of the arrival of the modules and the overwhelming task of preparing for inquiry-based science instruction were voiced by many of teachers, especially as they were missing the assistance that had been provided by the lead science teachers. The lead teachers had often helped set up the labs and sometimes taught lessons for the other science teachers.

"We really depended on the lead science teacher to get the materials and labs together for us. We don't have time to get into the lab and set things up with all the other planning we have to do."

- Eighth Grade Science Teacher

"I am teaching Properties of Matter and Force and Motion at the same time. I have a 50 minute class and have to shift to the module for the next class. No time to set up. I have 120 students in 5 classes."

- Middle Grade Science Teacher 
Teachers also said that they did not rely on data to guide instruction because the data from the district benchmark assessments and the state tests that was available to them was not of much help.

"We have state tests and Learnia." Neither is very useful to us. The district assessments are not aligned with what we are teaching. The FOSS assessments are too easy. We need help in this area."

- Sixth-Grade Teacher

One particularly well-taught lesson was a bilingual class of sixth-grade students. The teacher who had previously served as the lead science teacher combined a mini-lesson with group investigative work, and she and the bilingual teacher rotated among the groups. What we observed was a well-planned lesson with several carefully explained steps and two teachers who worked together to make sure all the students progressed through the investigation. Where other teachers might see this as an insurmountable challenge, these teachers recognized that the inability to read on grade level, a predictable challenge for many middle level bilingual students, could be mediated with a group investigation in which students helped one another.

"Investigations work well for bilingual students. The reading demand is not a barrier to their learning."

- Sixth-Grade Teacher

\section{Findings from the High School Classroom Observations}

Twenty-two high school classrooms (grades 9-12) were observed during October; only seven additional high school classrooms were observed in April. Table VII indicates the ratings given by the observers for the 29 classrooms. Here we see stronger ratings. Classroom organization and climate received high ratings, and the clarity of learning goals, connections with prior learning, conceptual clarity, teacher content knowledge, and monitoring student progress received relatively higher ratings. However, the observers still saw low cognitive demand lessons in half of the classrooms, and there was little extended student discussion, limited use of teams, and a serious problem with lesson closings.

"The students will participate as long as the assignment isn't too hard. They like to draw replicas of cells and things and use the colored pencils and make a poster board that we hang in the room; if I try to get them to read much or write much, I can anticipate that some of them will put their heads on their desks or ask for the bathroom pass and that will be the end of their work for the day."

- High School Biology Teacher

There is clearly more capacity in the high schools for teaching science as a result of state certification requirements. The certification requirements ensure that high school teachers have strong backgrounds in basic science and some knowledge of content pedagogy. The high schools also are departmentalized and there are more possibilities for job-embedded learning and joint planning as the science teachers have regular times to meet together. Two of the

\footnotetext{
${ }^{7}$ Learnia is a Pearson formative assessment product that has been customized for New Jersey and has been administered by grade 3-8 teachers in Newark. Typically the assessments are administered four times: twice each semester.
} 
schools observed were exam schools, one focused on science education and the other on college preparatory instruction.

"There is considerable expertise in our science department. We have teachers who were medical doctors and research scientists and they bring real-world knowledge to their teaching."

- Secondary Science Department Chair

"We have teachers who know the content but they don't relate well to urban kids; some of the teachers expect school to be like the ones they attended in their own countries where if students didn't show an interest they were sent home. That's not how it works. We have to engage the students and make the learning realworld. Some of the teachers don't think they should have to do that, and that is not only the case for foreign-born teachers."

-High School Principal

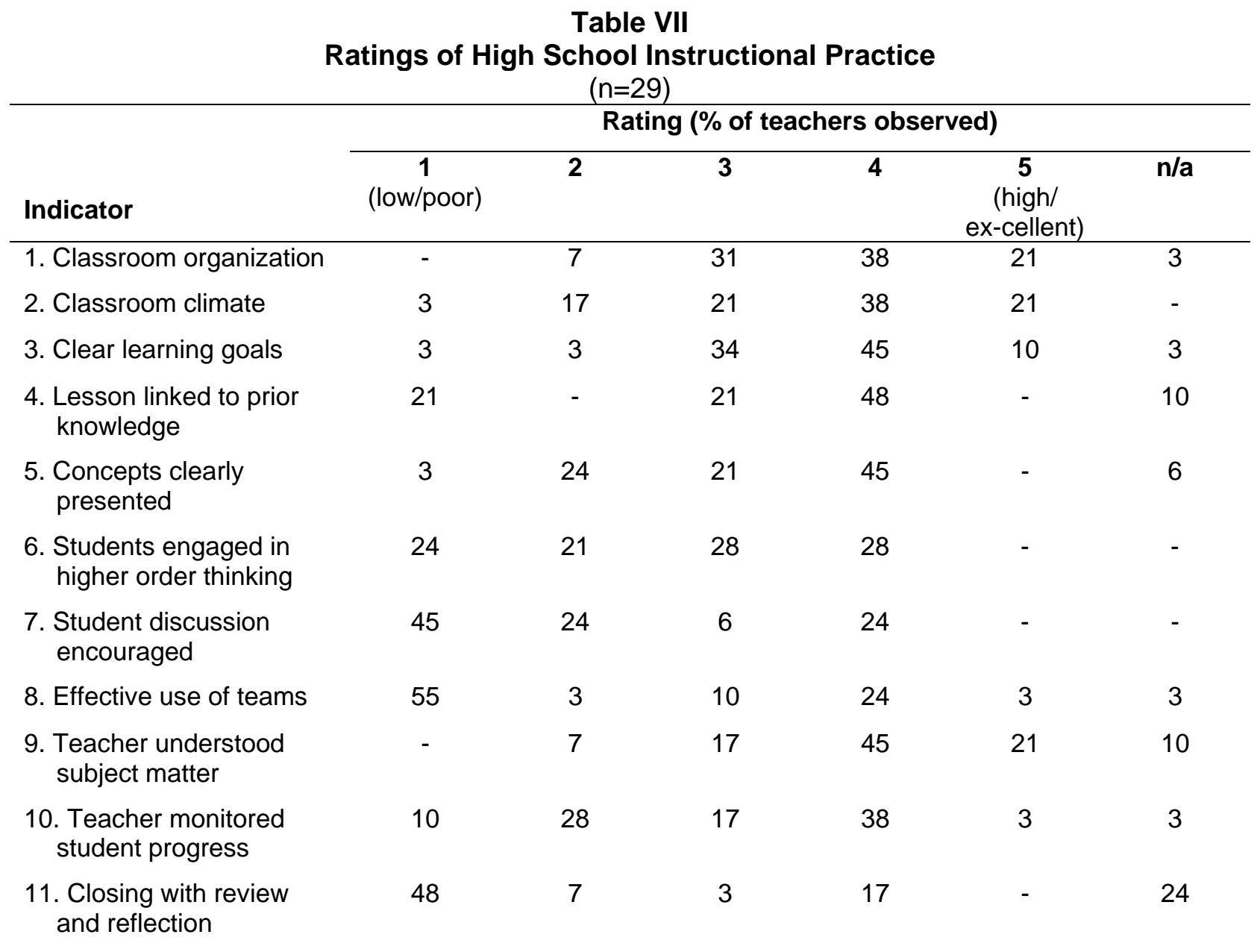

Source: CPRE/MISE site visits, Oct 2010 \& April, 2011; Rows may not add to 100 due to rounding error.

The high schools, and one middle school, were the only sites at which the use of science labs was observed. One of the four high schools visited was a magnet and the facilities and equipment far exceeded those of any other schools in which we conducted observations. It 
should be noted, however, that there were two student research lab rooms that were not in use because of lack of funds to equip them properly.

“Lack of resources is always a problem. We aren't able to get the consumables we need to do the labs. We end up spending our discretionary [school-based] money on lots of those things."

- High School Physics Teacher

In sum, in the high schools, the use of student teams in classrooms was limited; teacher monitoring for understanding and reviewing and reflecting at the close of a lesson were observed less than one-third of the time. In the majority of high school classrooms observed, teaching was didactic and often characterized by the teacher reading from a PowerPoint and by students taking notes. Teachers were specifically telling the students word for word what to copy. The cognitive demand of the work was generally low. Classroom management with active adolescents was often challenging.

"I am hopeful once we get all our curriculum maps completed teachers will have the general sequence and units laid out and then they will begin to think more about lesson design and how to open the lesson and close the lesson to make sure students start and end with the key concepts. We haven't done nearly enough in our team meetings with that. It seems like we are always playing catch up."

-High School Science Department Chair

\section{Teacher Behaviors and Characteristics}

While the data presented in Table VIII suggest that secondary teachers displayed stronger content knowledge and were more likely to use formative assessment strategies, most of the key elements of effective practice were infrequently observed at both the elementary and secondary level. The data in Table VIII indicate the need at both levels of schooling for more focus on student conceptual understanding through focused lesson design, for assignment of more challenging tasks, for more student discussion, and for increased use of higher-order questioning and other forms of formative assessment. It is notable that the classroom ratings on conceptual clarity of lessons, use of intellectually challenging tasks, student discussion, use of student teams, formative assessment, and lesson closings were consistently low in threequarters of the schools.

While there was some variation in these ratings within schools, there was much larger variation across schools. That is, instruction within the classrooms in a school tended to look similar. It was either relatively low demand, rote and focused on facts, and control-oriented or it was high demand, participatory, focused on skills and concepts, and student-centered. This pattern of consistency within schools is counterintuitive as researchers commonly find more variation within schools than across schools. Here the opposite pattern appears to hold suggesting the powerful interactive effects of professional and student cultures on classroom practice. In the eighteen schools visited, there appear to be modal forms of instruction that reflect the professional norms in the building, the quality and perhaps stability of school leadership, and the behavior and attitudes of the students. 
Table VIII

Teacher Behaviors and Characteristics:

Elementary ( $n=11 ;$ black) and Secondary ( $n=7 ; *$ gray) Indicator

Observed Condition or Practice

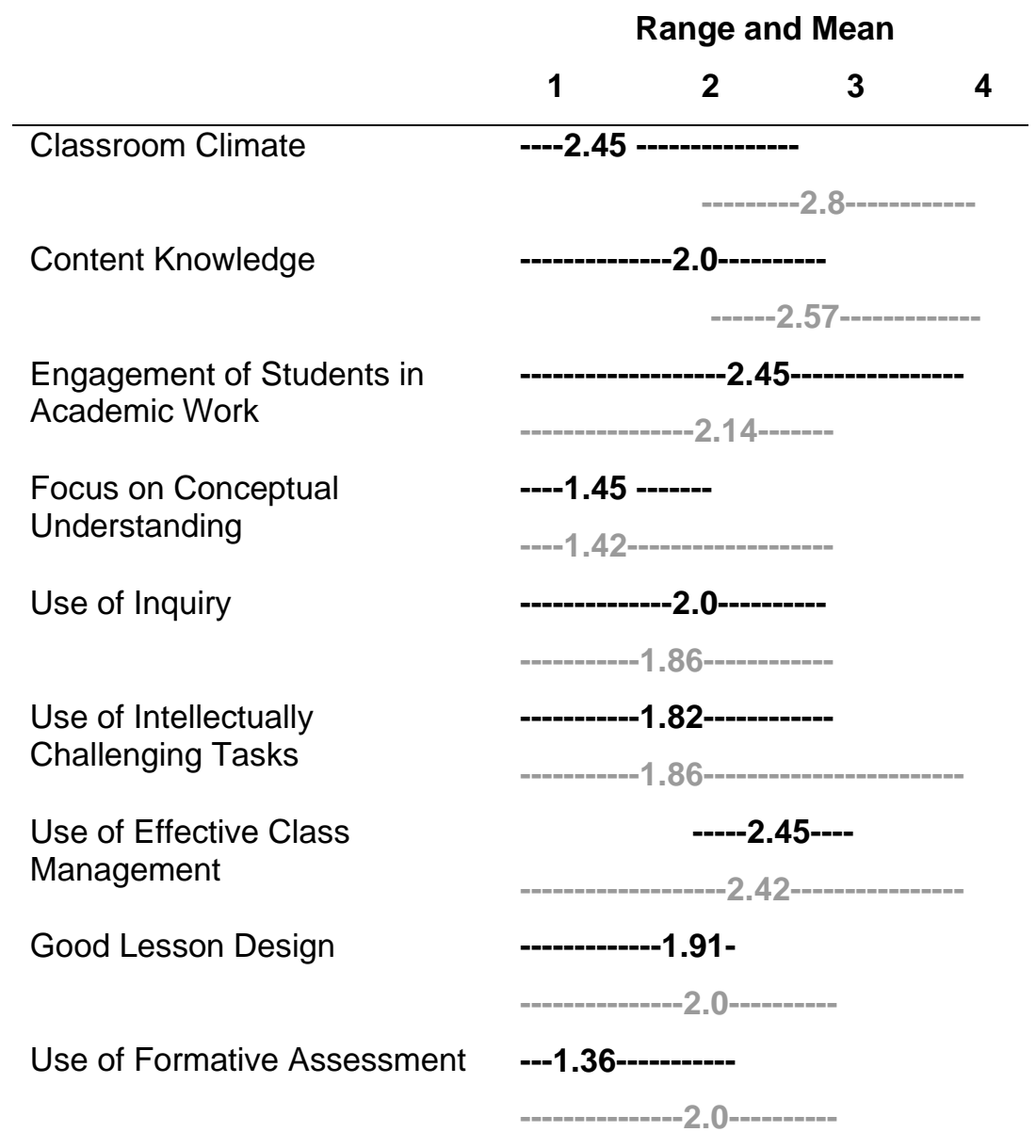

$* \overline{T h e}$ seven secondary schools include 6 high schools and one middle school. Source: CPRE/MISE site visits, Oct 2010 \& April, 2011 


\section{The Schools}

The CPRE/MISE teams also rated each of the 18 schools on indicators of school quality (see Appendix A). Each member of the team rated the school independently and then they compared their ratings and where they differed, they discussed their ratings and reached consensus on a rating. The ratings are presented in Table IX below. Only three of the indicator ratings show notable differences between elementary and secondary schools (secondary in this instance includes both middle and high schools). The three are class size, time allocations for science instruction, and organized efforts to improve instruction. Those differences are easy to understand. Class sizes have been kept low in the elementary grades by district policy aimed to improve literacy skills. Time allocations for science also are lower in elementary schools as a matter of policy. And organized efforts to improve teaching are more likely to be found in elementary schools because the district has made improving literacy and math performance in elementary schools a high priority and invested in these initiatives.

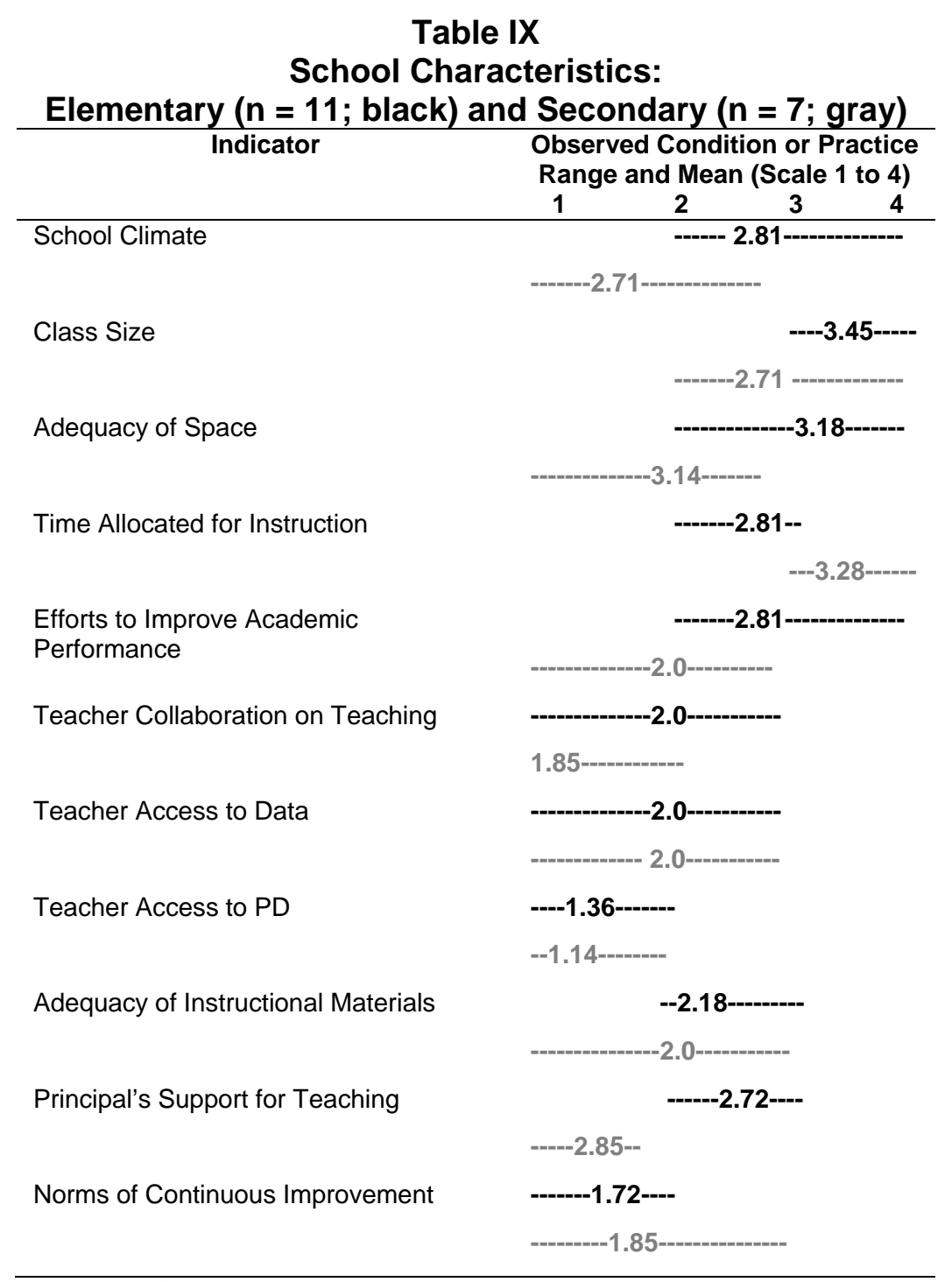

Source: MISE Survey, May 2011 
There is greater variation within the ratings for secondary schools for some indicators. This no doubt reflects the fact that the sample of high schools included both comprehensive neighborhood high schools that serve all children and exam schools that are selective based on performance. The conditions of teaching are dramatically different in Newark high schools. That is, there are large variations in the quality of school leadership, the rituals and routines within buildings, the relationships among staff, students, and parents, and the professional norms that shape teacher behavior.

In the rest of this section, we will discuss each of the eleven indicators briefly, drawing on the data from the school visits, including the principal interviews and teacher focus groups, and relevant data from the MISE survey.

\section{School Climate}

School climate tended to receive higher ratings than the other indicators in most of the schools. The schools were orderly and generally quiet during class time. Discipline problems were observed in some classrooms, but the halls were empty and quiet. One exception to this overall finding was a pattern of tardiness to class in several schools that created a lot of confusion and clamor in the halls in the first five to ten minutes of each class. Another exception was the abrupt manner of some teachers (Sit down, you will do it because I say so, etc.) in dealing with students. While teacher-student relationships were strained and tense in a number of classrooms, and more frequently in higher grades, most classrooms were warm and supportive.

"I'm a graduate of this school. I graduated and went to college because a teacher took an interest in me. It was not my family that encouraged me to do well and continue my education. They're proud of me and what l've accomplished but it was my biology teacher that helped me make this happen. I want to be like that to these kids. That's why I do what I do."

-High School Biology Teacher

There were no items on the MISE survey that addressed the overall climate in a school. There were items that addressed aspects of professional climate and they are discussed below under Teacher Collaboration.

\section{Class Size}

The MISE survey collected no data about class size. The teams did not systematically collect data on the size of science classes in the schools they visited, but they did record the sizes of the 121 observed classes. Based on this large but unscientific sample, class sizes seemed reasonable, averaging about 25 students and rarely over 30 . They were somewhat smaller in the primary grades. Although the class sizes seemed reasonable to the observers, it should be noted that in focus groups and interviews, some teachers indicated that class size was a barrier to teaching science.

"I need an aide or another teacher, like the lead science teacher last year, to keep the students focused and working on the task. They get distracted very easily and you can't be everywhere at once."

-Second-Grade Teacher 
Given the literacy needs of some students in the intermediate and middle grades, it is understandable that teachers might want smaller classes. Twenty-eight to thirty students seems reasonable but it does not allow for much individual attention.

\section{Space and Equipment}

Most of the elementary science lessons were conducted in regular classrooms. Some of the schools had dedicated science labs, but these were often poorly equipped-lacking microscopes, balances, and glassware-and in some cases, suffering from neglect.

The labs in the comprehensive high schools were more heavily utilized but those in the comprehensive high schools also suffered from lack of resources. In contrast, the labs in the magnet schools were excellent and heavily utilized. However, in the magnet schools, teachers also cited a failure to budget adequately for consumables.

The MISE survey asked teachers about the kinds of equipment they would like to have for the curriculum they have to teach. The results are presented for K-8 teachers in Table X and for 912 teachers in Table XI.

\begin{tabular}{lccc}
\multicolumn{4}{c}{$\begin{array}{c}\text { Table X } \\
\text { K-8 Teacher Responses on the } \\
\text { Need and Current Availability of Equipment }\end{array}$} \\
\hline Item & $\begin{array}{c}\text { Desirable } \\
\text { (\%) }\end{array}$ & $\begin{array}{c}\text { Not Available } \\
\text { (\%) }\end{array}$ & $\begin{array}{c}\text { Available but not } \\
\text { enough } \\
\text { (\%) }\end{array}$ \\
\hline Faucets and sinks & 61 & & 26 \\
Electric Outlets & 32 & 50 & 53 \\
Gas for burners & 18 & 13 & 2 \\
Lab tables & 46 & 95 & 12 \\
Fume hoods & 9 & 79 & 2 \\
Glassware & 18 & 95 & 12 \\
Microscopes & 58 & 77 & 21 \\
Scales/balances & 47 & 69 & 45 \\
\hline
\end{tabular}

Source: MISE Survey, May 2011

These data make the resource problems in the elementary schools vividly clear. K-8 teachers are attempting to teach science without basic equipment such as faucets and sinks, lab tables, microscopes, and balances. While the modules provide the materials needed for the investigations in the units, the lack of equipment limits what teachers can do to address the curriculum.

"We really are at a disadvantage with the lack of equipment for science. Often times when we open our kits we realize that we need additional scales or batteries or whatever. We have very little here at the school to support science"

-Seventh Grade Teacher 
Table XI

High School Teacher Responses on the Need and Current Availability of Equipment

\begin{tabular}{lccc}
\hline Item & $\begin{array}{c}\text { Desirable } \\
\text { (\%) }\end{array}$ & Not Available (\%) & $\begin{array}{c}\text { Available but not } \\
\text { enough } \\
\text { (\%) }\end{array}$ \\
\hline Faucets and sinks & 71 & 12 & 24 \\
Electric Outlets & 69 & 4 & 35 \\
Gas for burners & 52 & 41 & 13 \\
Lab tables & 69 & 18 & 12 \\
Fume hoods & 48 & 56 & 20 \\
Glassware & 58 & 11 & 37 \\
Microscopes & 62 & 17 & 47 \\
Scales/balances & 65 & 8 & 50 \\
\hline
\end{tabular}

Source: MISE Survey, May 2011

The data in Table XI show that high school teachers have more equipment to work with than their K-8 peers, but there are still basic needs to be met-shortages of balances, microscopes, glassware, and access to gas for burners. Providing effective lab experiences without this basic equipment is challenging.

Almost half of the principals surveyed (46 percent) indicated that lack of equipment inhibited the teaching of science. This included principals from high schools as well as elementary schools.

\section{Time Allocation and Use}

The elementary schools are expected to schedule three periods of science instruction for a total of 150 minutes per week in grades $\mathrm{K}$ to five and two periods of health. For grades six, seven and eight, there are five periods of science weekly or 250 minutes. In the high schools, students must pass three year-long science classes, including biology to graduate.

However, as discussed earlier, elementary teachers are in self-contained classes and have considerable discretion over time allocations in most schools. From comments made by teachers, it seemed that science was not being taught three times a week in all classes as teachers responded to the pressures to improve literacy and mathematics scores on the state tests. In two schools, the science modules had not been distributed to teachers two weeks after they had been delivered to the school. In other schools, unopened modules were observed in some classrooms.

"When what you are really judged on is how well your students do in math and reading, that's what you are going to spend your time on. Our kids need all the time they can get working on math and reading and I don't feel badly sometimes substituting math or reading for science."

-Fourth Grade Teacher

On the MISE survey, K-8 teachers reported teaching science on average 175 minutes a week. This is about what we would expect from averaging out the 150 minutes allocated in grades K-5 and the 250 allocated in grades 6-8. If many teachers were reducing the time for science, we would expect this average to be lower. The teachers may be giving the official response rather than an estimate of the actual instructional time. 
Fifty-four percent of the K-8 respondents and 73 percent of the high school teachers indicated that lack of time was a factor in their decisions to skip activities in the modules or curriculum they were using.

A majority of the K-8 teachers also reported that the amount of time available for planning (54\%) and the amount of time available for collaboration (64\%) inhibited their teaching.

"When we had a lead science teacher she would organize planning time meetings where we would talk about the modules and how to teach them. Now that we have to organize ourselves, this gets lost in all the other things we need to be doing."

-Seventh Grade Teacher

High school teachers were less likely to report planning time and time for collaboration as inhibiting factors, but still nearly half of them (47\%) reported a lack of time for collaboration inhibited their teaching.

\section{Efforts to Improve Instruction}

Instructional improvement efforts were underway in many of the elementary schools and some of the secondary schools. However, most of these efforts were focused on literacy and mathematics instruction. In many schools math and literacy coaches were working with individual teachers and groups of teachers. Other schools had developed additional strategies. For example, one school had developed its own system for monitoring the progress of all students in the core subjects on a monthly basis and planning interventions for students who feel behind and providing support to teachers who needed it. While discussions of science instruction were reported in a small number of schools, we observed no well-planned, systematic efforts to improve science instruction in any of the schools.

\section{Teacher Collaboration}

Teacher collaboration ratings were low in the elementary schools because the schools either lacked mechanisms for collaboration following the elimination of the lead science teacher or the mechanisms in place-meeting with the math coach or periodic team or departmental meetings--were weak or infrequent with regard to science. In the middle grades, there were grade-level team meetings, but in most cases, these seemed to deal with administrative issues or review of assessment data, with little attention to instruction. However, it should be noted that in some schools, the principal finds a way for teachers to meet and collaborate to plan for instruction.

"We have professional learning communities by grade levels and at the middle school grades by subject, math/science and reading/social studies. We expect the teachers to meet every week and talk about how to strengthen their teaching." -Elementary School Assistant Principal

There is detailed data from the MISE survey about teacher collaboration. Some of these data are summarized in Table XII. 
Table XII

Percent of Teachers Reporting

Opportunities to Collaborate

\begin{tabular}{lcccc}
\hline Area of Collaboration & $\begin{array}{c}\text { Self-contained } \\
\mathbf{K}-\mathbf{8} \\
(\mathrm{n}=170)\end{array}$ & $\begin{array}{c}\text { Departmental } \\
\mathbf{7 - 8} \\
(\mathrm{n}=26)\end{array}$ & $\begin{array}{c}\text { Departmental } \\
\mathbf{9 - 1 2} \\
(\mathrm{n}=52)\end{array}$ & $\begin{array}{c}\text { Special Ed } \\
(\mathrm{n}=24)\end{array}$ \\
\hline $\begin{array}{l}\text { Discuss innovative } \\
\text { practices }\end{array}$ & 45 & 71 & 69 & 39 \\
$\begin{array}{l}\text { Reflect on teaching and } \\
\text { learning }\end{array}$ & 63 & 76 & 76 & 39 \\
$\begin{array}{l}\text { Observe other science } \\
\text { teachers }\end{array}$ & 20 & 17 & 54 & 27 \\
$\begin{array}{l}\text { Discuss effective practices } \\
\text { for special needs students }\end{array}$ & 32 & 44 & 44 & 45 \\
$\begin{array}{l}\text { Plan and prepare lessons } \\
\text { during the day with other }\end{array}$ & 46 & 33 & 45 & 48 \\
science teachers & & & & \\
\hline
\end{tabular}

Source: MISE Survey, May 2011

The departmentalized teachers were somewhat more likely to report collaboration on practices, and the high school teachers were much more likely to have opportunities to observe other teachers. Overall only about half of the teachers reported opportunities for collaborative work, and we do not know how much time is allocated for such work. Based on the site visits, the time seems to be quite limited.

\section{Teacher Access to Data}

In most schools, there were meetings to discuss the results of the interim assessments, but the teachers did not find these assessments very helpful, in part because they were not always well-aligned with the modules being taught and in part because the results were provided to the teachers after the units were finished and there was little opportunity for or expectation of reteaching. Responding to the MISE survey, about three quarters of the K-8 teachers indicated that they had discussed the results of at least one, or typically two, of the benchmark assessments with colleagues, used these results to modify instruction, and reviewed the results with students. About 60 percent reported that the data from the benchmark assessments facilitated their teaching, and a similar percent reported the same about the state science assessment.

More attention was given the state assessment results in science; three-quarters of the K-8 and a slightly smaller percentage of high school teachers reported discussing how to prepare students for the state science assessment and reviewing the results with colleagues. However, given the limited diagnostic value of the state test and the fact that the results come after the school year ends, it is not clear if or how these data affect instruction other than by identifying broad topics that need attention.

There was little evidence of any form of formative assessments being used regularly by teachers across the district, with the exception of a carefully developed system for examining student work samples implemented in one school. While the approach taken in this school seemed quite effective and had been in use for a long time, the administrators reported there had been little interest in their practices from the central office or other schools. 


\section{Teacher Access to Professional Development}

Prior to the 2010-11 school year, K-8 teachers in Newark had access to at least three forms of professional development: on-site support from lead science teachers in each school as well as occasional visits from the Science Resource Teacher Coordinators and access to one-day or half-day workshops on specific modules at the Banneker Science Center. Access to professional development for high school teachers seemed to vary more by school and was highly dependent on the projects in which the individual teacher was engaged.

Following the budget cuts made in 2010, the lead science teachers' positions were eliminated and the Banneker Center was closed. Teachers in the K-8 schools reported little or no access to professional development in science. Many teachers were being asked to teach science modules for the first time, due to the re-assignments triggered by the budget cuts, and they often received no support. In some schools, the former lead science teachers continued to provide some support but this support was minimal. The Science Resource Teacher Coordinators (SRTCs) were asked to cover a large number of schools, and often were given other administrative duties so their support for individual teachers was limited. Only 22 percent of the K-8 teachers reported having opportunities to attend science conferences, 30 percent reported opportunities to attend professional development on the modules, and 23 percent reported opportunities to attend other forms of professional development. On the principals' survey, most of the respondents concurred with this grim assessment of the situation, indicating that the level of professional development was inadequate to support the goals of the science program (67\%).

In the high schools, the situation was a little better. About a third of the teachers reported attending professional development on teaching science and nearly half reported attending science conferences. But based on the discussions conducted with teachers during the site visits, it seems these opportunities were limited in duration.

As two of the four SRTC positions have been eliminated for the 2011-12 school year, the situation seems even grimmer. Presently, there is no district-wide strategy for providing professional development in science.

\section{Adequacy of Instructional Materials}

The ratings were relatively low on this indicator; four major issues were raised by K-8 teachers about the adequacy of the instructional materials provided by the district. First, teachers reported that the district had not allotted enough time for them to complete the activities in the modules. This was related to the second issue which was that many students lacked the literacy skills to use the materials in the modules. Others reported that the reading materials that went with the modules and that the teachers found helpful were not replenished and were often missing.

"The supplemental books that came with the modules were very useful, but they got lost or torn, or teachers kept them in their classrooms, and they were never replaced. So now there may be just a few copies left, maybe none. They helped get students engaged in science."

-Fifth-Grade Teacher 
The third issue was that teachers wanted a science textbook to supplement the modules and to use between modules. The fourth issue was that the benchmark assessments developed and used by the district were aligned with the CPIs rather than the modules, so students would encounter questions on content they had not studied.

"We need science textbooks and follow-up worksheets. Our students need to take some reinforcing activities home to do as homework and we have nothing to give them and not enough time to develop things. This is a real problem."

-Sixth-Grade Teacher

Some teachers raised issues about the delivery and replenishment of the modules, contending that they arrived late or were not distributed in a timely way in the school. The latter issue reflects the loss of the lead science teacher position as he/she often was responsible for checking and distributing modules and some principals had not put a new system in place. The issue of replenishment came up particularly for grades seven and eight where the modules are supposed to be replenished by the school rather than a contractor as in grades $\mathrm{K}$ to six. In some schools, this was not done in an organized way.

The MISE survey adds some useful information about the adequacy of materials. While over three-quarters of the teachers reported teaching the required three modules or more, 60 percent of them said that they used less than three-quarters of the activities and a third of all teachers reported skipping activities in the modules because of lack of materials. In fact, only 45 percent of the respondents indicated that the modules would constitute three-quarters or more of the curriculum for the year; 22 percent indicated that the modules would constitute only half of the curriculum or less.

Forty-three percent of the K-8 teachers reported that the quality of the instructional materials provided inhibited their teaching and 54 percent indicated that lack of access to technology inhibited their teaching.

At the high school level, the situation was different as the majority of teachers (57\%) reported relying on a single textbook. Eighty-nine percent of the respondents indicated that they had relied to a moderate or great extent on a textbook for the most recent unit they had taught. Over half $(57 \%)$ indicated they had followed the text page by page in the most recent unit they had taught. This is consistent with the observations made during the site visits in which the observers concluded that the curriculum was largely driven by textbooks.

Nearly 90 percent of the high school teachers reported that they were able to obtain the print materials that they needed. Ninety percent indicated they had to supplement the textbooks with other material because additional material was needed to address the CPIs and the state assessment, provide students with adequate practice, and because they needed to help students at different levels make progress.

\section{Principals' Support}

Data from the teacher focus groups conducted in the 18 schools visited by CPRE/MISE teams shows that science teachers felt that they received limited support from their principals. For the most part, they felt science was not a priority and that the principals were focused on literacy and mathematics. Given the accountability system and the district's investment in improving literacy and mathematics, this is not surprising. 
The principals themselves had a strongly positive view of their science programs. Responding to the MISE survey, two-thirds of them indicated that the science program was relevant and the science modules provided engaging experiences for students. Over 80 percent indicated that the interest of the science teachers in improving teaching was a positive factor. They also reported that they were able to provide adequate instructional time for science (80\%), could ensure that teachers followed the pacing guides (93\%) and taught all of the lessons in the modules (64\%), and 76 percent said they could provide time for science teachers to meet. A third indicated that they observed science lessons at least once a week, two-thirds indicated they observed science classes several times a month.

However, 67 percent of the principals indicated that the available professional development was inadequate, 65 percent reported they could not fill vacancies with teachers who were wellprepared to teach science, 57 percent said they could not provide orientations for teachers teaching a module for first time, 59 percent indicated that teachers lacked knowledge of effective practices, 47 percent indicated they had inadequate time to discuss science instruction with teachers, and 88 percent indicated that the budget cuts inhibited their capacity to improve science instruction. On the latter point, all of the principals agreed that the loss of the lead science teachers had a major impact on their science programs.

\section{Norms of Continuous Improvement}

A few principals espoused continuous improvement and were making efforts to build such cultures. At least three elementary schools had developed strong professional norms to guide instruction and were focused on improvement, but they stood out as exceptions to the overall pattern. The more general pattern appeared to be to review the state assessment scores, set priorities, and implement new strategies or materials in a rather random way. One might describe these schools as treating improvement as a responsibility of individual teachers rather than a collective responsibility. The test scores are analyzed, experts are consulted, but there is little or no follow-up to see if anything changes in the classrooms. Moreover, to the extent that principals were concerned about improving instruction, they were focused on math and literacy and not science.

Many teachers indicated on the MISE survey that they contributed to improvement of the science program in their school (44\%), felt supported by colleagues when they tried innovations $(68 \%)$, continually found ways to improve science teaching $(92 \%)$, and were willing to be observed by their peers (84\%). These self-reported "norms" of practice are somewhat at odds with what the review teams observed and reported.

\section{The Importance of School Culture}

In reviewing the observational data for the elementary, an interesting pattern was found. Over 70 percent of the high ratings (fours and fives) given for various aspects of classroom practice were assigned to teachers in three of the 11 elementary schools visited. In these three schools, the ratings were uniformly higher and were higher across a broader span of indicators. For example, in these schools the ratings for linking lessons to prior knowledge, engaging students in higher order thinking (cognitive demand of lessons), conceptual clarity, and monitoring of student understanding were higher.

The school ratings for the three schools are also much higher on the 11 indicators. They received higher ratings than other elementary schools on efforts to improve instruction, teacher collaboration, principal's support for improvement, and norms of continuous improvement. 
These schools deserve a much closer look, but a review of our data suggests that they have more involved and stable leadership, well-established norms of practice, mechanisms for monitoring performance of students on a regular basis, and opportunities for teacher collaboration. These schools may be serving somewhat different populations than other Newark schools; the families they serve may be slightly more affluent, more likely to be intact and employed, and more involved in their children's education. It is not clear whether the attitudes and behaviors of the children permit the observed practices or the observed practices are affecting the children positively or perhaps the two factors interact in a positive way. Whatever the causal relationships, it is clear that the coherent and positive professional cultures in these schools contribute to their success and allow them to make sustained improvements. They offer demonstrative proof that it is possible to develop strong professional cultures and provide high-quality instruction in Newark.

"I love working in this school. I am not afraid to ask any of my teacher colleagues for help. No one looks down at you if you ask for help. There is a family spirit here and it makes it a much better place for teachers, families and, most importantly, our students."

-Fifth-Grade Teacher 


\section{System Issues Related to Science Education}

As noted earlier in the report, the system support for science education is precarious. Teachers and principals expressed perceptions that support for science was eroding as evidenced by the closing of the Banneker Center, the elimination of lead science teachers in the elementary schools and the limited attention to science professional development at the district level. The entire central office science staff is one person. Further cuts to district staff for the 2011-2012 school year support these perceptions. The Science Resource Teacher Coordinator (SRTC) positions were reduced by 50 percent so that in the 2011-2012 school year, two staff members will work in this capacity; the position has been retitled Master Teacher.

In phone conversations with central office science staff there was optimism about new curriculum work that was being completed but some apprehension about the mechanism for enabling all teachers to be prepared to teach the new curriculum this coming school year. Plans to augment new units with materials were being developed and professional development was being planned for the roll-out of units. Subsequent to these interviews, the district announced that the new science curriculum was being reviewed by the new superintendent.

There was also concern that loss of district staff would make it even more difficult to support science implementation in the school. Additional conversations with English language arts, mathematics and professional development staff members confirmed the concerns about the loss of central office staff and the pressure this would create on already strained departments to meet the needs of the schools and teachers. When exploring the idea of interdisciplinary support of science, several leverage points surfaced. One area that appears to have promise in supporting literacy and research is the senior thesis requirement and the teaching of research skills in ninth grade using the lens of science. Media specialists received special training on how to support student acquisition of research skills. Another area where literacy and science could work more closely together would be on the science notebooks or journals that are common to most science courses. In addition, the new Common Core ELA curriculum emphasizes informational and nonfiction text, and there is a concerted effort being made to include science texts and themes in the curriculum.

\section{The MISE Review of Curriculum Materials}

MISE staff reviewed the curriculum documents used in the district. They examined examples both from the previously adopted version of the curriculum based on the 2004 New Jersey Core Curriculum Content Standards for Science (NJCCCS) and from a recently adopted version based on the 2009 state standards. Their full review is contained in Appendix F. Here we summarize their findings.

The review team looked at the curriculum guides for grades three, four, seven, eight, and high school biology. The review indicated that the documented authors of the guides were largely central office science staff, and that there was no evidence of broad-based input and support for the documents.

The curriculum guides propose a sequence of instruction that follows the order of the standards and Cumulative Progress Indicators (CPIs) in the NJ Core Curriculum Content Standards. The state standards are not intended to be an instructional sequence (NJSA 6A:8-3.1). Following a sequence matched to the CPI order interrupts the instructional sequence in the standards- 
based modules the district has adopted. For example, Properties of Matter is divided between grades six and eight rather than being used as a complete unit.

Related to this sequencing concern, the reviewers also report that the curriculum documents did not provide a clearly described plan "for the development of processes/skills/abilities over several years." The curriculum design did not offer "an order of introduction of concepts, either within a given year or across years" but was instead ordered around covering each CPI.

In many cases, the modules were separated into dissociated components within a grade level as well. The guide identifies only those investigations and lessons that correspond to the NJCCCS. For example, in the seventh grade Life Science unit, the module Organisms: Macro to Micro begins with Lesson 7, then moves next to Lesson 11, then back to Lesson 3, and so on. The reviewers highlight that the sequencing of the modules is based on documented developmental research and warn that, "Eliminating investigations or altering the chronological order may impact students' opportunities to develop an understanding of the targeted ideas."

The MISE report further notes that the curriculum guides identify many supplemental resources for teachers, largely from the Internet, and that many of the materials are not supported with research evidence, do not provide pedagogical support, and sometimes are not connected to the learning goals. For example, the cited CPI "5.8.A.2 Relate the structures of cells, tissues, organs and systems to their functions in supporting life" offers an associated resource called "Blow Up a Balloon with Yeast" from www.sciencebob.com. The proposed lab demonstration shows how adding yeast to warm water will result in the formation of carbon dioxide which is disconnected from the cited learning goal about the hierarchy of organization in living things.

Guidance for using the curriculum documents is lacking, and the documents vary in their contents. Based on the layout of the document, it is unclear what is required and which experiences are optional. For example, there are two categories of instructional materials offered to teachers to develop student understanding of each CPI. These are titled "Types of Research Based Activities and Assessments that could illustrate Objectives" and "Suggested Resources," and there is no indication as to which category has priority.

Overall, the reviewers reported that there was limited participation from teachers and schoolbased staff in developing the curricular materials, challenges with sequencing of concepts, inclusion of supplemental material recommendations that lacked a research base, and lack of guidance for using instructional time. Additionally, there is not sufficient time to provide all of the planned experiences. They also note, however, that the amount of time allocated to science seems to have increased in the new draft curriculum guides.

\section{HRI Review of the Newark Public Schools Benchmark Assessments}

As part of collecting information on Newark's existing science program, Horizon Research, Inc. (HRI) was asked to analyze two district-developed science assessments, one in the physical sciences and one in the life sciences. HRI examined two assessments: Force and Motion and Organisms Macro to Micro. Each assessment was reviewed by one or more HRI staff members and one external consultant. The purpose of the review was to examine the validity of the assessments. 
As HRI noted,

"There are a number of criteria that could be used to evaluate individual assessment items, or an entire assessment. In evaluating an item, one might examine the 'depth of knowledge' required, determining whether the item requires simple recall of information or is more demanding, asking students to apply or synthesize information. One might also look at the extent to which items are likely to identify misconceptions students have about an idea, either by utilizing common misconceptions in the writing of distractors for selected-response items, or by using scenarios for constructed-response items that are likely to elicit these misconceptions. Statistical techniques, such as factor analysis and item-response theory, can also be used to inform decisions about item validity. However, examining the two Newark assessments by these criteria was beyond the scope of the review."

HRI used four criteria for evaluating the assessment items that were based on principles of writing valid items utilized by a National Science Foundation-funded Math and Science Partnership project (ATLAST Award Number EHR-0335328). These criteria - necessity, sufficiency, content accuracy, and appropriate representations and language - are based upon work done by Project 2061. Applying the criteria helps determine whether answering an item correctly would likely be due to student comprehension of the ideas in the targeted content domain (i.e., the knowledge intended to be assessed), and whether answering incorrectly would likely be due to lack of understanding of those ideas. Items that could be answered correctly by students without knowledge of the content, or could be answered incorrectly by students with knowledge of the content, are not considered valid. The definitions of the criteria are found below along with summaries of the HRI findings.

Necessity: The "necessity criterion" specifies that answering an item requires knowing the targeted content.

HRI found about three-quarters of the 34 items on the Force and Motion assessment and twothirds of the 34 items on the Organisms Macro to Micro assessment clearly met the necessity criterion.

Sufficiency: Sufficiency means that the knowledge of the content being assessed is all the knowledge a student needs to answer the item correctly.

HRI found roughly two-thirds of the 34 items on the Force and Motion assessment and one-half of the 34 on the Organisms Macro to Micro assessment clearly met the sufficiency criterion.

Content Accuracy: Content accuracy means the item does not have multiple correct answers or items with no correct answers.

Overall, HRI concluded that most of the items on the two assessments met the content accuracy criterion, though the Force and Motion assessment had more items that did not meet this criterion than the Organisms Macro to Micro assessment.

\section{Appropriate Representations and Language: Would the use of language or representations cause students to answer an item incorrectly whether or not they understand the concept? \\ HRI found nearly all of the items on the Force and Motion assessment and most on the Organisms Macro to Micro assessment clearly met the appropriateness criterion.}

Overall, the HRI reviewers concluded that many of the seventh-grade items reviewed met the criteria on which they were examined. They concluded: "Responding correctly to these items 
requires knowledge from the targeted content domain to select the correct answer and to rule out the incorrect response options." HRI also stated: "...some items were identified as requiring knowledge outside of the targeted content domain, having content inaccuracies, and/or other issues which might impact students' ability to understand what the item was asking." Their report concludes that these problems could be solved by careful editing and by giving more attention to general principles of item writing. 


\section{The Challenges and Opportunities}

The assessment of science teaching in Newark has revealed a number of contradictions between the expressed desires of educators and their actual practice and between the district's aspirations for improvement, the quality of support provided, and the progress made. Such contradictions are commonplace in human affairs as our aspirations often exceed our reach and our capacity and work effort fall short of our aspirations. In Newark, many people work hard and the conditions for teaching are often difficult. Many school leaders and teachers are committed to the children they serve, but their efforts to improve often seem to fall short. Some blame the lack of progress on the children and their parents, on the lack of support from the district, on the lack of resources, or on poor leadership. Yet in some schools, principals and teachers have taken responsibility for improving performance and created positive cultures for learning--both by students and the professionals serving them. Nevertheless the aspirations in many schools are low, perhaps blunted by the experience of dealing with students lacking adequate literacy skills and a district without adequate resources. Newark needs to raise its aspirations--in science and in other disciplines--and encourage its educators to take more risks on behalf of much larger gains.

The Mayor's increased role in education, the possibility of new investments in the district's schools, and the arrival of the new superintendent present great opportunities for renewal of the public schools but are also serious distractions for those currently employed in them. There is considerable uncertainty about the future, and this is unsettling to most administrators and many teachers. Nonetheless, the current situation offers hope for a new direction and sustained improvement. However, in most of the schools visited, enrollment was declining, which was attributed to the expansion of charter schools, and some administrators expressed concern that the anticipated changes in leadership and governance would mean more charters and continued enrollment declines. Minimizing harm, while undertaking the transition from the old school system to a new, quite different one is the major challenge facing the new leaders.

In this section, we reflect on all of the data we have collected and on our experiences in Newark and raise a set of questions and issues for consideration by the MISE external review team and the NPS administration. We have organized these reflections into six broad categories that represent the domains in which actions might bring large dividends.

\section{Reflections}

In every instance, the principals and teachers in the visited schools were welcoming and expressed strong interest in working on improving science teaching and learning. Most of the schools were orderly and the class sizes were generally reasonable. Although many of the principals were new in their positions, most were able to articulate strong and clear visions for improving student achievement and most also expressed strong support for science, although science teachers often said that policies and actions did not reflect the principals' rhetoric.

There was a widespread belief that the students benefited from, and enjoyed the hands-on activities contained in the modules. Teachers indicated that the students responded well to the science kits in most classrooms. Yet our site visit teams saw few lessons from the modules, observed un-opened modules in numerous classes, and heard from many teachers that they selected lessons from the modules rather than teaching the entire module. 
There was universal agreement that students in Newark Public Schools deserved and needed high-quality science learning opportunities, and teachers and principals said they wanted to be able to provide them. However, here again the rhetoric was seldom matched with action. Science was not a priority in most of the elementary schools where time and resources were directed to the subjects that mattered most for accountability--literacy and mathematics. One could not blame the schools for focusing on what counts as it was also what students needed most. One could fault them, however, for failing to take advantage of science classes to extend literacy instruction and for failing to recognize the possibilities science offered for engaging and motivating students.

Responses to the teacher surveys indicated a willingness by the vast majority of teachers to engage in professional development activities that would improve their science practice, including being visited and observed by peers while they were teaching. While the teacher responses may be telling us what we want to hear, they also offer an opportunity to move forward. The teachers do not need more general professional development on science, they need to engage in serious, well-designed efforts linked to the instructional materials they are asked to use and to refine their teaching practices to meet the needs of the students in their classrooms. This means a large part of the professional development must be organized around their school and engage teachers in design, test, redesign experiences that will produce visible results and motivate them to continue.

In all of the schools in 2010-11, there were coaches in literacy and mathematics; in some cases principals indicated that it was their intention to ask these coaches to also support science learning of both the teachers and students. The literacy and mathematics coaches would need professional development on how to support science teachers in order to be effective. This practice, however, was not in place at the time of our visits and most teachers did not expect that they would be receiving any internal support for science teaching.

Budget worries dominated some conversations and the loss of staff and resources weighed heavily on the minds of principals and teachers. The elimination of the lead science teachers was seen as a major loss, and an obstacle to the continued use of science modules. Teachers felt they needed the support and expertise of the lead science teacher to plan and deliver quality science lessons. Right or wrong, the loss of the lead science teacher position and the closing of the district science center in the same year signaled to many that science was being given a lower priority in the overall district instructional plan.

The reduction of time given to science instruction in some of the schools visited was disheartening but predictable in a high-stakes accountability climate. The tremendous pressure many schools feel to improve reading and mathematics scores as well as the scrutiny that the schools are under from the state education department results in reductions in actual instructional time to subjects other than literacy and mathematics.

The low levels of cognitive demand of the tasks assigned to students and the lack of opportunity for student discussion pose serious challenges to the effectiveness of hands-on, inquiry-based investigations. To significantly improve science learning, teachers will need to work differently with their students, and students will need to be more actively engaged in higher-order thinking and more rigorous and challenging tasks. More effective use of student teams and peer support could contribute to improved learning, but teachers need professional development to use this strategy effectively. 
There was considerable frustration, especially at the intermediate and secondary levels with the lack of students' basic skills in reading and mathematics, as well as the lack of background knowledge in basic science concepts. This lack of preparedness may contribute to the disengagement of some students, and the low motivation reported by some teachers. These factors made teaching science to adolescent learners particularly challenging in the visited schools.

Nevertheless, some schools are providing effective instruction in science and could serve as "points of light" in the district. These schools provide models of strong, collaborative teacher and principal leadership on which district leaders could build. A strategy is needed for improving science in an environment of scarcity, and that strategy will have to include mechanisms to transfer good practices from one classroom to another and one school to another.

In sum, the fiscal crisis facing the state and the district poses enormous challenges for the improvement of science education, but there also is a strong foundation upon which to buildthe FOSS modules, a cadre of teachers experienced in teaching them, and a commitment to science on the part of some building principals. This is where the new partnership will begin its work.

\section{Areas of Action}

Based on our visits to classrooms and our conversations with principals, teachers and district staff, we believe that immediate attention must be given to six critical system components in order to provide the support for instruction needed to improve teaching and learning in science in Newark. These six components are as follows: curriculum and science literacy; materials support; administrative support; assessment; student engagement and motivation; and professional development. Below we have laid out some of the key issues that emerged in each of these areas from our work in NPS and some questions that might facilitate planning actions to address the challenges.

\section{Curriculum and Science Literacy}

Issues:

- The science curriculum was developed by district staff with little input from teachers; the vision underlying the curriculum is unclear to some teachers and may not be shared by many who are implementing it.

- The curriculum is organized for coverage rather than conceptual development.

- The curriculum breaks up curriculum modules apparently to align with perceptions of NJCCS's sequence, but NJCCS is not intended to be an instructional sequence. Using the modules this way compromises their design and benefits and could confuse teachers and students.

- The district curriculum pacing guide has gaps and overlaps of concepts; there are cases where the same investigations are repeated across grade levels and other cases where investigations span two grade levels without assurance that the activities build to full understanding.

- There is insufficient explicit attention to the development of literacy in science classrooms; for example, leveled supplemental reading materials have not been identified or provided. 
- At the secondary level, much of the science is text-driven and there is a concern that many students cannot access the material due to reading difficulties.

- Scaffolding and bridging activities for students who are struggling or need more help are not included in the curriculum to the degree that teachers need these strategies and activities.

Questions:

- How might practitioners be included in developing or selecting, piloting and providing feedback on the curriculum and instructional materials in a more systematic and intentional way to ensure that the curriculum improves over time, is feasible in NPS classrooms, and is "owned" by the broader Newark science education community?

- Could the sequences of learning experiences proposed in the curriculum be made more developmental so that learning of key concepts is deliberately scaffolded over time?

- Given the projected development of new national science standards, and the likelihood that state standards and science assessments will be revised in the next few years, is it wiser to make incremental improvements in the current curriculum rather than major changes in curriculum or materials? Can the alignment of the modules with the state standards be improved or should the district consider alignment by grade band rather than by grade?

- How can alignment issues be addressed so that modules are taught in their entirety to ensure the integrity of the developmental process underlying the modules is preserved?

- How should the curriculum pacing guides be amended to eliminate repetition, overlap and gaps in investigations and concept instruction?

- Is the high school sequence of courses consistent with what we know about student learning in science?

- What is the most effective way to ensure that the curriculum includes, and teachers use, formative assessment strategies so that struggling students are monitored and receive more instructional support?

- What should be done to increase use of science investigations that support active and inquiry-based learning by secondary teachers?

- What kinds of reading materials might be provided that would enable science teachers to strengthen student content literacy skills?

- How can science teachers most effectively leverage the writing students do in science to build higher levels of science literacy?

\section{$\underline{\text { Instructional Materials Support }}$}

Issues:

- Science inquiry and hands-on activities are critical for student understanding and engagement, and materials that support this pedagogy are not readily available to students and teachers at all grade levels.

- There is an inequitable distribution of science materials, particularly in the high schools.

- There is inconsistent availability and maintenance of lab space in schools in the district.

- In grades K-8, there continue to be concerns in some schools about the availability, refurbishment and usability of the modules. 
- In grades K-6, current module delivery and implementation schedules do not allow for the alignment of instruction, assessment, and professional development nor do they account for the mobility of students.

- The time periods for use of the modules need to be re-considered as many teachers find them unrealistic given the needs of the students and the available instructional time.

- The burden of replenishing modules for use in grades seven and eight falls entirely on school-based teachers and administrators, a problem exacerbated by re-assignments and turnover.

- Teachers and administrators are concerned about the lack of science text materials for content reading and other supplementary materials that would allow students to do work on science as an independent activity in the classroom or at home.

- Teachers have the option to select from a variety of supplementary materials which are not arrayed by reading difficulty, are often insufficient and are not always research-based.

- At the high school level, there continue to be concerns about availability of consumables and basic laboratory equipment.

Questions:

- Are the available instructional materials adequate to support science inquiry and hands-on learning at all developmental levels?

- Is it a system expectation that science resources including equipment and materials be distributed equitably?

- How can the scheduling and distribution of modules be managed so that teachers have the opportunity to prepare for and use these materials to the optimum benefit of their students?

- How can more text-based materials be made accessible to teachers and students to supplement the modules and allow for extended learning?

- How can we ensure that there are sufficient supplementary instructional materials that are proven, research-based and adhere to tenets of good practice?

- Is there a system in place to insure that materials and consumables are ordered in a timely fashion?

- Can library resources be accessed to support the purchase of science text materials?

\section{$\underline{\text { Administrative Support }}$}

Issues:

- Principals are being given increased autonomy to make decisions about schedules, teaching assignments, and budgets, leading to concern that without the active and explicit support of the district, science instruction will not be a priority in many schools given the pressures to improve performance in literacy and mathematics.

- Not all administrators are observing science instruction, nor do they have an informed understanding of what constitutes effective science instruction.

- Not all schools allocate time for teachers and administrators to work together as a community of practice around quality science instruction. 
- Many schools lack "science leaders" who have the knowledge required to ensure that teachers have the appropriate materials to teach quality science lessons, the professional development to understand and practice good science instruction, and the school budgets to support the requirements of an effective science program.

- At K-8, many principals are assigning their stronger teachers to subjects other than science, i.e., math and literacy.

- District staff reassigns K-8 teachers to schools without regard for their experience and/or grade-level professional development in science.

- Reductions in district-level staff are limiting the science support available for principals and teachers.

Questions:

- What policy changes are needed to ensure that the most qualified people are assigned to teach science, even when budget cuts require re-assignments?

- What policy changes are needed to give some priority to teachers who participate in staff development in science when re-assignments are necessary?

- What opportunities can be created for principals to engage in discussions focusing on the importance of dedicated instructional time for science?

- How can administrators become more skillful in making appropriate staffing choices in science?

- How can administrators become more skillful in recognizing and supporting effective science instruction?

- How can principals organize planning time to ensure that teachers and administrators study and discuss effective science instruction?

- How can administrators become more skillful in creating budgets that include adequate allocations for science?

- What district systems are necessary for principals to provide access to materials and opportunities for professional development in effective science instruction?

- How are district supports coordinated to meet schools' needs?

\section{Assessment}

Issues:

- Most teachers are not using formative assessment in an intentional and consistent way to monitor student progress and inform their teaching.

- While the district benchmark assessments may be technically adequate, they do not always align well with what is being taught. This misalignment frustrates teachers and student results are misinterpreted by some principals.

- Teachers are not consistently using the results of the district benchmark assessments and they have little confidence that these assessments provide them with useful information to guide teaching and learning. 
- The state assessment system is the primary driver of decisions about instructional time and effort.

- Teachers are not accessing the assessment resources that the modules provide.

- Reliance of some teachers on Learnia to provide information on student achievement in science may be misplaced.

Questions:

- What professional development could be planned and delivered to ensure teachers have the skills and knowledge to design and use formative assessments in science?

- What systems could be put in place that would support principals and/or department chairs to encourage the use of formative assessment?

- How can the alignment of the benchmark assessments, the state science standards, and the assigned modules be improved?

- How can the district leverage effective formative assessment practices currently being used by some schools?

- How could the district data system be leveraged to provide teachers and principals with current information on student achievement and, furthermore, support science learning?

- How could teachers be encouraged and supported to use assessment results from literacy and mathematics to inform instruction in science?

\section{Student Engagement and Motivation}

Issues:

- There was high variation in the quality of the science instruction observed and the degree to which the learners were at the center of science lessons.

- The majority of the observed science lessons were of low cognitive demand.

- In classrooms where the quality of instruction was poor, many students were observed to be disengaged from the science learning tasks.

- Didactic teaching practices were observed in many classrooms, which inhibited the opportunity for student-centered discussions.

- Group work was observed occasionally but it was clear that not enough attention was being paid to teaching and practicing the roles and routines of working in groups.

- The lack of established norms, routines and structures in classrooms prevented students from benefiting fully from the science instruction.

- Inadequate literacy skills seem to be a major cause of disengagement for many intermediate and middle-grade students.

Questions:

- What are the most common causes of student disengagement in science classes?

- Would raising the cognitive demand of the tasks given to students raise or lower engagement and achievement? 
- Are there particular approaches to the use of the science modules that could raise engagement levels?

- How could student teams be used to enhance the levels of engagement?

- Would more consistent norms, routines and structures raise the levels of engagement?

- What could be done to address the differential literacy skills of students in science classes?

- Could more experiences be provided to promote more interest in STEM careers and more experiential learning for secondary students?

- What extracurricular programs could be instituted or expanded to increase student interest and engagement in science?

- What perceptions do students and parents have about science and the science program?

\section{Professional Development}

Issues:

- Many teachers lack the content knowledge and/or pedagogical content knowledge to provide effective science instruction in an inquiry-based curriculum.

- Teachers reported limited opportunity to participate in professional development that would help improve their understanding of science content and teaching practices.

- Professional development opportunities and support in science have been diminished by closing the Banneker Center and eliminating lead science teachers.

- Many teachers are not adequately prepared to implement the science curriculum and are unsure of how to use the modules and other materials.

- On-site support for teachers is very limited.

- Literacy and math specialists rarely support science instruction by assisting teachers with science literacy and mathematical concepts inherent in science learning.

\section{Questions:}

- What strategies might we employ that would ensure teachers have the knowledge and skills to teach the curriculum and to use the materials in a manner that will assist students in reaching science standards?

- What assistance should be given to principals, department chairs and others so that teachers have the on-site, in-time support needed to feel confident in their ability to teach science?

- How can teachers be given greater access to professional development opportunities that would improve their teaching practice in science?

- How could teaching assignments be adjusted so that highly proficient teachers take on science classroom support roles?

- How can principals and department chairs maximize the potential of common planning time for professional growth?

- What steps would be needed to use a more integrative approach to science instruction that would employ literacy and mathematical concepts as foundational skills to science learning? 
- Would the teachers at the secondary level benefit from professional development focused on encouraging students to pursue careers in science?

- What types of professional development could be provided related to the use of laboratories for effective learning experiences?

- How can the professional development system take into account delays in the hiring process and the high mobility of teachers in the district? 


\section{Appendices}

Appendix A: Definition of the School Quality Indicators ...................................... 47

Appendix B: Definition of the Classroom Quality Indicators................................. 49

Appendix C: Classroom Observation Protocol................................................. 51

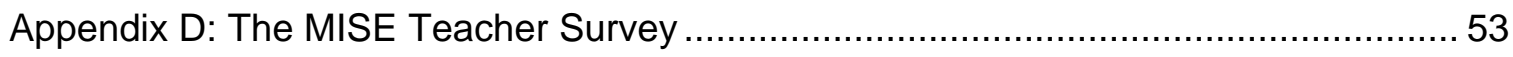

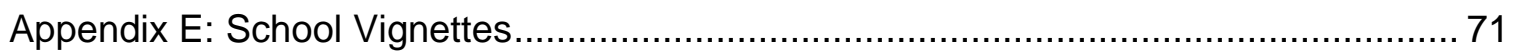

Appendix F: The MISE Review of the NPS Curriculum Documents ............................ 79

Appendix G: HRI Review of the Interim Assessments ........................................... 89 


\section{Appendix A Definition of the School Quality Indicators}

1. School climate: This indicator refers to the student behavior within the building including overall orderliness, the degree of respect shown for others, the level of trust, the level of noise in halls, the relationships between students and adults, and compliance with school rules.

2. Class Size : This indicator refers to the average class size observed during the visit. The numbers are imprecise as they do not take absenteeism into account. Class size has been shown to be related to achievement especially for low-income students, but the effects are modest. $^{2}$

3. Adequacy of Classroom Space: This indicator is based on observations made in the schools and addresses whether the space allows for the teacher to move freely in the classroom and for students to work in groups. There is little research directly linking space to achievement but space may be a mediating factor.

4. Time allocated to science: The number of minutes per week actually provided for science instruction. The time allocated in the school schedule is a proxy for this measure. ${ }^{3}$

5. Evidence of efforts to improve instruction: This indicator reflects the presence in a school of deliberate and sustained efforts to improve instruction either through professional development, adoption of new practices, the work of a professional learning community or other improvement strategies. ${ }^{4}$

6. Teacher collaboration on science teaching: This indicator refers to the amount of sharing and/or co-planning of lessons in science and opportunities for discussion of science that occur in the school. ${ }^{5}$

7. Teachers' access to useful data on science learning: This indicator refers to the timely availability of data on student performance. ${ }^{6}$

8. Teachers' access to professional development in science: This indicator is a measure of the amount of professional development in science teaching and learning provided for teachers. ${ }^{7}$

9. Provision of adequate instructional materials: This indicator is a measure of both the quantity and quality of the instructional materials provided for teachers. ${ }^{8}$

10. Principal's support for science education: This indicator refers to the principal's attention to the quality of science instruction and provision of adequate time allocations and budget and engagement in science teaching as evidenced in attending science team meetings, observing science classes, and promoting extracurricular science activities. ${ }^{9}$

11. Evidence of norms of continuous improvement: This indicator represents the degree to which teachers actively seek to improve achievement in science through reflection on their practice, discussing practice with other teachers, monitoring student work and progress, reviewing and revising lessons and units, and participating in professional development. ${ }^{10}$ 
${ }^{1}$ Bryk, A. S. and Schneider, B. (2002), Trust in schools: A resource for improvement. New York: Russell Sage Foundation; Danielson, C. A framework for teaching. Alexandria, VA: ASCD; Hattie, J. (2009). Visible learning. New York: Routledge; Marzano, R. J. (2003). What works in schools: Translating research into action. Alexandria, VA: ASCD.

${ }^{2}$ Hattie, J. (2009). Visible learning. London: Routledge.

${ }^{3}$ There is little empirical evidence that classroom space is directly related to achievement. However, classroom space does seem to be a mediating variable that affects the likelihood of using student groups effectively and the kinds of investigations that can be conducted.

${ }^{4}$ Borg, W. (1980). Time and school learning In National Institute for Education (ed.) Time to learn. Washington, DC: author; Carroll, J. (1963). A model for school learning. Teachers College Record, 64, pp 723-733; Cotton, Kathleen, (2001). Educational Time Factors, North West Regional Educational Laboratory; and National Education Commission on Time and Learning. (1994). Prisoners of Time. Report of the National Education Commission on Time and Learning. The Education Commission of the States.

${ }^{5}$ Goddard, Y. L., Goddard, R. D., Tschannen-Moran, M. (2007). A theoretical and empirical investigation of teacher collaboration for school improvement and student achievement in public elementary schools. Teachers College Record, 109(4), 877-896; Hattie (2009); Herman, R., Dawson, P., Dee, T., Greene, J., Maynard, R., Redding, S., \& Darwin, M. (2008). Turning around chronically low-performing schools: A practice guide (NCEE \#2008-4020). Washington, D.C.: U.S. Department of Education, Institute of Education Sciences, National Center for Education Evaluation and Regional Assistance.

${ }^{6}$ Black, P., Harrison, C., Lee, C., Marshall, B., and Wiliam, D. (2003). Assessment for learning: Putting it into practice. Maidenhead, UK: Open University Press; Foster, D. and Noyce, P. (2004). The mathematics assessment collaborative: Performance testing to improve instruction. Phi Delta Kappan, pp. ;Institute for Education Sciences, USDE (2009). Using student achievement data to support instructional decisionmaking: IES practice guide. Washington, DC: author; Marzano, R., Pickering, D., and Pollock, J. (2001). Classroom assessment that works. Alexandria, VA: ASCD.

7 Blank, R.K. and de las Alas (2009). Effects of teacher professional development on gains in student achievement: How meta-analysis provides information useful to education leaders. Washington, D.C.: CCSSO; Corcoran, T.B. (2005). Review of research on effectiveness of professional development. Unpublished paper for the Noyce Foundation; Disimone, L. (2009). Improving impact studies of teachers' professional development: Toward better conceptualizations and measures. Education Researcher, 38(3), 181-199;

Porter, A.C., Garet, M., DeSimone, L. M., and Birman, B. (2003). Providing effective professional development: Lessons from the Eisenhower program. Science Educator, 12 (1), 23-40;

${ }^{8}$ Corcoran, T.B., Mosher, F., and Rogat, A. (2010). Learning progressions in science: An evidencebased approach to reform. New York, CPRE; Kowalski, S., Van Scotter, P. Stuhlsatz, M. and Taylor, J. (2007). Using instructional materials to close achievement gaps. Colorado Springs, CO: BSCS; Lee, O., \& Luykx, A. (in press). Science education and student diversity: Race/ethnicity, language, culture, and socioeconomic status. In S. K. Abell \& N. G. Lederman (Eds.), Handbook of research in science education. Mahwah, NJ: Lawrence Erlbaum Associates; National Academy of Science (1999). Selecting instructional materials: Guidelines for K-12 science. Washington, D.C.: National Academy Press;

${ }^{9}$ May, H. and Supovitz, J (2011). The scope of principal efforts to improve instruction. Educational Administration Quarterly, 47, 332- ; Robinson, V. (2007). The impact of leadership on student outcomes: Making sense of the evidence. Annual Conference, Australian Council of Education Leaders; Wahlstrom, K.L., Seashore Louis, K., Leithwood, K., and Anderson, S.E. (2010). Investigating the links to improved student learning: Executive summary of research findings. Minneapolis, MN: Center for Applied Research and Educational Improvement.

${ }^{10}$ Little, J. (1982). Norms of collegiality and experimentation: Workplace conditions of school success. American Educational Research Journal, 19(3), 325-340. 


\section{Appendix B Definition of the Classroom Quality Indicators}

1. Classroom climate: This indicator refers to the overall management of the classroom, the behavior of students, the level of respect, warmth, and trust observed, the effectiveness of teachers in maintaining an orderly and productive environment. ${ }^{1}$

2. Time allocated to science: The number of minutes per week actually provided for science instruction. The time allocated in the school schedule is a proxy for this measure. ${ }^{2}$

3. Teachers' science knowledge: This indicator refers to the teachers' pre-service education in science. Degrees held in science and certification in a field of science or the elementary science specialization are used as measures. ${ }^{3}$

4. Provision of adequate instructional materials: This indicator is a measure of both the quantity and quality of the instructional materials provided for teachers. ${ }^{4}$

5. Engagement of students in science. ${ }^{5}$

6. Focus on conceptual understanding in science instruction. ${ }^{6}$

7. Use of investigations (guided inquiry). ${ }^{7}$

8. Use of intellectually challenging tasks. ${ }^{8}$

9. Use of effective classroom management strategies. ${ }^{9}$

10. Good lesson/unit design. ${ }^{10}$

11. Use of formative assessment strategies. ${ }^{11}$

${ }^{1}$ Danielson, C. A framework for teaching. Alexandria, VA: ASCD; Hattie, J. (2009). Visible learning. New York: Routledge; Marzano, R. J. (2003). What works in schools: Translating research into action. Alexandria,

${ }^{2}$ Borg, W. (1980). Time and school learning In National Institute for Education (ed.) Time to learn. Washington, DC: author; Carroll, J. (1963). A model for school learning. Teachers College Record, 64, pp 723-733; Cotton, Kathleen, (2001). Educational Time Factors, North West Regional Educational Laboratory; and National Education Commission on Time and Learning. (1994). Prisoners of Time. Report of the National Education Commission on Time and Learning. The Education Commission of the States.

${ }^{3}$ Allen, M. B. (2003). Eight questions on teacher preparation: What does the research say? Denver, CO: Education Commission of the States.; Goldhaber, D. D., \& Brewer, D. J. (1999). Teacher licensing and student achievement. In M. Kanstoroom \& C. F. J. Finn (Eds.), Better teachers, better schools (pp. 83102). Washington, DC: Thomas B. Fordham Foundation.; Hattie, J. (2009), op. cit.; Wayne, A. J., \& Youngs, P. (2003). Teacher characteristics and student achievement gains: A review. Review of Educational Research, 73(1), 89-122.

${ }^{4}$ Reviews of research conducted by the What Works Clearinghouse and also by the Best Evidence Encyclopedia show significant differences in learning outcomes associated with different science and mathematics curricula. It can be inferred from these studies that the nature and quality of instructional matter affects the learning outcomes.

${ }^{5}$ Marks, H. (2000). Student Engagement in Instructional Activity: Patterns in the Elementary, Middle, and High School Years. American Education Research Journal, 37 no. 1 153-184; Newman, F. (ed.) (1992). Student engagement and achievement in American secondary schools. New York, NY: Teachers College Press; Fredricks, J.A., Blumenfeld, P.C., \& Paris, A.H. (2004). School engagement: Potential of the concept, state of the evidence. Review of Educational Research, 74(1), 59-109. 
${ }^{6}$ Duschl, R. A., Schweingruber, H. A., and Shouse, A. W. (eds) (2007). Taking science to school: Learning and teaching science in grades K-8. Washington, D.C.: National Academies Press; Gabel, D. (2003). Enhancing the Conceptual Understanding of Science. Horizon, Winter, pp. 70-76

${ }^{7}$ Minner, D., Levy, A., and Century, J. (2009) Inquiry-Based Science Instruction-What Is It and Does It Matter? Results from a Research Synthesis Years 1984 to 2002. Journal Of Research In Science Teaching, pp. 1-24.

${ }^{8}$ AERA (2006). Do the math: Cognitive demand makes a difference. Turning Points, 4 (2); Porter, A (2002). Measuring the Content of Instruction: Uses in Research and Practice Educational Researcher October 1, 2002 31: 3-14.

${ }^{9}$ Hattie, J. (2009) op. cit., p. 102; Marzano, R. (2000). A new era of school reform: Going where the research takes us. Alexandria, VA: Ascd. There is limited empirical evidence linking specific classroom management strategies with student learning. But it is clear that classroom management is a mediating variable that affects the time available for instruction, student engagement, and other factors linked to achievement.

${ }^{10}$ Marzano, R. (2007). The art and science of teaching. Alexandria, VA: ASCD; Pianta, R., Belsky, J., Hous, R., and Morrison, F. (2007). Teaching: Opportunities to learn in America's elementary classrooms. Science, 315, pp. 1795-96; Stallings, J. and Krasavage, E. (1986). Program implementation and student achievement in a four-year Madeline Hunter follow-through project. The Elementary School Journal, 87 (2).

${ }^{11}$ Black, P., Harrison, C., Lee, C., Marshall, B., and Wiliam, D. (2003). Assessment for learning: Putting it into practice. Berkshire, UK: Open University Press; Heritage, M. (2010). Formative assessment: Making it happen in the classroom. Thousand Oaks, CA: Corwin; OECD (2005). Formative assessment: Improving learning in secondary classrooms. Paris: author; 


\section{Appendix C \\ Classroom Observation Protocol}

School:

Date:

1

Grade Level(s):

1. Description of the unit that provides the context for the lesson:

\section{Number of Participants:}

Students

Teachers

Teachers' Aides,

.Other adults (describe)

3. Setting:

O Classroom 0 Lab 0 Other

\section{Organization of the Classroom:}

\section{o Traditional rows \\ o Small clusters of 3-5 student desks \\ o Lab Desks arranged so that students face each other \\ o Desks in circles or semi-circles}

\section{Classroom Management:}

Please rate the severity of classroom management problems (specifically, behavior management issues or conflicts on the part of students):

No problems $\quad$ Minor problems $\quad$ Significant problems

If significant problems are observed, please describe them briefly.

\section{Brief Description of Lesson and Major Activities (Cognitive Demand of Tasks)}

Note the nature of the interactions occurring between the teacher and students (lecture, teacher-led discussion, student-initiated discussion, group work, student presentation, teacher-led question and answer, etc.) and rate the cognitive demand of the work using the following scale:

1. Students are asked to memorize material or present from memory

2. Students learn procedures or perform procedures previously learned.

3. Students are asked to communicate understanding of content.

4. Students are asked to make connections, apply concepts to solve a problem and justify strategies or answers.

5. Students are asked to generalize, analyze, make conjectures, offer alternative explanations, solve unfamiliar problems, or create new questions. 
7. Perceptions of Teacher Behavior (answer when appropriate)

\begin{tabular}{|c|c|c|c|c|c|c|}
\hline Practice & & & of & & & $\begin{array}{l}\text { a great } \\
\text { tent }\end{array}$ \\
\hline $\begin{array}{l}\text { 1. The classroom was well-organized and } \\
\text { equipment was distributed efficiently. }\end{array}$ & 1 & 2 & 3 & 4 & 5 & NA \\
\hline $\begin{array}{l}\text { 2. The classroom climate was warm and } \\
\text { supportive. }\end{array}$ & 1 & 2 & 3 & 4 & 5 & NA \\
\hline 4. There was a clearly articulated learning goal. & 1 & 2 & 3 & 4 & 5 & NA \\
\hline $\begin{array}{l}\text { 5. The teacher linked the lesson to students' } \\
\text { prior knowledge. }\end{array}$ & 1 & 2 & 3 & 4 & 5 & NA \\
\hline $\begin{array}{l}\text { 6. The concepts being taught were clearly } \\
\text { presented and emphasized. }\end{array}$ & 1 & 2 & 3 & 4 & 5 & NA \\
\hline $\begin{array}{l}\text { 7. The teacher engaged the students in higher } \\
\text { order thinking. }\end{array}$ & 1 & 2 & 3 & 4 & 5 & NA \\
\hline $\begin{array}{l}\text { 8. The teacher encouraged student discussion. } \\
\text { 9. The teacher made effective use of student } \\
\text { teams. }\end{array}$ & 1 & 2 & 3 & 4 & 5 & NA \\
\hline $\begin{array}{l}\text { 10. The teacher demonstrated a solid grasp of } \\
\text { the subject matter content. (or: Students were } \\
\text { engaged in significant subject content.) }\end{array}$ & 1 & 2 & 3 & 4 & 5 & NA \\
\hline $\begin{array}{l}\text { 11. The teacher asked questions to monitor } \\
\text { student progress and understanding. }\end{array}$ & 1 & 2 & 3 & 4 & 5 & NA \\
\hline $\begin{array}{l}\text { 12. There was a closing/review/reflection of } \\
\text { progress toward the learning goals. }\end{array}$ & 1 & 2 & 3 & 4 & 5 & NA \\
\hline
\end{tabular}




\section{Appendix D \\ The MISE Teacher Survey}




\section{Newark Public Schools Science Program K-8 Teacher Questionnaire}

Instructions: Please complete this form using a \#2 pencil or a blue or black ink pen. Darken circles completely, but do not stray into adjacent circles. Erase completely or white out any stray marks. All of your responses will remain strictly anonymous.

\section{Professional Background Information and Experience}

1. Including this year, how many years of experience do you have as each of the following? (Count part of a year as 1 year.

Darken one circle on each line.)

a. A teacher

b. A science teacher

c. A lead science teacher

2. Which of the following best describes your teaching position for the 2010-11 school year? (Darken one circle.)

Self-contained classroom teacher

Science specialist

Special education teacher

3. Which grades did you teach in the 2010-11 school year? (Darken all that apply.)

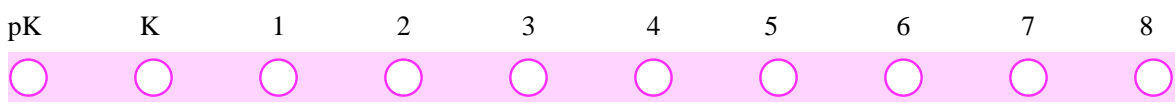

4. Which of the following best describes your primary New Jersey teaching certification: (Darken one circle.)

Elementary (Grades K-5)

Elementary with Science Specialization (Grades 5-8)

Subject Specific (Grades P-12)

Biological Science

Chemistry

Earth Science

Physical Science

Physics

5. What is the highest degree you have earned? (Darken one circle.)

Bachelor's degree

Master's degree

Doctorate or professional degree (Ph.D., Ed.D., M.D., L.L.B., J.D., D.D.S.)

Questions 6-21 ask about a particular science class you teach. If you teach science to more than one class, please answer for your first science class of the day.

6. What is the grade level of this class? (If this class includes students from multiple grade levels, select the grade level of the majority of students in this class.) (Darken one circle.)

$\begin{array}{llllllllll}\mathrm{pK} & \mathrm{K} & 1 & 2 & 3 & 4 & 5 & 6 & 7 & 8 \\ \bigcirc & \bigcirc & \bigcirc & \bigcirc & \bigcirc & \bigcirc & \bigcirc & \bigcirc & \bigcirc & \bigcirc\end{array}$


7. Indicate whether or not this class is formally classified as each of the following: (Darken one circle one each line.)

$\begin{array}{lll} & \underline{\text { Yes }} & \text { No } \\ \text { a. Self-contained special education } & \bigcirc\end{array}$

8. When you taught science during the 2010-11 school year, how many minutes per week did you spend teaching science to this class? (Please write your answer in the space provided, then darken the corresponding circle in each column. Enter your responses as a three digit number: e.g., if 90 , enter as 090.)

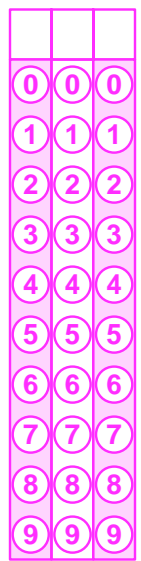

9. Over the course of the 2010-11 school year, how many different science units will you teach to this class? (Darken one circle.) $\begin{array}{llll}1 & 2 & 3 & 4 \\ 5 & \text { or more }\end{array}$

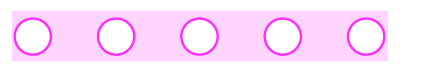

10. Which best describes your use of the district-provided pacing guide for science units you taught this class during the 2010-11 school year?

I followed the pacing guides for all of the units I taught in science.

I followed the pacing guides for some but not all of the units I taught in science.

I was unable to follow the pacing guides for the units I taught in science.

11. Over the course of the 2010-11 school year, how many science kits/modules (e.g., FOSS, STC) are designated for use with this class? (Darken one circle.)

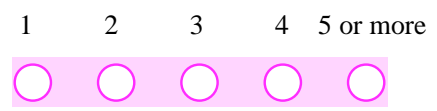

12. How many of the science kits/modules (e.g., FOSS, STC) designated for use with this class: (Darken one circle.)

a. Did you use in your science instruction during this school year?

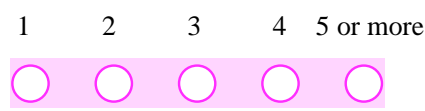

b. Did you use for the first time during this school year?

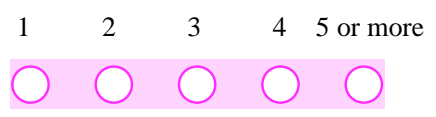

13. Over the course of the 2010-11 school year, approximately what percentage of the science instructional time will students in this class spend using a science kit/module (e.g., FOSS, STC)?

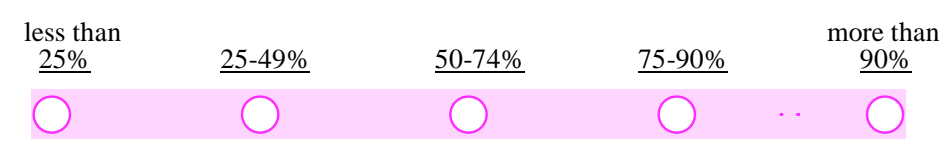


14. Thinking about the most recent science kit/module (e.g., FOSS, STC) used with this class, approximately what percentage of all of the activities (e.g., investigations, readings) within this kit/module will students in this class engage with during instruction or as part of a homework assignment?

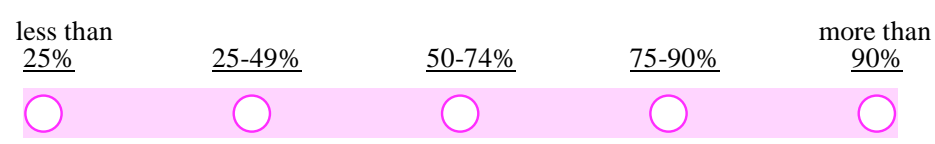

15. Thinking about the most recent science kit/module (e.g., FOSS, STC) used with this class, which best describes your use of this science kit/module (e.g., FOSS, STC): (Darken one circle.)

I taught all or nearly all of the lessons/activities essentially as they are laid out in the materials.

I taught all or nearly all of the lessons/activities but modified some of the lessons quite a bit.

I taught only some of the lessons/activities from the module, using most of these lessons/activities as they are laid out in the materials.

I taught only some of the lessons/activites from the module, but modified most of these lessons/activities.

16a. Did you skip any activities (e.g., problems, investigations, readings) during the most recent science kit/module you taught with this class?

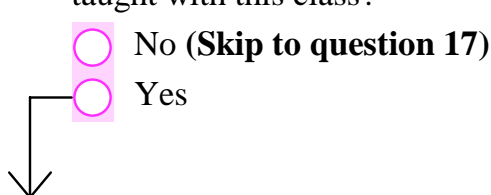

16b. During the most recent science kit/module you taught with this class, when you skipped activities (e.g., problems, investigations, readings), how much was each of the following a factor in your decisions? (Darken one circle on each line.)

a. The science ideas addressed in the activities you skipped are not included in the district pacing guide.

b. You did not have the materials needed to implement the activities you skipped.

c. The activities you skipped were too difficult for your students.

d. Your students were able to learn the science ideas without the activities you skipped.

e. You have different activities for those science ideas that work better than the ones you skipped.

f. You used a different activity listed in the district pacing guide.

g. There was not enough time to teach the activities you skipped.

h. You did not feel prepared to teach the activity.

17. Considering all of the science kits/modules (e.g., FOSS, STC) you were required to teach to this class during the 2010-11 school year, which best describes your access to these materials. (Darken one circle.)

The kits/modules were available and ready to use when I needed them.

The kits/modules were available but didn't have the needed materials that should have been in the kits/modules.

The kits/modules were not available when I needed them, but were ready to use when I finally received them.

The kits/modules were not available when I needed them, and didn't have all the needed materials that should have been in the kits/modules. 
18. Different courses may make use of different kinds of facilities for teaching science. In the ideal, which of these would you like to have available for this science class? (Darken all that apply.)
Faucets and sinks
Fume hoods
Electric outlets
Glassware
Gas for burners
Microscopes
Lab tables
Scales/Balances

19. Please indicate the current availability of each of the following. (Darken one on each line.)

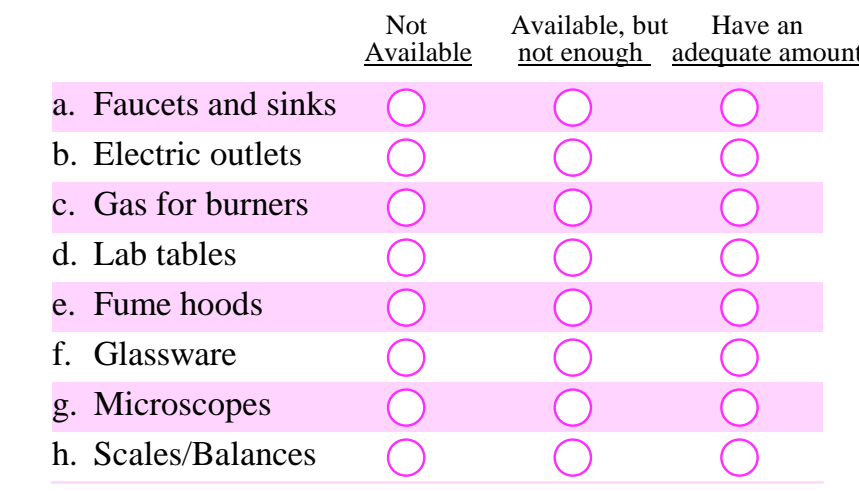

20. How many district benchmark assessments have you administered so far this school year to this class?

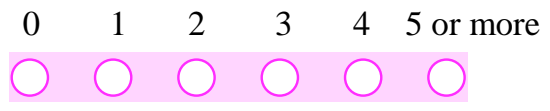

21. For how many of the district benchmark assessments you have administered to this class, did you do the following? (Darken one circle on each line.)
a. Discuss the results of a district benchmark assessment with other teachers.
b. Used the results of a district benchmark assessment to modify subsequent lessons.
c. Reviewed the results of district benchmark assessments with students.

\section{Collaboration and Professional Development}

22. At my school, during the 2010-11 school year, I was provided with opportunities to: (Darken one circle on each line.)

$$
\begin{aligned}
& \text { Strongly } \\
& \text { Disagree } \text { Disagree } \\
& \text { Agree }
\end{aligned} \begin{gathered}
\text { Strongly } \\
\text { Agree }
\end{gathered}
$$

a. Discuss innovative science instructional practices.

b. Reflect on science teaching and learning with other teachers.

c. Observe other science teachers in my building.

d. Discuss how to teach science effectively to students with special needs (e.g., ELL, Special Education needs).

e. Plan and prepare lessons for science with other teachers during the school day.

f. Attend science conferences.

g. Attend professional development on teaching with science kits/modules. (e.g., FOSS, STC).

h. Attend other professional development for teaching science. (i.e., not focused on the kits/modules like FOSS and STC). 
23. How often did you discuss or do each of the following with other science teachers at your school during the 2010-11 school year? (Darken one circle on each line.)

b. How to manage a classroom

c. How to teach a lesson in a kit/module (e.g. FOSS, STC)

d. Science lessons that were not very effective for teaching a concept

e. Science lessons that were very effective for teaching a concept

f. My teaching situation in general (e.g., my classroom, my students, my administration)

g. Research on effective methods for science teaching

h. Teaching approaches for under-performing students

i. Preparing students for district/state science tests

j. Student performance on district/state science tests

k. Share lesson plans with other teachers

l. Have my classroom observed by other teachers to improve my science instruction

24. Indicate the extent to which you agree with each of the following statements for the 2010-11 school year: (Darken one circle on each line.)

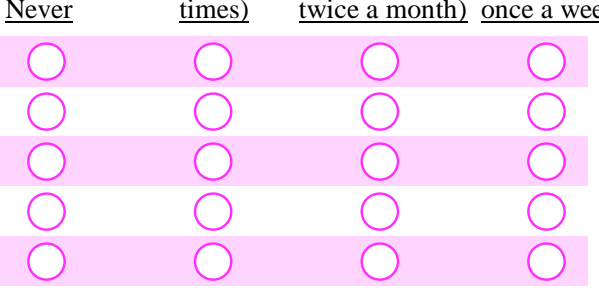

\begin{tabular}{|c|c|c|}
\hline $\begin{array}{l}\text { Rarely } \\
\text { i.e., a few } \\
\text { times) }\end{array}$ & $\begin{array}{l}\text { Sometimes } \\
\text { (i.e., once or } \\
\text { twice a month) }\end{array}$ & $\begin{array}{c}\text { Often } \\
\text { (i.e., at least } \\
\text { once a week) }\end{array}$ \\
\hline
\end{tabular}
a. I contribute to planning and improving the science program at my school.
b. I influenced the quality of science instruction for all students at my school.
c. Science teachers at my school prefer to work individually, rather than collaboratively, to improve science and learning.
d. Science teachers at my school have a shared vision of effective science instruction.
e. I feel supported by colleagues to try out new ideas in teaching science.
f. The quality of my teaching influences student achievement in science.
g. I continually find better ways to teach science.
h. I generally teach science effectively.
i. I am typically able to answer my students' science questions.
j. I know how to motivate students to learn science.
$\mathrm{k}$. It is important for students to learn science to develop their problem solving skills.
l. I am willing to have my classroom observed by other teachers to improve my science instruction.
$\mathrm{m}$. I am interested in attending professional development on how to teach science.
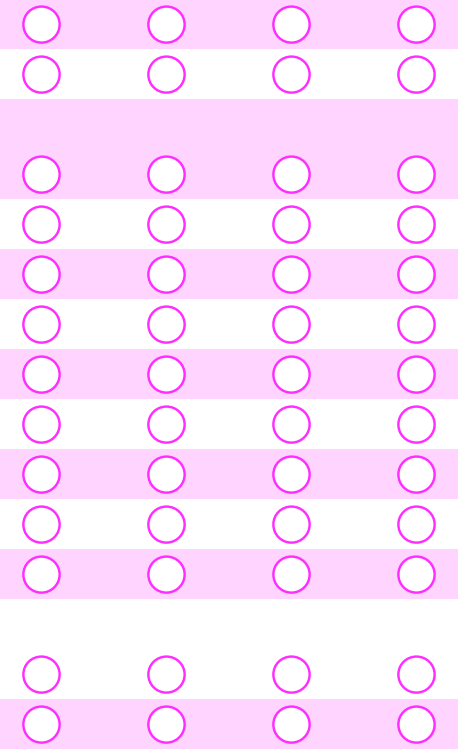

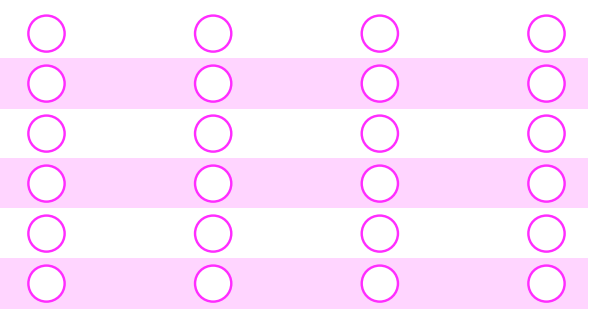




\section{Factors Influencing Science Instruction}

25. To what extent did each of the following impact your ability to teach science effectively during the 2010-11 school year? (Darken one circle on each line.)

a. Amount of time available to plan for science lessons.

b. Amount of time available to collaborate with other science teachers.

c. Alignment between the NJCCCS Cumulative Progress Indicators (CPIs) and state science assessments.

d. Alignment of the kits/modules (e.g., FOSS, STC) to the NJCCCS CPIs.

e. Alignment of the kits/modules (e.g., FOSS, STC) to the district benchmark assessments.

f. The behavior of students during science activities.

g. Parental interest in their children's science instruction.

h. Access to print materials/equipment/supplies for teaching science.

i. Quality of facilities for teaching science.

j. School/district/state educational initiatives in subjects other than science.

k. Focus/content of required state science assessments.

l. Focus/content of required district benchmark assessments.

$\mathrm{m}$. Quality of the district's instructional materials for science.

n. Access to technology for science instruction (e.g., lab equipment, calculators, etc).

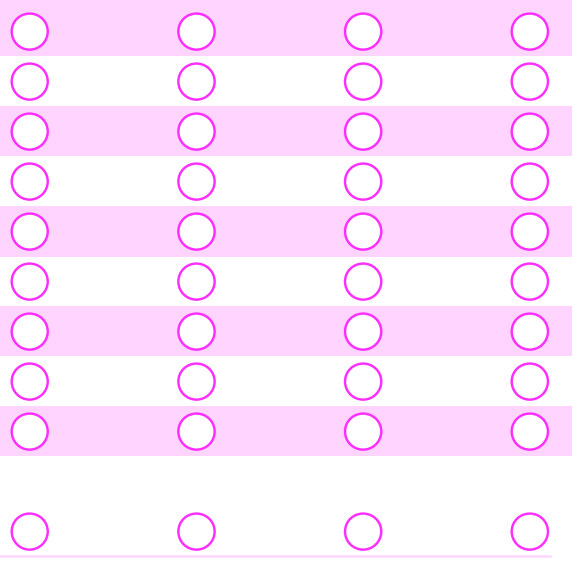




\section{Newark Public Schools Science Program 9-12 Teacher Questionnaire}

Instructions: Please complete this form using a \#2 pencil or a blue or black ink pen. Darken circles completely, but do not stray into adjacent circles. Erase completely or white out any stray marks. All of your responses will remain strictly anonymous.

\section{Professional Background Information and Experience}

1. Including this year, how many years of experience do you have as each of the following? (Count part of a year as 1 year.

Darken one circle on each line.)

a. A teacher

b. A science teacher

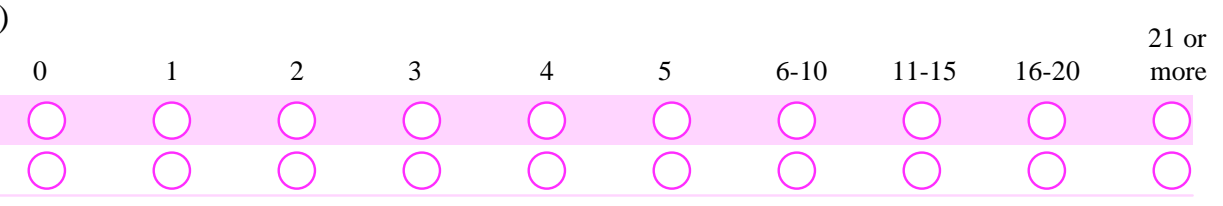

2. Which of the following best describes your teaching position for the 2010-11 school year? (Darken one circle.)

Science teacher

Special education teacher

3. Which of the following best describes your primary New Jersey teaching certification: (Darken one circle.)

Biological Science

Chemistry

Earth Science

Physical Science

Physics

4. What is the highest degree you have earned? (Darken one circle.)

Bachelor's degree

Master's degree

Doctorate or professional degree (Ph.D., Ed.D., M.D., L.L.B., J.D., D.D.S.)

5. Which grades are you teaching in the 2010-11 school year? (Darken all that apply.)

$\begin{array}{lllll}9 & 10 & 11 & 12 & \text { Ungraded }\end{array}$

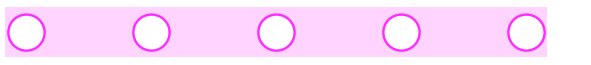

6. In the 2010-11 school year, are you teaching an Advanced Placement (AP) or International Baccalaureate (IB) course ?

(Darken one circle.)

Yes

No

Questions 7-11 ask about a particular science class you teach. If you teach science to more than one class, please answer for your first science class of the day.

7. Which best describes the instructional materials students use in this science class? (Darken one circle.)

Use one textbook or set of science modules from the same publisher all or most of the time.

Use multiple commercially-published textbooks or a combination of textbooks and commercially-published modules most or all of the time.

The class does not use commercially-published materials most of the time.

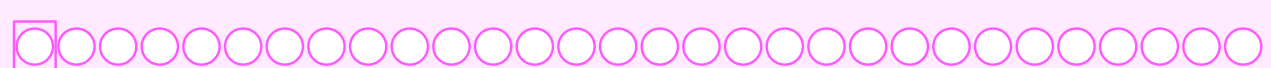

[QID] 
8. Thinking about the most recent unit you taught to this class, which best describes the instructional materials students used ?

(Darken one circle.)

Used one textbook or science module for all or most of the unit.

Used multiple commercially-published textbooks/science modules to teach the unit. (Skip to question 12.)

Did not use commercially published materials. (Skip to quesiton 12.)

9. Thinking about the most recent unit you taught to this class, please indicate the extent to which you did each of the following in this unit. (Darken one circle on each line.)

a. You used a textbook/science module to guide the overall structure and content emphasis of the unit.

b. You followed a textbook/science module page by page.

c. You picked what is important from a textbook/science module and skipped the rest.

d. You incorporated activities (e.g., problems, investigations, readings) from other sources to supplement what the textbook/module was lacking.

10a. Did you skip any activities (e.g., problems, investigations, readings) in your textbook/science module during this unit?

\section{No (Skip to question 11) Yes}

10b. During this unit, when you skipped activities (e.g., problems, investigations, readings) in your textbook/science module, how much was each of the following a factor in your decisions? (Darken one circle on each line.)

Not a A minor A major

a. The science ideas addressed in the activities you skipped are not included in the NJCCCS Cumulative Progress Indicators (CPIs).

b. You did not have the materials needed to implement the activities you skipped.

c. The activities you skipped were too difficult for your students.

d. Your students already knew or were able to learn the science ideas without the activities you skipped.

e. You have different activities for those science ideas that work better than the ones you skipped.

f. There was not enough time to teach the activities you skipped.

g. You did not feel prepared to teach the activity.

11a. Did you supplement the textbook/science module during this unit?

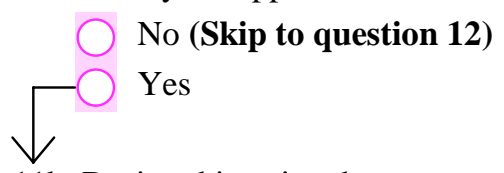

11b. During this unit, when you supplemented the textbook/science module with additional activities, how much was each of the following a factor in your decisions? (Darken one circle on each line.)

a. Supplemental activities were needed to address NJCCCS Cumulative Progress Indicators (CPIs).

b. Supplemental activities were needed to provide additional preparation for standardized tests. 
11b. (continued)

c. Supplemental activities were needed to provide students with additional practice.

d. Supplemental activities were needed so students at different levels could make progress on the targeted ideas.

\section{Facilities and Supplies for Teaching Science}

12. Considering the range of science instructional units you were required to teach in all of your science classes during the 2010-11 school year, which of the following best describes the overall availability of print materials/equipment/supplies?

a. Print materials (e.g., teacher's manual, student reading materials, activity sheets) (Darken one circle.)

I had easy access to what I needed to implement the science units.

It took a little effort, but I was able to get all/almost all of what I needed.

It took considerable effort, but I was able to get all/almost all of what I needed.

Despite my efforts, I was not able to get some of what I needed.

b. Equipment/supplies (e.g., microscopes, consumable supplies such as plants, chemicals, etc.) (Darken one circle.)

I had easy access to what I needed to implement the science units.

It took a little effort, but I was able to get all/almost all of what I needed.

It took considerable effort, but I was able to get all/almost all of what I needed.

Despite my efforts, I was not able to get some of what I needed.

13. Different courses may make use of different kinds of facilities for teaching science. In the ideal, which of these would you like to have available for your science classes? (Darken all that apply.)

Faucets and sinks

Electric outlets

Gas for burners

Lab tables
Fume hoods

Glassware

Microscopes

Balances

14. Please indicate the current availability of each of the following. (Darken one circle on each line.)

$\begin{array}{lll}\text { a. Faucets and sinks } & \begin{array}{c}\text { Not } \\ \text { Available }\end{array} \\ \text { b. Electric outlets } & \begin{array}{c}\text { Available, but } \\ \text { not enough }\end{array} & \begin{array}{c}\text { Have an } \\ \text { adequate amoun }\end{array} \\ \text { c. Gas for burners } & & \\ \text { d. Lab tables } & & \\ \text { e. Fume hoods } & & \\ \text { f. Glassware } & & \\ \text { g. Microscopes } & & \\ \text { h. Balances } & & \end{array}$

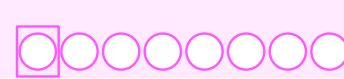

Horizon Research, Inc. 


\section{Collaboration and Professional Development}

15. At your school, during the 2010-11 school year, you were provided with opportunities to: (Darken one circle on each line.) Strongly Strongly Disagree Disagree Agree Agree

a. Discuss innovative science instructional practices.

b. Reflect on science teaching and learning with other teachers.

c. Observe other science teachers in my building.

d. Discuss how to teach science effectively to students with special needs (e.g., ELL, Special Education).

e. Plan and prepare lessons for science with other teachers during the school day.

f. Attend science conferences.

g. Attend professional development on teaching science.
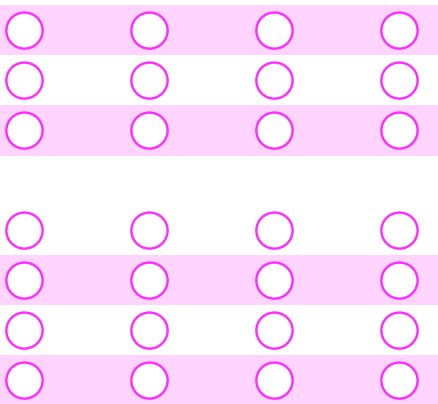

16. How often did you discuss or do each of the following with other science teachers at your school during the 2010-11 school year? (Darken one circle on each line.)
a. Samples of student science work.
b. How to manage a classroom.
c. Science lessons that were not very effective for teaching a concept.
d. Science lessons that were very effective for teaching a concept.
e. My teaching situation in general (e.g., my classroom, my students, my administration).
f. Research on effective methods for science teaching.
g. Teaching approaches for under-performing students.
h. Preparing students for district/state science tests.
i. Student performance on district/state science tests.
j. Share lesson plans with other teachers.
k. Have my classroom observed by other teachers to improve my science instruction. $\underline{\text { Never }} \begin{array}{ccc}\begin{array}{c}\text { i.e., a few } \\ \text { times) }\end{array} & \begin{array}{c}\text { (i.e., once or } \\ \text { twice a month) }\end{array} & \begin{array}{c}\text { (i.e., at least } \\ \text { once a week) }\end{array}\end{array}$
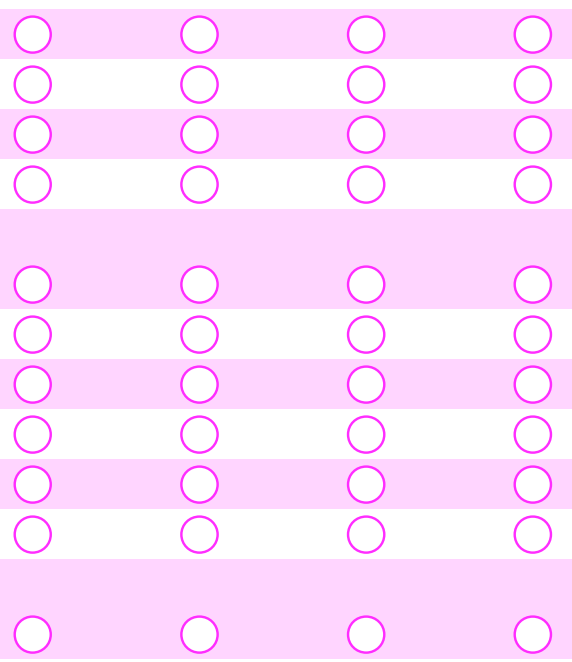

17. Indicate the extent to which you agree or disagree with each of the following statements for the 2010-11 school year: (Darken one circle on each line.)
a. I contribute to planning and improving the science program at my school.
b. I influence the quality of science instruction for all students at my school.
c. Science teachers at my school prefer to work individually, rather than collaboratively, to improve science teaching and learning.
d. Science teachers at my school have a shared vision of effective science instruction.
e. I feel supported by colleagues to try out new ideas in teaching science.
f. The quality of my teaching influences student achievement in science.
g. I continually find better ways to teach science.
h. I generally teach science effectively.
i. I am typically able to answer my students' science questions.
$\begin{array}{lll}\text { Strongly } & & \text { Strongly } \\ \text { Disagree Disagree } & \text { Agree } & \text { Agree }\end{array}$ 
17. (Continued)

j. I know how to motivate students to learn science.

$\mathrm{k}$. It is important for students to learn science to develop their problem solving skills.

l. I am willing to have my classroom observed by other teachers to improve my science instruction.

m. I am interested in attending professional development on teaching science.

\section{Factors Influencing Quality of Science Instruction}

18. To what extent did each of the following impact your ability to teach science effectively during the 2010-11 school year? (Darken one circle on each line.)

$\begin{array}{cccc}\begin{array}{c}\text { Greatly } \\ \text { inhibited }\end{array} & \begin{array}{c}\text { Somewhat } \\ \text { inhibited }\end{array} & \begin{array}{c}\text { Somewhat } \\ \text { facilitated }\end{array} \quad \begin{array}{c}\text { Greatly } \\ \text { facilitated }\end{array}\end{array}$

a. Amount of time available to plan for science lessons.

b. Amount of time available to collaborate with other science teachers.

c. Alignment between NJCCCS Cumulative Progress Indicators (CPIs) and state science assessments.

d. Alignment between my primary science textbook/set of science modules to the NJCCCS Cumulative Progress Indicators (CPIs).

e. The behavior of students during science labs/activities.

f. Parental interest in their children's science instruction.

g. Access to print materials/equipment/supplies for teaching science.

h. Quality of facilities for teaching science.

i. School/district/state educational initiatives in subjects other than science.

j. Focus/content of required state science assessments.

k. Focus/content of required district science assessments.

l. Quality of the district's instructional materials for science.

m. Access to technology for science instruction (e.g., lab equipment, calculators, etc).
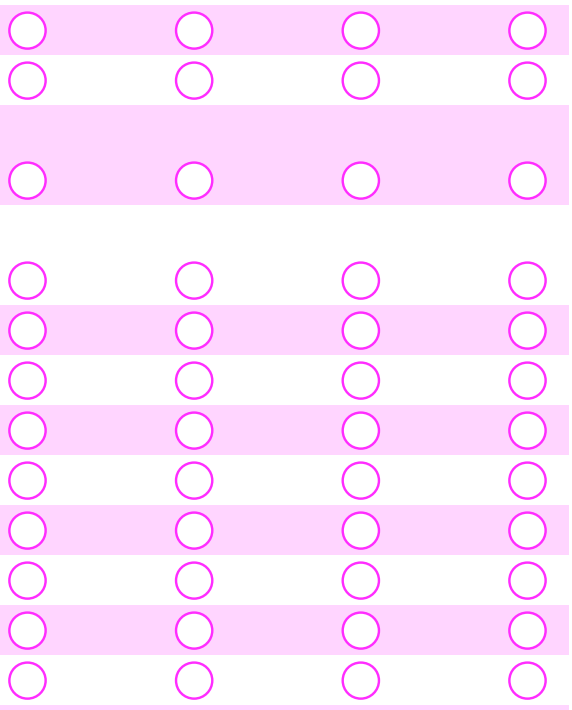


\section{Newark Public Schools Science Program Principal Questionnaire}

Instructions: Please complete this form using a \#2 pencil or a blue or black ink pen. Darken circles completely, but do not stray into adjacent circles. Erase completely or white out any stray marks. All of your responses will remain strictly anonymous.

\section{Background Information}

1. Including this year, how many years of experience do you have as each of the following? (Count part of a year as 1 year.

Darken one circle on each line.)

a. A principal

b. The principal at this school

c. A principal in this district

d. A teacher

e. A science teacher
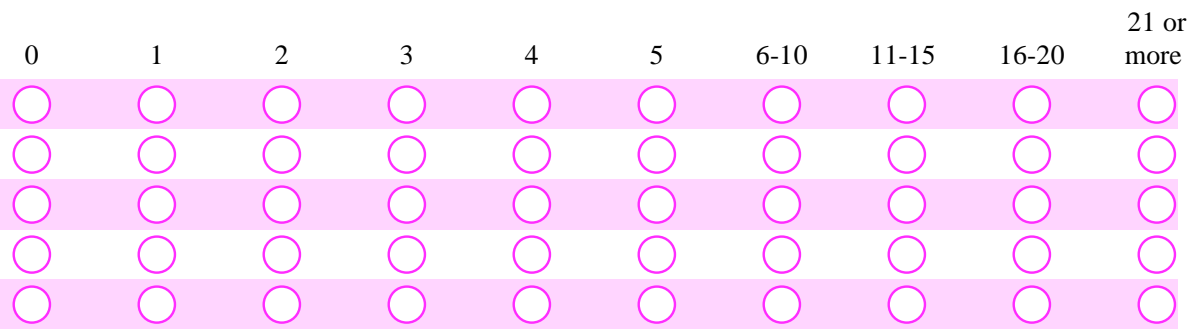

2. What is the highest degree you have earned? (Darken one circle.)
Bachelor's degree
Master's degree
Doctorate or professional degree (Ph.D, Ed.D, M.D., L.L.B, J.D., D.D.S.)

3. What grade levels are currently at your school? (Darken all that apply.)

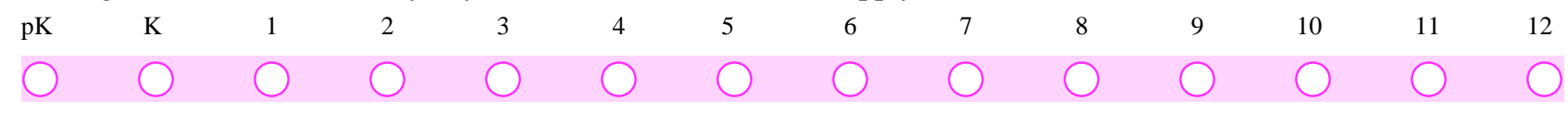

\section{Your School's Science Program}

4. To what extent do you agree or disagree with the following statements? (Darken one circle on each line.)
Strongly
disagree
Disagree
Agree
Strongly
Not Sure/
a. Our level of professional development was sufficient to support the goals of our school's science program.
b. Our core science program was relevant for a wide range of student needs.
c. Science teachers made use of diagnostic assessment information to tailor instruction for individual students.
d. Science teachers communicated with parents about science learning (e.g., through newsletters, parent-teacher conferences, invitations to observe classrooms informally).
e. I am able to provide time for teachers to meet to discuss science instruction.
f. I am able to fill teaching vacancies with teachers who are well-prepared to teach science.
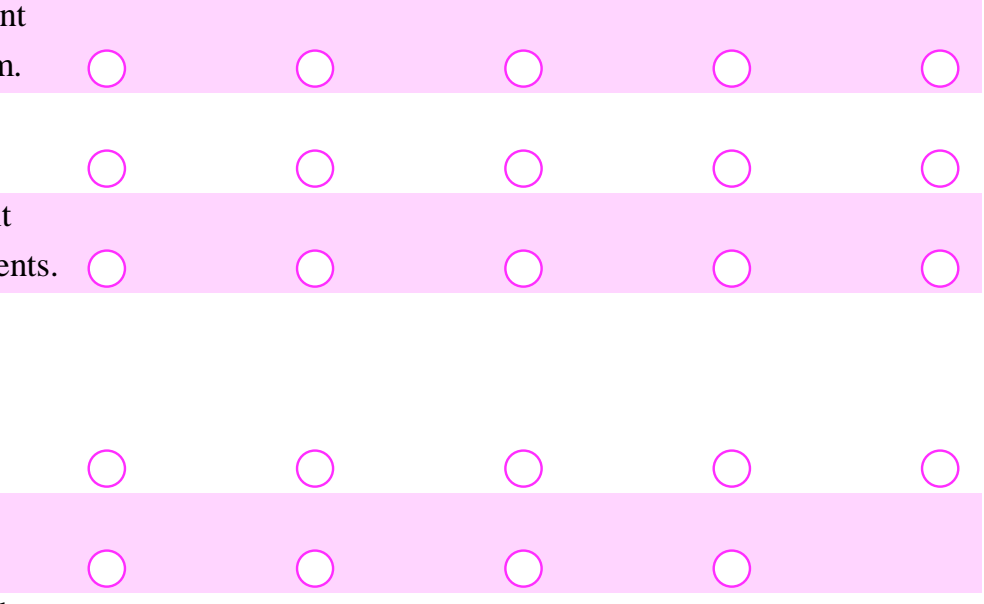
$\bigcirc$

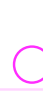
$\bigcirc$

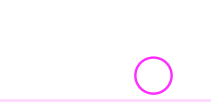

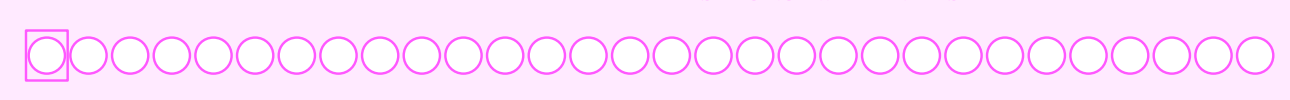

[QID]

Horizon Research, Inc. 
Question 5 is intended for administrators whose schools include any grades $K-8$. If your school includes any of these grades, please complete question 5. If your school does not include any grades K-8 (e.g., you are an administrator of a 9-12 school), skip to question 6.

5. To what extent do you agree or disagree with each of the following statements? (Darken one circle on each line.)

\begin{tabular}{|c|c|c|}
\hline $\begin{array}{l}\text { Strongly } \\
\text { disagree }\end{array}$ & Disagree & Agree \\
\hline
\end{tabular}

a. The science kits/modules (e.g., FOSS, STC) used to teach science provide engaging experiences for students.

b. Most of the students in my school have the literacy skills to read the materials in the science kits/modules (e.g., FOSS, STC).

c. Teachers have enough time to teach all of the lessons in the science kits/modules (e.g., FOSS, STC).

d. The science kits/modules (e.g., FOSS, STC) are available for teachers when they need them.

e. The science kits/modules (e.g., FOSS, STC) are sufficiently refurbished and ready for use when teachers receive them.

f. The district provides teachers with adequate professional development to support their use of science kits/modules (e.g., FOSS, STC).

g. I am able to ensure that teachers allocate sufficient time to teaching science.

h. I am able to ensure that teachers are following the district-provided pacing guides for each of the science units they teach.

i. I am able to ensure that teachers teach all of the lessons in the science kits/modules (e.g., FOSS, STC).

j. I am able to ensure the teachers new to a particular science kit/module (e.g., FOSS, STC) have an orientation prior to using those materials.

6. During the 2010-11 school year, science teachers were provided with administratively-supported opportunities (e.g., time and resources) to: (Darken one circle on each line.)

a. Discuss innovative science instructional practices.

b. Reflect on science teaching and learning with other teachers.

c. Observe other science teachers in the school.

d. Discuss how to teach science effectively for students with special needs (e.g., ELL, Special Education).

e. Discuss connections between the literacy curriculum and the science curriculum.

f. Plan and prepare lessons for science with other teachers.

g. Discuss the results of district-administered assessments in science.

h. Attend science conferences.

i. Attend professional development for science.

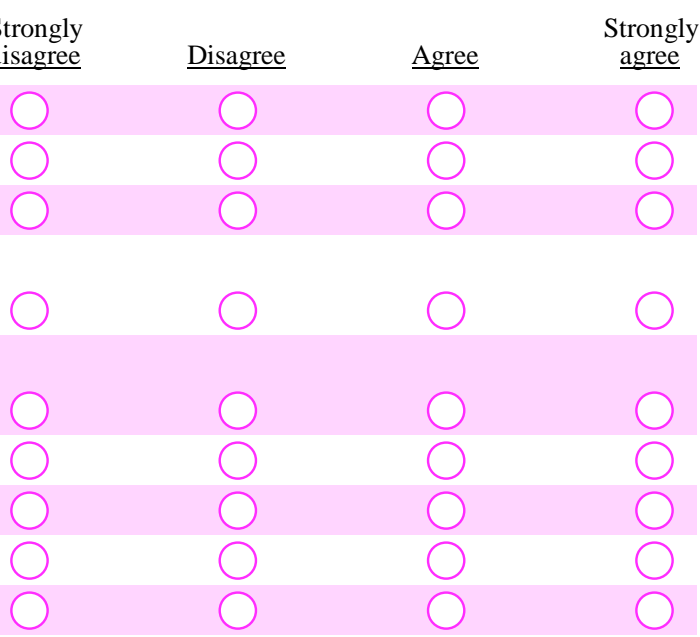


7. How often did you personally participate in the following science-related activities during the 2010-2011 school year?

(Darken one circle on each line.)

$\underline{\text { Never }}$

A few

times a

A few

times

At least

year

month

a. Attend formal meetings with science teachers to discuss science teaching and learning

b. Informally discuss science teaching and learning with science teachers

c. Observe science lessons

d. Discuss effective science teaching strategies with teachers

e. Discuss results of district-administered assessments with teachers

f. Work with teachers to use assessment data to inform instruction

g. Share science teaching literature with teachers

\section{Factors Influencing Quality of Science Instruction}

8. To what extent did each of the following impact the ability of administrators at your school to work collaboratively to improve science teaching and learning during the 2010-2011 school year? (Darken one circle on each line.)

a. Amount of time available to focus on issues pertaining to science

Somewhat Somewhat Greatly instruction

b. Level of interest of science teachers at your school for improving science teaching and learning

c. Level of support provided by your district

d. The pressure to improve literacy and mathematics scores

e. The reduction in school budget

f. Teachers' science content knowledge

g. Teachers' knowledge of effective instructional practices in science

h. Teachers' beliefs or practices about effective science teaching

For administrators whose schools include any grades K-8

i. Elimination of the lead science teacher

inhibited inhibited facilitated facilitated

9. To what extent did each of the following impact the ability of science teachers at your school to teach science effectively during the 2010-11 school year? (Darken one circle on each line.)

a. Amount of time available to plan for science lessons

b. Amount of time available to collaborate with other science teachers

c. Alignment between NJCCCS Cumulative Progress

Indicators (CPIs) in science and state science assessments

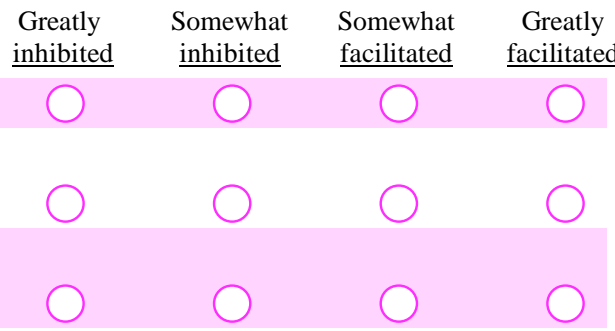

Continued on next page...

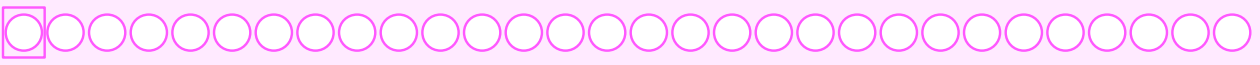


9. (continued)

d. Parental interest in their children's science instruction

e. Access to print materials/equipment/supplies for teaching science

f. School/district/state educational initiatives in subjects other than science

g. Focus/content of required state science assessments

h. Focus/content of required district science assessments

i. Quality of the district's instructional materials for science

j. Access to technology for science instruction (e.g., lab equipment, calculators, etc)

k. Teacher reassignments due to budget cuts

For administrators whose schools include any grades $\mathbf{K}-8$

l. The elimination of the lead science teacher

\section{Support for Improved Science Instruction}

10. To what extent do you agree or disagree with each of the following statements regarding district support for improving science instruction during the 2010-2011 school year? (Darken one circle on each line.)

nhibited $\begin{gathered}\text { inhibited } \\ \text { facilitated }\end{gathered}$

a. My district makes improving science instruction a high priority.
b. My district provides a coherent science curriculum for teachers.
c. My district provided timely access to high-quality instructional materials and
equipment for teaching science.
d. My district helped with efforts to promote student interest in science careers.
e. District policies and practices ensured that students had the necessary pre-requisite
knowledge and skills to enroll in challenging high school science courses.
f. My district provided adequate support (e.g., professional development, instructional
materials) for tailoring science instruction to students with special needs.
g. School-level policies and practices encouraged staff collaboration on improving
science instruction.

11. Indicate the extent to which you agree or disagree with each of the following statements for the 2010-2011 school year:

(Darken one circle on each line.)

Strongly Strongly Not Sure/

a. Science teachers at my school worked individually, rather than collaboratively, to improve science teaching and learning.

b. Science teachers in this school regularly shared ideas and materials related to science teaching.

c. Science teachers at this school had their classroom observed by other teachers for the purposes of improving their instruction.

d. Science teachers in this school worked to improve the quality of school-wide science instruction.

e. Science teachers at my school regularly shared lesson plans with one another. 


\section{Student Interest in Science}

12. Which of the following science-related activities were available to students in your school during the 2010-2011 school year? (Darken one circle on each line.)

a. Science fairs/competitions at your school

b. Science fairs/competitions that include other schools (e.g., regional/national competitions)

c. Extracurricular science clubs

d. Opportunities for science internships/mentorships

e. Guest speakers from science-related fields

f. Science-related field trips

g. Career fairs that highlight science careers

h. Robotics competitions

i. Access to college credits
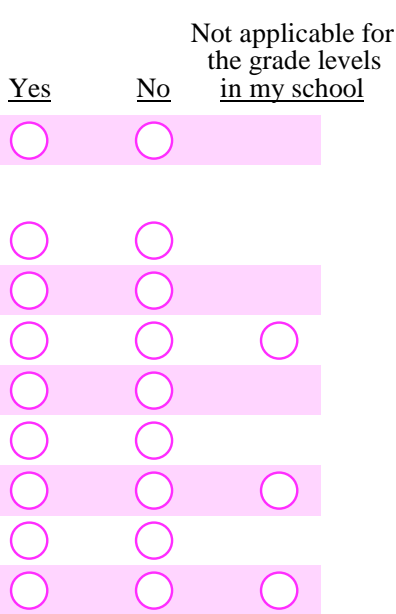

13. Indicate the extent to which you agree with each of the following statements for the 2010-2011 school year: (Darken one circle on each line.)

$\begin{array}{lll}\text { Strongly } & & \text { Not applicable for } \\ \text { Disagree } & \text { Strongly } \begin{array}{c}\text { the grade levels } \\ \text { Agree } \quad \text { in my school }\end{array}\end{array}$

a. Counseling in my school was strong regarding science courses needed for postsecondary education.

b. Counseling in my school was strong regarding science-oriented career paths.

c. Students at this school participated in science extracurricular activities (e.g., science club, science fairs, etc). 



\section{Appendix E School Vignettes ${ }^{1}$}

\section{Rainbow's End School}

Rainbow's End Elementary is a new, light-filled, three-story building with a large asphalt play area and a huge city park with flowering cherry trees across the street. Entering the multistoried, bright foyer minutes after classes started, visitors are struck by the purposefulness of children and adults alike. Five-year-olds in blue, white and khaki uniforms are scurrying to the office with lunch counts and notes, and adults are checking mailboxes and messages with efficient and friendly office staff. Two middle school female students in short navy skirts and white blouses enter the office area with a message from their teacher; they smile at and greet the visitors. The front office area is full of activity, and the visitors are struck by the feeling of positive energy that seems to invade every space.

The front office receptionist welcomes the visitors, clearly expecting them on this spring morning. She states that the principal, Ms. Sanchez, was in a meeting, so the assistant principal, Ms. Cooper, would be starting the visits to classrooms. As if on cue, the assistant principal entered the foyer from the now empty hallway and greeted the visitors. She confirmed that the teachers were expecting visitors, and that adult guests were often in classrooms. Additionally, students were comfortable with the presence of and questions from adults and were encouraged to explain their work to visitors.

Ms. Cooper explains that she observes science classes weekly and her perception is that while science instruction was not as inquiry-based and hands-on as she would like, the teachers were working hard on improving their practice. She liked the science kits and believed that the teachers did as well. She indicated that we might hear from teachers that they wanted textbooks to supplement the kits and modules, but there was agreement that the primary instruction should be student teams doing experiments, using the kits and modules.

Ms. Cooper led the visitors through the building and they entered a first grade classroom. It was bright and full of student artwork and writing. The daily plan was on the white board and the science objectives outlined. The teacher was in a small chair at the front of the classroom and the twenty-two students were gathered around her on the rug.

Teacher: "Last time, remember you rubbed rocks together, and they made sand. What kind of questions did we ask last time?"

Student: "Why does rock dust come out when you rub the rocks?"

Teacher: "Where do rocks come from?

Students raise their hands and make predictions such as, "Maybe red rocks come from the hot desert, volcanoes, asteroids..."

Teacher comments on each prediction: "What made you think that?" Teacher then asks students to "pair and share," discussing where rocks come from.

Students discuss excitedly.

Teacher then gives directions: "Find one bag and one lens for each partner. Work as a group, in partners. Use the rock record sheet (photocopied sheet of area for drawing and sentence to complete). Cut it in half and fill out one - compete the sentence with your observation. Write as many sentences as it takes."

\footnotetext{
${ }^{1}$ These three vignettes are based on the observations made during the October, 2010 and April, 2011 school visits and are composites of the schools visited.
} 
Teacher reads the directions: "Put one rock in the cup of water."

Teacher: "Why only one rock?"

Students raise hands and answer.

Teacher: "Next, observe the rock carefully. What does that mean?"

Student: "Use the lens."

Teacher: "Why use lens? And how do you use it?"

Students raise hands to answer.

Teacher: "Next, put your rock on paper towel to dry. Do the same for each rock. You have ten to fifteen minutes to wash the rock."

Students go off in groups and wash the rocks. Students drop rocks in the cup of water and observe.

Student in a group to visitor: "Some rocks make bubbles."

Students comment and write. Students give their group record to the teacher.

Students finish, clean up and teacher calls them back to the rug.

Teacher reads a few records aloud. There are observations about bubbles and about dust coloring the water.

Students raise hands and comment.

Teacher: "We are going to make a book about records. We are going to study rocks and make observations."

Teacher reads another observation: "Rocks look darker when wet. Anything else we can say about that?"

Students give other examples of material that looks darker when wet: hair, school uniform.

Teacher: "I read some awesome observations and questions today. What did we learn today?"

Students raise hands and reply: "Putting rocks in water makes rock dust. Putting rocks in water makes bubbles."

Teacher: "I need one good question."

Student: "Why does dust come off rocks?"

Teacher writes question on board. Teacher then introduces three new words, writes them on the board and reads the definition to the class: Basalt: that was the grey rock; it comes from hot liquid out of the volcano. Tuff : that was the light soft rock; it has ashes in it from the volcano. Scoria: that is the red bubbly rock, from the top of lava.

The visitors move out in the hallway looking into second and third-grade classrooms where students are engaged in literacy learning. At this point, they are met by the principal, Ms. Sanchez, and Ms. Cooper leaves to meet with a contractor who is working on the elevator. Ms. Cooper indicates that she will join the group later to debrief and discuss the Merck program. She is extremely interested in feedback from the visitors, and exploring possibilities of support for their school. After the assistant principal leaves, the principal apologizes to the visitors for not being immediately available when they arrived. She indicates that she is very interested in improving science instruction at Rainbow's End and that the visitors will see a range of effective teaching science and are working to improve but they still need lots of help and support.

The visitors walk up two flights of stairs to the third floor where the middle school classes are held. There are two rooms dedicated entirely to science and they were built as fully-functional labs. There are interactive white boards, fifteen computers across the back wall and twelve microscopes lining the prep areas. Students are clustered around work stations with water and gas lines and some are on lab stools and some are standing. There are twenty-six students in the room and there is a productive hum. Ms. Sanchez walks with the visitors to where the teacher is bent over a work station conferring with four students. They have a large poster paper 
in the middle of the table and are using a pencil to craft a drawing representing their thinking. Two students are debating the best way to depict one of their ideas and the teacher is listening intently. She looks up and sees the principal and indicates to the students that they should continue the conversation and perhaps try it both ways on their scrap paper to which one works out the best. She dusts off her hands on her khakis and turns to the visitors to shake their hands. Ms. Sanchez indicates that the teacher, Ms. Simpson, was the lead science teacher "until the district cut them" but that she has found funding so that Ms. Simpson can work halftime as a science support teacher. They are concentrating on third and fourth grades where the teachers seem to be struggling the most to find the time and the resources to do the modules.

Ms. Simpson indicates that she will join the visitors after this class to share her thoughts on Rainbow's End science program and her perceptions of needs in the district, but encourages them to talk to the kids about their work. "They love to talk to visitors about what they are learning. We are studying genetics, which totally fascinates them," she continues, "and they have been working with the punnett squares and the boards and stuff. They are now creating their offspring posters and as you can tell there is lots of conversation." She chuckles. "No one wants their offspring to have a tail, even though I've told them these are not human offspring that they are creating." She laughs and turns back to a group.

Ms. Sanchez moves to a group and sits down and the visitors divide up, each going to a separate group. There is an aide and a student teacher also in the room. With the exception of two boys who are pencil-fighting in the corner all the other students are engaged with groups. One group has moved to the bank of computers and is writing a summary of their work; another is busily drawing a picture of their offspring. Two groups are huddled around tables still debating what characteristics their offspring will have. As the visitors leave the room, the students barely notice.

Although Ms. Sanchez did not schedule a focus group of teachers, she did arrange for Ms. Cooper and Ms. Simpson to join the visitors in a debrief. The three women were positive about their school but concerned about the direction science education was headed in the district. They had seen a decrease in services and were frustrated that so little professional development was occurring.

"We can't fault the teachers for being hesitant about using the kits; many of them have not received any training. These are teachers that want to do it right and if they think they are going to mess up, they just won't do it," Ms. Cooper explained.

"That's why I found funding for Ms. Simpson to spend half her time working with the teachers," Ms. Sanchez said. "But it isn't enough."

"You can say that again," Ms. Simpson said. "I'm not sure I have the energy to teach the seventh and eighth graders and help the teachers next year. I know the other teachers need help, and I want to be helpful, but these kids need me too. I don't want to hear from the high schools that our kids weren't prepared."

"We are very proud that so many of our students get into the competitive high schools," Ms. Sanchez continued. "But we want them to be successful there. Our families deserve nothing less. That's what keeps me up at night."

The other two women nodded in unison. 
Authors' Note: During several weeks in February 2011, five public elementary schools were visited in Newark, New Jersey. The description of Rainbow's End Elementary School is a composite of these five schools.

\section{Sunshine Elementary}

Sunshine Elementary is a large, old, three-story brick building; it is land-locked with limited playground space and no parking areas. Four hundred twenty students are currently attending kindergarten through eighth grade at Sunshine, almost $10 \%$ less than the previous year. The halls have little student work or art work.

Visitors check in with security personnel who point them to Sunshine's main office. About a dozen students are waiting in line to sign in for late arrival. In the halls, late arrivals are hurrying to class. The halls are clean, and the building seems well-maintained on the inside in contrast to the aging exterior.

Four desks are crowded into a small outer office separated from the waiting area by a bolted half-door. The principal's office off the main office is small and filled with books, files and chairs. The visitors are struck by the multiplicity of video security camera displays in the main office and in the principal's office. Children in uniforms and parents wait in the cracked plastic chairs in the waiting area and teachers come in and check their mailboxes and bring forms to the secretaries.

The principal, Mr. Joe Smith, is cordial and welcomes the visitors. There are numerous interruptions from the secretary and the phone as the visitors discuss Sunshine's science program. In the background, morning announcements are being made over the intercom. Mr. Smith pulls the teachers' schedules and the visitors check for when during the day the 50-minute, 3-times-per-week science block is taught in grades kindergarten through five.

A quick walk through the school reveals some empty classrooms and other classrooms with as few as five students in them, as well as classrooms with students and teachers working at desks and tables. No students are in the media center, computer lab or science lab. On further exploration, there appear to be limited books in the media center, the computers in the lab are outdated and the science lab is dirty, ill-equipped, and houses boxes of books and materials.

Although in a number of classes the scheduled science period is being used for literacy or mathematics instruction, a few primary teachers are teaching science. Two of them are using kits, and the third explains that the modules only arrived last week and he has not had time to open the boxes. So he is teaching a lesson on measurement from a unit developed by the district. The modules that the students are engaging in are recognizable as part of the curriculum for the observed grade.

At Sunshine there was a lead science teacher last year who was released full-time to help organize science materials, set up labs, demonstrate use of the modules, and co-teach some lessons. She also did some coaching with the new teachers and organized occasional science meetings to discuss curriculum. This position was cut for the 2010-2011 school year, and now two of the science teachers each have one period a week to perform administrative and science materials distribution functions. Some of the teachers tell us that because of deep cuts in teaching staff and the elimination of departmentalization in grades 4 and 5 , many teachers have new grade assignments or are teaching some content areas they haven't taught before. Two former science teachers are teaching in self-contained classrooms, and a math teacher is 
teaching middle grade science. As a result, by October some teachers are still focusing on learning the curricula and materials for literacy and math, the two areas of instruction that are the most critical.

The middle level is departmentalized and the seventh and eighth grade science classes, meeting 45 minutes per day, appear to be further along in the science curriculum as the modules remain in the building. We are told that the district is developing new curricula and pacing guides but we do not see copies of these materials. Sunshine and other schools in the south region in Newark are served by a science instructional coach who works as a Resource Teacher Coordinator and visits schools on a rotational basis. She has not been to the schools yet this year, but is expected in the next two weeks.

We enter a seventh-grade class and students are engaged in hands-on science inquiry activities. Small groups of students are clustered around student desks and balances, scales and rocks are out on the desks. The teacher is rotating from group to group helping students answer questions on a hand-out and record data in student composition notebooks. The purpose of the activity is not clear from the worksheet and there are no objectives on the board. The scales aren't working and it becomes clear that the batteries are old and need replacing. The students take this in stride and continue with their weighing and measuring.

There are twelve students in the classroom and two adults. The principal, Mr. Smith, who accompanied us into the classroom, also assists the students as they work through the activity. There is discussion at the tables and the students seem interested in and engaged in the science task.

Although we see several other science lessons, this is the only lesson where the students are working mostly independently in groups. In other classes the teacher is much more directive, teaching to the entire class, and the student interaction limited to answering questions from the teacher or on the hand outs but there is no discussion about the content. The teachers' questions are factual or definitional and do not encourage students to consider patterns, offer explanations, or make connections. An emphasis on isolated vocabulary memorization and note taking seemed to prevail across grade levels.

In a first-grade class, the teacher is reviewing the seven-step scientific method with the class. She writes each step on the board and then explains it. The students struggle with words like hypothesis, data and procedure, but they enthusiastically make choral responses to the teacher's questions (What step comes next?). She then asks them to draw a picture of a scientist at work. They seem confused, but begin to draw.

A fourth grade teacher is asking the class "which has more density, water or an apple? How do you know? She reviews the scientific method on the board, and rhetorically asks "What is our question?" and then answers herself. She asks the class "What will happen if they mix water, corn syrup, and vegetable oil together? What part of matter are we using?" The students answer "liquids!" What is our hypothesis? Students are silent, then a few offer suggestions that the teacher ignores, and the teachers says "Corn syrup will win because it has more density." So what will it look like when I put the three liquids into a cup?" The class continues in this fashion with the teacher answering her own questions and the students politely listening and occasionally answering in choral fashion.

We meet with teachers in a focus group and they share some of their perceptions about science education. Most teachers admit to feeling at a disadvantage without the lead science teacher. 
They indicate that the lead science teacher helped them prep for science classes and co-taught or even taught some of the classes for them. They are nervous that without science textbooks the students have no ability to do work outside of class and there is little continuity from one unit to another. They indicate that materials for the kits that should include student readers, but these are not available so in-class activities are not supported by any texts or resources.

Teachers are also frustrated by their limited professional development opportunities and many indicate that there has been no training on the kits in several years. Others indicate that they have changed grade levels and have not had the opportunity to prepare to teach the kits for their new assignment. The kits arrived late and teachers were busy learning the curricula for mathematics and literacy. Primary teachers indicated that there is so much pressure to bring up test scores in reading and math that teachers spend more time on these subjects. One said, 'Science is not a priority,' and the others agreed.

During the focus group session teachers related examples of positive student-teacher and student-student interactions in science lessons and talked about student interest and excitement during science instruction. They indicated that they would like to teach more science but that it was difficult given all the other demands on their teaching time. They expressed a professional interest in becoming better at teaching science and looked forward to a partnership where they could improve their practices around science teaching and learning.

\section{Blue Skies School}

Blue Skies School is a seventies-era two-story building with lots of windows and large rooms. It is on a busy street and takes up the entire block in a bustling community with stores and businesses. Although the student population has decreased slightly in recent years, it still serves over seven hundred students, grades K-8. In this vignette, we focus on the middle grades.

The principal, Mr. Sam George, meets visitors in the foyer of the school and scurries them past security which is busily checking in late arriving students and other visiting adults. Mr. George stops briefly to talk with a student who is in the hall about adherence to dress code. He explains to the visitors that the students are always looking for ways to dress "around the code" as you would expect from kids this age. The halls have brightly painted murals and outside the main office is a large poster commemorating a geology project that middle grade students from Blue Skies and other Newark schools participated in with area colleges the previous summer. Mr. George proudly points to the high number of students from his school who were part of the project. The visitors enter the principal's office and their attention is immediately drawn to charts posted on the wall that illustrate the student achievement levels at Blue Skies. The principal has notebooks and packets ready to share with the visitors outlining student achievement at the school. Although Mr. George is in his first year as principal, he has a clear understanding of the historical patterns of achievement at Blue Skies. He points out that the school ranks near the middle of the school rankings in the district, but that scores have declined slightly in the past two years on the $8^{\text {th }}$ grade mathematics and science assessments. He wants to get the mathematics passing rate up to 40 percent, and the science passing rate up to 60 percent. The visitors note that very few students had achieved Advanced Proficiency on the NJASK8.

Mr. George has arranged for the visitors to talk with teachers at their PLC which meets early in the day and when the visitors arrive in the room they are greeted by a dozen faculty members. 
What is immediately evident is the pride the teachers take in Blue Skies and their students and their goal of helping their students gain entrance into competitive high schools. They believe the loss of the lead science teacher has handicapped them in their efforts to make science instruction as robust and prominent as other content areas. The lack of emphasis on science, they suggest, is due to the state assessment system and the testing of science at only a few grades in contrast to the yearly focus on reading and mathematics scores required by NCLB and the state.

The teachers also are concerned about limited support at the district level and virtually nonexistent professional development opportunities in science. In addition to the loss of the lead science teacher, they also talked about the closing of the Banneker Center and the decreased services available to them through the Newark Museum. When asked about overall professional development opportunities, few can identify anything in the past two years except for workshops at Banneker which are no longer available.

Mr. George had indicated that the PLC time created opportunities for collaboration and shared planning and learning; however; the teachers did not indicate that this work had really taken seed. The math coach was one of the teachers in the group and she played a particularly dominant role in explaining the internal supports available to teachers. She noted that the group had focused on mathematics so far, but would get to science in the near future. The visitors were not convinced that the PLC time was used to do the planning and collaboration envisioned.

After the meeting with teachers, Mr. George walks the visitors through the school and stops are made in language arts and math classes. The language arts teacher was particularly skillful in using cooperative groups and creating tasks that required students to team and problem solve. In the math classroom, students were in rows and were doing problems in their textbooks. There were some empty classrooms and some classrooms with only a few students in the room. The halls contained some student work and there were brightly painted murals such as the one that was evident in the foyer of the building. The inside space appeared to be cleaned routinely but maintenance appeared to be mostly patching and temporary repairs. A science class was interrupted by two maintenance workers to repair floor tiles and the class was redirected to the computer lab.

There were two dedicated science teachers at Blue Skies serving the middle grades. .One teaches four $8^{\text {th }}$ grade sections and one $6^{\text {th }}$ grade section; the other is assigned four $7^{\text {th }}$ grade sections and one $6^{\text {th }}$ grade section. The eighth grade science teacher, Ms. Jameson, was the former lead science teacher at Blue Skies and the observers visit her teaching an ELL inclusion class. Ms. Jameson begins the lesson by having students do a "Quick Write" answering the question, "Is all sediment the same?" This requires them to recall what they had learned about sediments in previous lessons. As students complete the writing, the teacher returns quizzes. She then commends the class for success on the quiz and gives directions and a strategy for students to check the answers to any parts of the quiz that they got wrong.

Ms. Jameson uses recall questions and begins with the Quick Write question to review the ideas students had studied in previous lessons. These ideas included: the sources of sediment, the components of sediments, and the textures and colors of sediments. She introduces the "diameter" of sedimentary particles as an important characteristic. After presenting the "Wentworth" scale for classifying the size of sedimentary particles, she guides students to compare the diameters in that scale with a ruler and with the size of familiar objects. 
She gives students a handout with directions for examining samples of particles typical of sedimentary particles. As students examine the samples and record their observations, the teacher monitors the progress of groups and asks questions of both individuals and groups. The ELL teacher also assisted students as they worked in small groups and completed the handout.

Mr. Rogers, the seventh grade teacher, is working with students on the calculation of speed. He begins the lesson by reviewing the formula for calculating speed, and then gives the students two problems on the board that they are to solve. There are 19 students sitting in five groups, but most of the students appear to be working individually. There are three students sleeping, several who are drawing pictures, and another group that seems totally off-task engaged in some kind of horseplay. The teacher moves about the room ignoring the sleeping students but intervening in the group that is fooling around, trying unsuccessfully to get them engaged in the work. As the work session ends, the teacher calls on each group of students to report their results to establish an expectation for reasonable results.

In a sixth grade class, the lesson begins with students being asked 'what do we do when we are curious about something?' Students reply, 'we ask questions.' The teacher then poses the question, 'why don't ships sink since they are very heavy?' Students reply with 'force,' 'the motor,' and that ships are 'heavy.' The teacher then demonstrates the difference between the rate of fall a flat sheet of paper and the same sheet crumpled into a ball. Asking about what changed, she uses the student response that the 'shape' changed to suggest that it is the shape of a ship that keeps it afloat. She then asks what we would have to do if we wanted to design something. Students reply that we would do 'research,' use the Internet, and use our experience. The teacher suggests that we might 'do an experiment.' Asking about the features of an experiment, she accepts answers such as 'have a hypothesis,' 'make predictions,' and 'repeat the experiment.' She then asks about predicting which would float in water, a can of diet Coke or a can of regular Coke. The whole group discussion ends with the teacher saying that 'we would need to see which floats.' Although the students are engaged in the lesson, it is clear that limited planning had gone into lesson design.

Although there is variability in instructional capacity, there is a clear focus on teaching and learning at Blue Skies Middle; teachers seem concerned about providing learning opportunities for students that will not only prepare them for competitive high school coursework, but also help them develop habits that will benefit them in post-secondary work. There is clearly capacity to build on, and the teachers and Mr. George expressed the desire to partner with MISE and create better science learning for the teachers and students. 


\section{Appendix F \\ The MISE Review of the NPS Curriculum Documents}

\section{Background}

As part of its preparation for a science education partnership with the Newark Public Schools, the Merck Institute for Science Education (MISE) staff reviewed the curriculum documents used in the district. This is a summary of that review. Two types of curriculum documents were available, school board adopted versions and "in draft" versions being prepared for internal review and adoption. The publicly available versions are dated 2005 and onward and are available on the Newark Public Schools' website: http://www.nps.k12.nj.us/.

Most of the guides published on the district web site are based on the 2004 New Jersey Core Curriculum Standards (NJCCCS). The draft versions are organized around the 2009 NJCCCS. For the reviewed grade levels, the review team used the most recently available versions. The review team makes note that the published and draft versions appear to have been developed with different approaches. The more recent, or draft, versions indicate a decision to address all the Cumulative Progress Indicators (CPIs) for each grade. The existing, web published versions often use the adopted materials as the primary organizational framework. To focus on specifics within the documents, the review team looked closely at the curriculum guides for Grades 3 and 4, Grades 7 and 8 , and high school Biology.

In reviewing the Newark curriculum documents the MISE review team drew upon the model of curriculum development found in Designing Mathematics or Science Curriculum Programs: A Guide for Using Mathematics and Science Education Standards (NAP, 1999). This document refers to a curriculum framework, which we will interpret as the set of curriculum guides. The "Designing" publication suggests that curriculum guides:

- Assign concepts to grade levels based on what students are capable of learning.

- Indicate development of processes/skills/abilities over several years.

- Indicate clearly what standards are prerequisites for other standards.

- Assign content across grade levels to be appropriately balanced or concentrated.

- Group concepts to form the basis of units or courses, with logical connections shown both within a grouping and across grades.

- Account for all standards.

This review is organized around these suggestions. 


\section{Assign concepts to grade levels based on what students are capable of learning}

The Newark curriculum authors created the guides tightly around the 2009 NJCCCS, which are based on the National Science Education Standards, the Benchmarks and Atlases for Science Literacy, and the National Assessment of Educational Progress (NAEP) Framework. All three of these documents focus on a growth in understanding of science content over time in an appropriate developmental sequence. Because the curriculum authors accurately assigned the NJCCCS CPIs to their respective grade bands, the developmental appropriateness of the majority of learning targets is accurate.

However, in some cases, the district-constructed benchmarks that correspond with the CPIs are not developmentally appropriate. For example, the high school Biology curriculum features a district benchmark, NPS 4 Differentiate between living and non-living things by identifying and utilizing the characteristics of life. This is comparable to the NJCCCS CPI intended to be met by the end of grade 2, 5.3.2.A.1 Group living and nonliving things according to the characteristics that they share. Spending valuable instructional time on a developmentally inappropriate concept can limit students reaching the core content intended for their grade level.

\section{Indicate development of processes/skills/abilities over several years}

As mentioned above, the curriculum authors organized the NJCCCS CPIs around their appropriate grade bands, which have developmental progressions inherent in their structure. However, the curriculum guides do not contain information to link the development of processes/skills/abilities over several years.

While there are grade band lists of CPIs, there are no suggestions to the teacher about how to bridge or scaffold learning development of the concepts and skills. The "Designing" publication recommends a specific description to identify the order of introduction of concepts, within and across years. This description could resemble the "HRI module frameworks" used in the Partnership Peer Teacher Workshops or the Project 2061 Atlas. By contrast, the reviewers did not identify the necessary coherence in the Newark curriculum plan. In some guides (grades $3,4,7,8)$, there are tables that show which CPIs are covered at which grade within a grade band, but there is no comprehensive list that shows the intentional development of core concepts over time.

An additional concern is curriculum continuity across the grade levels. In some cases, students will experience the exact same investigations multiple times throughout their schooling. This occurs in grades 6 and 7 in the use of the module Organisms: Macro to Micro (STC) where lessons 3 and 7 are repeated. In another case, the Properties of Matter (STC) module is divided over two years 
without suggestions for developing continuity or review for managing the instructional gap in between the instruction.

\section{Indicate clearly what standards are prerequisites for other standards}

As highlighted above, there is no explicit acknowledgement of how students will construct their knowledge over time. The curriculum guides should identify the set of prerequisite knowledge and skills required for student progress. If such information is contained in the adopted instructional materials, the curriculum guide should reference those resources.

\section{Assign content across grade levels to be appropriately balanced or concentrated}

The reviewers noted an uneven allocation of time for the content, seen in the allocations of various standards and CPI's. At grade 7, 38\% of the school year is devoted to life science topics and at grade $8,45 \%$ of the school year is devoted to life science. At grade 3, no time is allocated for earth and space science topics and only 132 class periods are allocated for science during the year. Of the 132 periods, 98 (or $74 \%$ ) are given to physical science topics. The draft, or most recent, versions of the curriculum guides do indicate a stronger commitment of time for science instruction; the 2005 grade 5 science curriculum guide projected 74 science sessions or lessons whereas the 2009 version projects 121 sessions or lessons, still only $67 \%$ of the school year.

In contrast, the general Biology curriculum seems overburdened with concepts to be addressed within one course. The NJDOE has published a Biology Core Content document (referenced in the Newark Biology curriculum) to serve as a basis for curriculum development. It proposes that districts focus their Biology courses on 21 Life Science content CPIs. The Newark General Biology curriculum proposes a course that addresses 30 content CPIs, 9 of which are outside of the Life Science domain proposed by the NJDOE. The higher number of concepts to be mastered within one course increases the likelihood that students will not have sufficient opportunity to learn well the highest priority content.

\section{Group concepts to form the basis of units or courses, with logical connections shown both within a grouping and across grades}

The reviewers note that the primary basis for the sequence of instruction in most of the guides is the order of the standards and CPIs in the NJCCCS. This is notable because the NJDOE does not propose the sequence in the NJCCCS as an intended instructional sequence (NJAC 6A:8-3:1). Often, the curriculum plan and pacing guide identifies only those investigations and lessons that correspond 
to the NJCCCS, thus preventing the recommended use of the modules. While this may have been an effort to conserve limited instructional time, implementing the modules in this fashion will disrupt the instructional benefits documented in the development of the modules. Most standards-based modules are constructed so an idea is introduced, mastered and reinforced through multiple investigations. Eliminating investigations or altering the chronological order may impact students' opportunities to develop an understanding of the targeted ideas (Saul \& Reardon, 1996).

The reviewers observe that the Newark sequence results in implementing standards-based instructional modules at more than one grade (for example, Properties of Matter (STC) at grades 6 and 8 and Macro to Micro (STC) at grades 6 and 7). In many cases, the modules were broken into dissociated units within a grade level. The guide identifies only those investigations and lessons that correspond to the NJCCCS. For example, in the grade 7 Life Science unit, the module Organisms: Macro to Micro begins with Lesson 7: (also included in the 6th grade curriculum), then moves next to Lesson 11, then back to Lesson 3 , then jumps forward to Lesson 16, next to Lesson 18, then back to Lesson 8 , once again forward to Lesson 15, then back to Lesson 10, then a final return to Lesson 14. Jumping from lesson to lesson outside of the sequence proposed by the material developers may render the instruction ineffective (Saul \& Reardon, 1996).

Parts of modules for all three content strands (Physical, Life and Earth) are often used without attention to the designated sequence. In some cases, outside content is inserted within a module. For example, in grade 8, there is an inexplicable insertion of seven lessons about weather in the curriculum between investigations 1 and 3 in the Earth History (STC) module. The reviewers highlight that the intended sequencing of the modules are based on documented developmental research and warn that eliminating investigations or altering the chronological order may impact students' opportunities to develop an understanding of the targeted ideas (Saul \& Reardon, 1996).

\section{Account for all standards}

The reviewers commend Newark for their strong efforts to plan to meet each and every NJCCCS CPI in Science. The authors had a clear focus on creating a framework that would meet every science content proficiency expectation the NJDOE put forward.

Unfortunately, the reviewers find that in some cases the learning outcomes in the curriculum guides are misinterpretations of the CPIs. As a result, the curriculum guides do not give accurate representations of the targeted ideas and may guide teachers away from the intent of the CPI. For example, the CPI 5.3.8.B.1 Relate the energy and nutritional needs of organisms in a variety of life stages and 
situations, including stages of development and periods of maintenance, highlights the changing energy requirements for living things over time. The Newark benchmarks created to help teachers address the development of this understanding are as follows: NPS 2 Observe and draw a stomatal unit by examining a lettuce leaf and NPS 3 Use a model to demonstrate how guard cells operate to form a stoma. The benchmarks focus on students identifying parts of a plant, rather than constructing meaningful understandings of energy requirements of living things.

In the Biology curriculum, a number of CPIs have been rewritten by the curriculum writers, and the revision has significantly distorted the intended learning target. For example, CPI 5.3.12.C.1 Analyze the interrelationships and interdependencies among different organisms, and explain how these relationships contribute to the stability of the ecosystem was rewritten to Describe the three different types of ecological pyramids by analyzing the interrelationships and interdependencies among different organisms, and explain how these relationships contribute the stability of the ecosystem. The NJCCCS focus is on students understanding how interrelationships among organisms generate stable ecosystems, where the Newark revision seems to limit students to identifying and describing three different types of graphical representations of biomass generation. In an effort to create an easily assessable learning goal, the writers may have limited an experience to develop students' understanding of a core concept in biology.

The "Designing" publication also suggests the following criteria for the selection of curriculum materials:

- The content of the instructional materials should be mathematically and scientifically accurate, consistent with the outcomes in the standards, and targeted at the level called for in the framework.

- The instructional strategies consistently used by the material should be supported by learning research and make it possible for students to attain the specific outcomes identified in the first criterion, above.

- The assessments that accompany the material should be aligned with the content in the standards and the level or skill expected by the standard.

- The support for the teacher in the teacher's guide and ancillary materials should be adequate.

- There should be evidence from field trials that students can learn from the specified content and skills if the materials are used as intended.

The reviewers were not able to examine all curriculum materials. The comments that follow are based on information about the use of instructional materials gleaned from the review of the curriculum guides. 
The content of the instructional materials should be mathematically and scientifically accurate, consistent with the outcomes in the standards, and targeted at the level called for in the framework.

The instructional strategies consistently used by the material should be supported by learning research and make it possible for students to attain the specific outcomes identified in the first criterion, above.

\section{There should be evidence from field trials that students can learn from the specified content and skills if the materials are used as intended.}

The recommended selection of the research materials has been achieved at grades K-8. The curriculum is primarily built upon the use of module-based materials, and the selection includes modules from Science, Technology, and Children (STC) and Full Option Science System (FOSS). Research indicates that the use of science modules such as FOSS and STC generate greater active participation among students, empower and engage populations that otherwise feel disenfranchised, promote positive classroom environments, increase teacher content knowledge, increase teacher confidence to teach science, and provide enjoyment for teachers who use them (Gennaro \& Lawrenz, 1992; National Research Council, 2000; Houston, Fraser, \& Ledbetter, 2003).

In high school, however, the General Biology curriculum is not based on a careful selection of research-based materials. In high school, there are three curriculum guides that are posted online for Biology. Two of them are designed around a recommended text, Biology by Miller and Levine. One of the guides is designed around the research-based BSCS (Biological Sciences Curriculum Study) texts Biology: A Molecular Approach. This course includes Biology by Miller and Levine as a supplementary text. If there are transitions between the texts in this course, this would negate the benefits of the research-based materials.

The reviewers do recognize that it is currently difficult, if not impossible, to identify materials aligned with the content and teaching standards for the entire spectrum of standards. While the foundation for the curriculum is researchbased, as mentioned in the previous section of the report, the curriculum authors have added a number of supplemental materials that may render the modules less effective, negating their benefits.

In attempting to compensate for a lack of instructional resources on some topics, the Newark curriculum guide developers identified many supplementary resources, typically Internet links. In many cases, the supplemental materials are not research-based, may not include any pedagogical support, and may not be connected at all to the targeted idea or learning goals. For example, to support the CPI 5.3.8.A.2 Relate the structures of cells, tissues, organs and systems to their functions in supporting life, the curriculum guide offers an associated resource called "Blow Up a Balloon with Yeast" from www.sciencebob.com. 
An additional concern is that there is no guidance for the teacher in using the materials at the Internet links; should the screens be printed out, should the teacher use a large screen display for the whole class, or should students work independently or in small teams at computer workstations? Within a "unit" associated with a CPI, there are often redundancies among the suggested Internet resources and there is no suggested priority for implementation. This was noted especially in the materials suggested for geologic time and for plate tectonics. Several of the resources in the "lesson" column for a CPI "unit" are so short and the set of them so fragmented that the description of them as a lesson, or even a part of a lesson, may communicate confusion about good lesson planning.

The "Designing" publication includes the reminder, "modifying existing units or writing new units is an expensive and time-consuming solution to creating better transitions or covering gaps between the instructional materials from different sources. Finding units from other sources is an alternative way to fill gaps. However, this approach may result in a "patchwork" program that creates additional inconsistencies." The Newark curriculum developers may have been caught in this dilemma.

\section{The support for the teacher in the teacher's guide and ancillary materials should be adequate.}

The curriculum guides should complement the use of the well-developed teachers' guides included in the adopted materials. A useful curriculum guide will be easy to use, and give guidance for using the guide in conjunction with the instructional materials. Although a curriculum guide should not serve as an instructional resources, some Newark guides include "blackline" originals for making student copies. Some have "model lessons." It is unclear in many cases which experiences are optional, and which are required to meet the expectations of the district. Some curriculum guides include two columns that may lead to this ambiguity; they are titled "Types of Research Based Activities and Assessments that could illustrate Objectives" and "Suggested Resources." It is not clear if a teacher can select his or her own activities and lessons from one or both of these columns, or if they are expected to provide students with access to any or all of the experiences.

For example, at the end of the grade 8 Earth Systems Science unit, 19 periods are allocated to one CPI (5.4.8.G.2), but no guidance exists on how teachers might use the suggested resources. These resources include assorted standalone data sets, short videos, various articles that are not all at reading levels appropriate for the grade, and over 33 lesson plans. It is unclear how teachers might be spending this large chunk of instructional time. 
In addition, the approved General Biology curriculum does not contain any instructional guidance. There is a recommended text, but it offers no suggestions of selected content or pacing of the material. It simply provides the "Course Proficiencies" which are a listing of CPIs pulled from Physical Science, Life Science, and Earth Systems Science, as well as a page entitled "Curriculum Units" which was extracted directly from the NJDOE Biology Core Content Document. This page lists general descriptors of the strands (the level of organization of the NJCCCS just above the CPIs), but it does not include the Physical and Earth Systems Science CPIs that were listed in the "Course Proficiencies" page. Students are expected to become proficient in content that is not included in any of the course curricular units, and teachers receive no guidance on instruction.

Lastly, guidance for using instructional time is also minimal and sometimes nonspecific. Grades 7 and 8 sequence and pacing charts project 169 days each. With only 180 school days and mandated state testing, etc., there is not sufficient time to provide the planned experiences.

\section{Conclusion}

It is clear to the reviewers that the current curriculum documents represent a strong effort made by the authors. What is not clear from the documents is the extent to which there was a "common vision" for science education that supported the curriculum design process. In fact, the documented authors of the guides, the "Curriculum Committee" named in each guide, number from two to nine with most being central office science education staff. The "common vision" and the "building consensus" steps are not referenced in the curriculum guides. To the extent that a curriculum guide should be self-documenting, indicating how it was developed and supported, there is no indication that the Newark curriculum has broad-based understanding and support by teachers, administrators, or parents. Revisiting and revising this curriculum with these key criteria in mind, then vetting it with all critical stakeholders will lead to a product that will serve Newark students well.

The reviewers recognize that the curriculum writing teams in Newark had to operate in circumstances that may have inhibited "best practice." This review is written from the perspective that science education leaders in Newark are initiating aggressive steps to provide teachers with multiple resources, including curriculum guides, for enhancing the science learning of students. This review may encourage the examination and re-examination of the curriculum guides that these science education leaders are undertaking at this time. 


\section{Works Consulted}

Gennaro, E. \& Lawrenz, F. (1992). The effectiveness of take-home science kits at the elementary level. Journal of Research in Science Teaching, 29(9), 985-994.

Houston, L.S., Fraser, B.J., \& Ledbetter, C.E. (2003, April). An evaluation of elementary school science kits in terms of classroom environment and student attitudes. Paper presented at the meeting of the American Educational Research Association, Chicago, IL.

National Research Council. (2000). Inquiry and the National Science Education Standards: A guide for teaching and learning. Washington, DC: National Academy of Sciences.

New Jersey Administrative Code. (2009). 6A:8-3:1

Saul, W. \& Reardon, J. (Eds.) (1996). Beyond the science kit: Inquiry in action. Portsmouth, NH: Heinemann. 


\section{Appendix G HRI Review of the Interim Assessments}

As part of collecting information on Newark's existing science program, Horizon Research, Inc. (HRI) was asked to analyze two district-developed science assessments, one in the physical sciences and one in the life sciences. HRI examined two assessments: Force and Motion and Organisms Macro to Micro. Each assessment was reviewed by one or more HRI staff members and one external consultant. The purpose of the review was to examine the validity of the assessments.

As HRI noted, "There are a number of criteria that could be used to evaluate individual assessment items, or an entire assessment. In evaluating an item, one might examine the "depth of knowledge" required, determining whether the item requires simple recall of information or is more demanding, asking students to apply or synthesize information. One might also look at the extent to which items are likely to identify misconceptions students have about an idea, either by utilizing common misconceptions in the writing of distractors for selected-response items, or by using scenarios for constructed-response items that are likely to elicit these misconceptions. Statistical techniques, such as factor analysis and item-response theory, can also be used to inform decisions about item validity. However, examining the two Newark assessments by these criteria was beyond the scope of the review."

HRI used four criteria for evaluating the assessment items that were based on principles of writing valid items utilized by a National Science Foundation-funded Math and Science Partnership project (ATLAST Award Number EHR-0335328). These criteria - necessity, sufficiency, content accuracy, and appropriate representations and language - are based upon work done by Project 2061. Applying the criteria helps determine whether answering an item correctly would likely be due to student comprehension of the ideas in the targeted content domain (i.e., the knowledge intended to be assessed), and whether answering incorrectly would likely be due to lack of understanding of those ideas. Items that could be answered correctly by students without knowledge of the content, or could be answered incorrectly by students with knowledge of the content, are not considered valid. The definitions of the criteria are found in the full report which is in Appendix XX. Here we summarize the HRI findings.

Necessity: HRI found about three-quarters of the 34 items on the Force and Motion assessment and two-thirds of the 34 items on the Organisms Macro to Micro assessment clearly met the necessity criterion.

Sufficiency: HRI found roughly two-thirds of the 34 items on the Force and Motion assessment and one-half of the 34 on the Organisms Macro to Micro assessment clearly met the sufficiency criterion.

Content Accuracy: Overall, HRI concluded that most of the items on the two assessments met the content accuracy criterion, though the Force and Motion assessment had more items that did not meet this criterion than the Organisms Macro to Micro assessment

Appropriate Representations and Language: HRI found nearly all of the items on the Force and Motion assessment and most on the Organisms Macro to Micro assessment clearly met the appropriateness criterion. 
Overall, the HRI reviewers concluded that many of the $7^{\text {th }}$ grade items reviewed met the criteria on which they were examined. They concluded "Responding correctly to these items requires knowledge from the targeted content domain to select the correct answer and to rule out the incorrect response options." HRI also said: "... some items were identified as requiring knowledge outside of the targeted content domain, having content inaccuracies, and/or other issues which might impact students' ability to understand what the item was asking." Their report concludes that these problems could be solved by careful editing and giving more attention to general principles of item writing. 


\section{Want to learn more about new and upcoming CPRE publications, project research findings, or where CPRE researchers are presenting?}
Visit our website at www.cpre.org or sign up for our e-newsletter, In-Sites, at insites@gse.upenn.edu.

\section{Nondiscrimination Statement}

The University of Pennsylvania values diversity and seeks talented students, faculty, and staff from diverse backgrounds. The University of Pennsylvania does not discriminate on the basis of race, sex, sexual orientation, religion, color, national, or ethnic origin, age, disability, or status as a Vietnam Era Veteran or disabled veteran in the administration of educational policies, programs or activities; admissions policies, scholarships or loan awards; athletic, or University administered programs or employment.

Questions or complaints regarding this policy should be directed to Executive Director, Office of Affirmative Action, 1133 Blockley Hall, Philadelphia, PA 19104-6021 or (215) 898-6993 (Voice) or (215) 898-7803 (TDD). 